

\section{AfTER THE RELEASE: \\ The Long-Term Behavioral Impact of Piracy on Seafarers and Families}

An Oceans Beyond Piracy and OEF Research Report

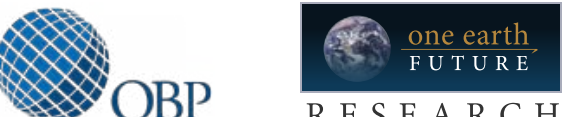

\section{Conor Seyle}

lead author

June 2016

OEF Research and Oceans Beyond Piracy are programs of the One Earth Future Foundation

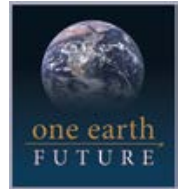

www.oneearthfuture.org 


\title{
ACKNOWLEDGMENTS
}

\author{
Contributing Authors: \\ Chirag Bahri, Maritime Piracy Humanitarian Response Programme \\ Kellie Brandt, OEF Research \\ Alexander Dimitrievich, Crisis Response Eastern Europe \\ Karina Fernandez, Ateneo de Manila University \\ Tom Holmer, Martitime Piracy Humanitarian Response Programme \\ Niyati Malhotra, OEF Research \\ Design and Layout:
}

Andrea Jovanovic and Timothy Schommer of One Earth Future Foundation

This report was supported by the One Earth Future Foundation and the TK Foundation, and executed in partnership with the Maritime Piracy Humanitarian Response Programme, with coordination and contributions from the Seamen's Church Institute of New York and New Jersey, and Ateneo de Manila University. 


\section{TABLE OF CONTENTS}

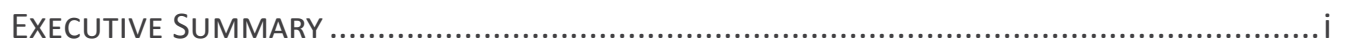

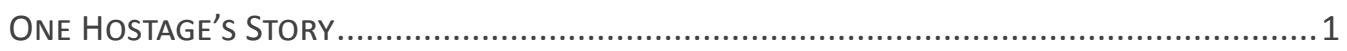

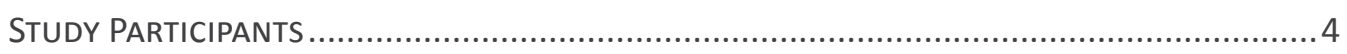

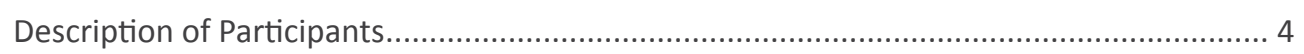

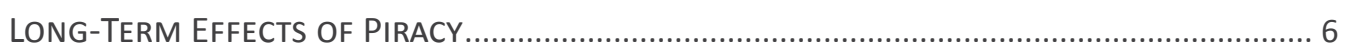

Results: Probable Post-Traumatic Stress Disorder …..................................................... 8

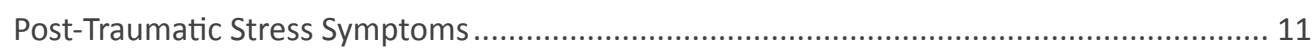

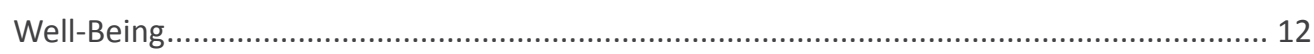

Impact on Work-Related Attitudes and Decisions............................................................ 14

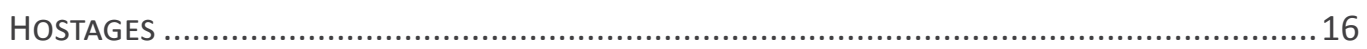

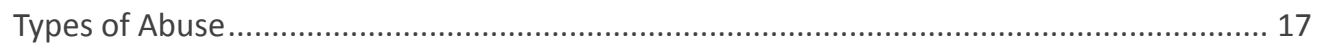

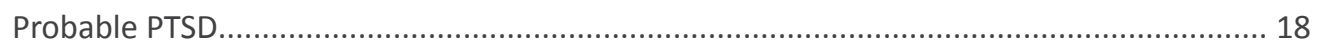

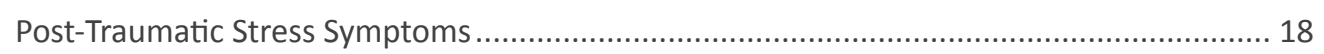

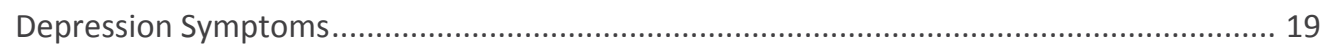

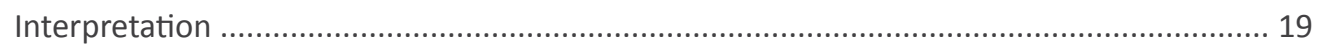

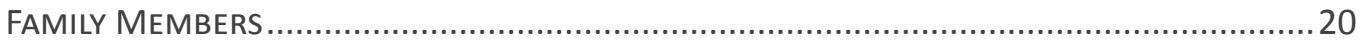

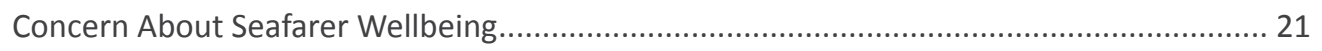

Knowledge About How to Get Information About Seafarers............................................... 21

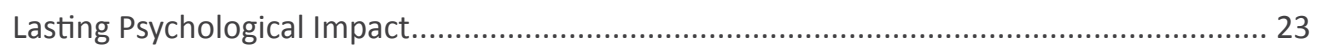

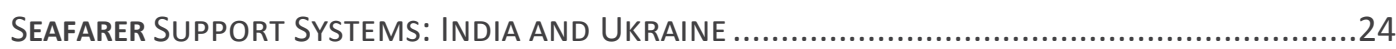

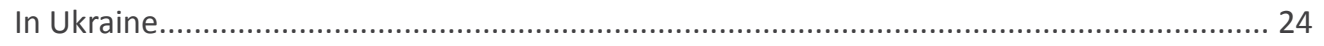

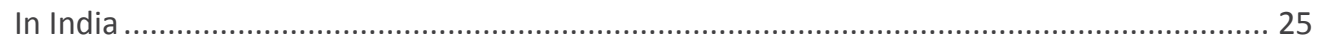

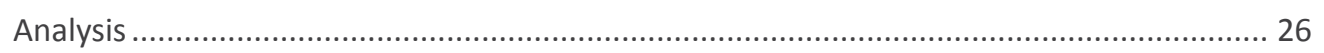

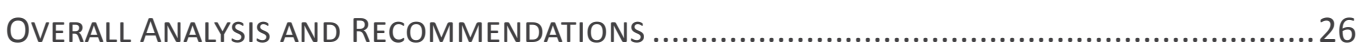

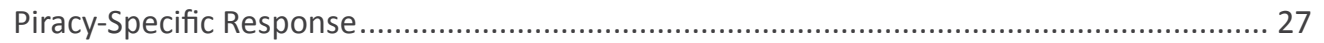

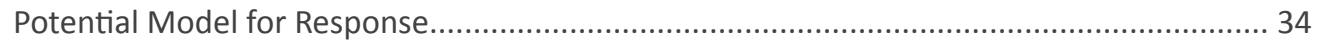

NOTES

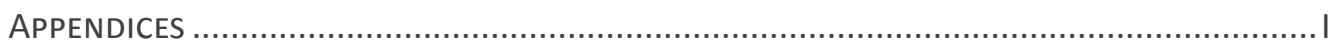

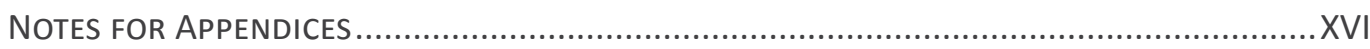




\section{EXECUTIVE SUMMARY}

More than 3,000 seafarers have been held hostage by Somali pirates since 2001, with a significant, but unknown, number of seafarers kidnapped in other parts of the world. These seafarers, and their families, have faced fear and uncertainty, and in some cases, direct abuse. In addition to the 41 seafarers who remain in captivity as of the release of this report, the thousands of seafarers who have returned to their regular lives after being held hostage must address the challenges of reintegration and coping with their experiences.

This research report explores the long-term impact of piracy on seafarer and family recovery. It is based on a series of interviews and structured surveys collected from 465 seafarers in three major seafaring countries: India, the Philippines, and Ukraine. These seafarers included 101 former hostages and 364 non-hostages, and also 38 family members of seafarers.

\section{KEY FINDINGS}

- Seafarers are resilient, but a sizeable minority of hostages show lasting effects. Most seafarers who have been held hostage do not show lasting impairment in their mental or behavioral health, but $25.77 \%$ of former hostages have symptoms consistent with Post-Traumatic Stress Disorder (PTSD). These seafarers are at higher risk of having poor overall well-being, as well.

- Being held hostage, more than any other type of piracy experience, leads to lasting effects. Many seafarers are exposed to different types of threats from pirates, ranging from the tensions of transiting through the high-risk areas to actually being attacked. Only hostage experiences are related to a significantly increased risk of PTSD.

- Seafarers are exposed to a fairly high number and degree of traumatic experiences in the course of their regular employment. The maritime environment is dangerous, and seafarers are regularly exposed to traumatic experiences other than piracy. These experiences have an independent impact on posttraumatic stress symptoms and can negatively affect seafarer well-being.

- Traumatic experiences impact the decisions seafarers make about their work.Seafarers with higher levels of post-traumatic stress symptoms are more likely to think about piracy when taking contracts, and more likely to have declined a job due to piracy risk.

- Families of hostages can have problems getting information about their loved ones, and many suffer lasting distress. Less than $50 \%$ of family members of hostages feel that they had good information about what was happening to their seafarer, and more than $30 \%$ of spouses of seafarers report that they have no idea how they would get information if something bad happened while their seafarer was at sea. A large minority of the family members of hostages show lasting behavioral effects from their experiences. 
ii | The Long-Term Behavioral Impact of Piracy on Seafarers and Families

\section{THREE PILLARS TO PIRACY RESPONSE:}

1. Part of the response to maritime piracy should be an integrated and standardized framework that can help seafarers prepare for potential exposure to pirate attack and cope with their experiences during and after the event. This should be an integrated response including pre-event planning and training and during-event management as well as postevent support and care. Care for the families should be considered an integral part of the response.

2. Post-event care should include social integration and support as well as targeted mental health support. All hostages will benefit from the former, and a minority will need the latter.

3. Programs designed to mitigate the long-term impact of piracy should also support resilience in the face of other maritime traumatic events, if possible.

In practice, addressing these issues will require a coordinated effort from seafarer support organizations, industry, and states. This will require a corresponding increase in appreciation for the breadth and depth of the impact of piracy and other traumas on the seafarer population. However, this research also demonstrates that seafarers are a resilient community and suggests that with the development of more robust systems for support, this resilience can be reinforced. 


\section{ONE HOSTAGE'S STORY}

In 2009, Mark ${ }^{1}$ was a seafarer aboard a merchant vessel that was attacked by pirates in the Indian Ocean. He described his experience:

I woke up Sunday quite late, as we slept quite late the other night. Suddenly, the emergency alarm went off. The emergency alarm was the most common alarm on board. Then it was followed by a public address by the duty officer, the Third Mate, asking all of the crewmembers to go up the bridge. So, I immediately run to the bridge from the cabin. All the officers were already at the bridge. The master said that there was a speedboat chasing us, the ship. So, we look for it. At that time, we can see the speedboat with our bare eyes, approximately two miles away. It was really fast, and our ship was running only at 14 knots. ...After 30 minutes, the speedboat was very close to the ship. Within 30 minutes, the speedboat was approximately half a mile near the ship.

The ship defended itself with maneuvers to create waves to swamp the pirates, which the pirates easily avoided in their morenimble craft. Seafarers manned the water hoses, but abandoned them when the pirates began firing at the crew.

They were still pointing the RPG at the bridge as if signaling they will not miss anymore if the ship does not stop. The master ordered to stop the ship's engine. Then we stopped.
Then the pirates fired a 30-caliber gun. They fired a warning shot. It was a burst of fire that they fired.... They were on the starboard side, continuously firing. When they were really near, they were signaling the bridge to stop while they kept firing.

They were five or six. They were wearing camouflaged jackets; some were wearing shorts, faces covered. They were drawing attention to their guns; a RPG [rocket propelled grenade]. The pirates then, using the RPG, fired at the bridge without hitting the bridge. It was a clear warning shot, as the RPG was really close to hitting the bridge. They were still pointing the RPG at the bridge as if signaling they will not miss anymore if the ship does not stop. The master ordered to stop the ship's engine. Then we stopped.

The pirates, one by one, were boarding the ship. They were shooting each passage that they were passing through. From the upper deck to the bridge, the pirates were shooting with their AK-47's each corner that they pass[ed] by.

They used the ladder with the hook that they had in the speedboat. When they reached the upper deck, they used the ship's stairways. The doors leading to the upper deck were all locked, so they used the stairs at the side of the vessel. When they reached the bridge, we locked ourselves in the bridge and we decided to squat, all of us, anyway, when we saw them reaching the bridge area. As we locked the doors of the bridge, most of the sides of the bridge were visible anyway as it was all glass. The pirates pointed their guns on us. They were signaling for us to open the door. [When the door was opened] one of the pirates immediately shouted, "Captain? Captain?" I think it was clear to all of us that they were looking for the captain/master. The master raised his hand. Then the pirate asked, "You captain?" Without the master saying a word, he was immediately kicked in the thighs. The captain said something to the effect of, "Who are you? What was my fault? We are just working here." The pirate said "Pirates, pirates." Obviously, all of us knew who they were. I think the captain asked those questions because he was attacked immediately. I think his reaction was normal under those circumstances. The captain was continuously attacked. He did not do anything, but he was man-handled. As if they were trying to scare him off by kicking him, punching him, and even striking him with the butt of the AK-47.

One of them who can speak some English ordered all personnel to assemble in the wings of the bridge. That is, they brought us outside and ordered us to give them our passports and crew list. They counted us, the passports, as reflected in the crew list. We were all there, the 24 of us, and our passports were all with the pirates. They told us to stay squatting outside with three armed pirates guarding us. They each had an AK-47, a 30-caliber and some handguns. One of the

\section{CC}

Then the pirate asked, "You captain?" Without the master saying a word, he was immediately kicked in the thighs.

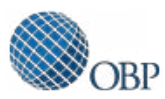


2 | The Long-Term Behavioral Impact of Piracy on Seafarers and Families

pirates was talking over a mobile phone. Around 2:00 p.m., we were ordered to go in the bridge. It was really humid outside. We were really sweating hard because of the heat.

The pirates systematically robbed the crew, and then the vessel and the crew were taken to a coastal town in Somalia. As the months passed and the pirates began the process of negotiating for ransom, the crew did what they could to keep their spirits up. As the time passed, the pirates grew frustrated with the delay in negotiation and began to abuse the crew.

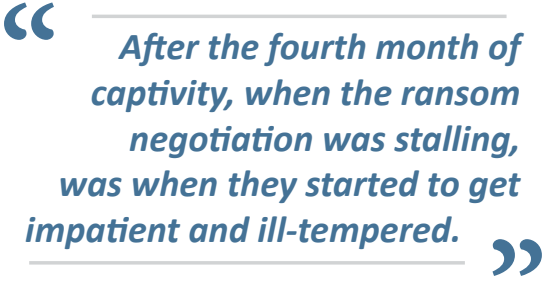

What happened to us was, during the first three months they were ok, not that violent. After the fourth month of captivity, when the ransom negotiation was stalling, was when they started to get impatient and illtempered. They started to be physically violent and abusive. They were really getting impatient with the ransom negotiation. In our case, when the ransom negotiation was stalling, we ourselves were getting anxious, though we were used to wait[ing], anyway. When the pirates were getting impatient, they were starting to be physically violent.

The crew was held hostage for more than a year before negotiations were completed and the crew and vessel was released. From Somalia, they were initially escorted by international naval vessels to a nearby port. After their release, the crew was provided with medical support, then flown home. Afterwards, they were debriefed by lawyers to document their experiences, and at the request of their employer went through another medical examination to assess the impact of their long imprisonment. While waiting to return home, Mark described the support that was given:

We took care of ourselves in the hotel. There were some staff from the [national] embassy in [that city] who visited us in the hotel. But it was just us crew members who took care of ourselves. What was really hurtful, too, was that when we were in [that city], we requested our onboard wages. Obviously, we needed clothes, shoes, etc. I was wearing flip flops and the boiler suit that I used for the seven months that we were there. I still had that boiler suit with me here back home.... What happened was they gave us each $\$ 500$.

While Mark was captured by pirates, his family suffered in the absence of information. His wife lived far from the port city where Mark's employers were, and so had to regularly travel at her own expense to talk to the company or government agencies to get information. She reports that at one point, a government agency working on Mark's release advised her not to search the internet for information about her husband. Understandably, she ignored that suggestion and discovered that the pirates had threatened to start killing crew members if the ransom went unpaid. She described her experience this way:

I knew about their captivity three days after they were captured. The problem was the company had my old and unused mobile phone number. The company sent me a letter regarding the news about their captivity. After which I cannot sleep for a straight seven days. It was straight seven days without sleep. I also cannot eat well. Our son took [it] hard. He was acting differently here in our house and in school. When I would go to [the port city], I cannot bring our son as it was expensive. So I left him with a relative. Our relative told us that our son would hide under [furniture] for hours. I was frequently travelling to [the port city]. When I was home, our son would feel and act a little bit better.

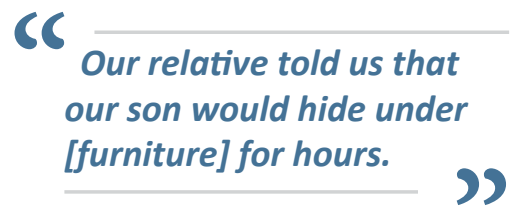

Mark was returned to his wife and son in 2010, and by the time of this interview had been home for almost a year and a half. He still struggled to deal with his experiences: he had not returned to sea, and he felt that he had experienced changes in his emotions and his relationships with other people. The triumph of his release had faded into the work of rebuilding his life and coping with the extremely upsetting experiences that he had dealt with. His wife and family face challenges in their recovery as well. 


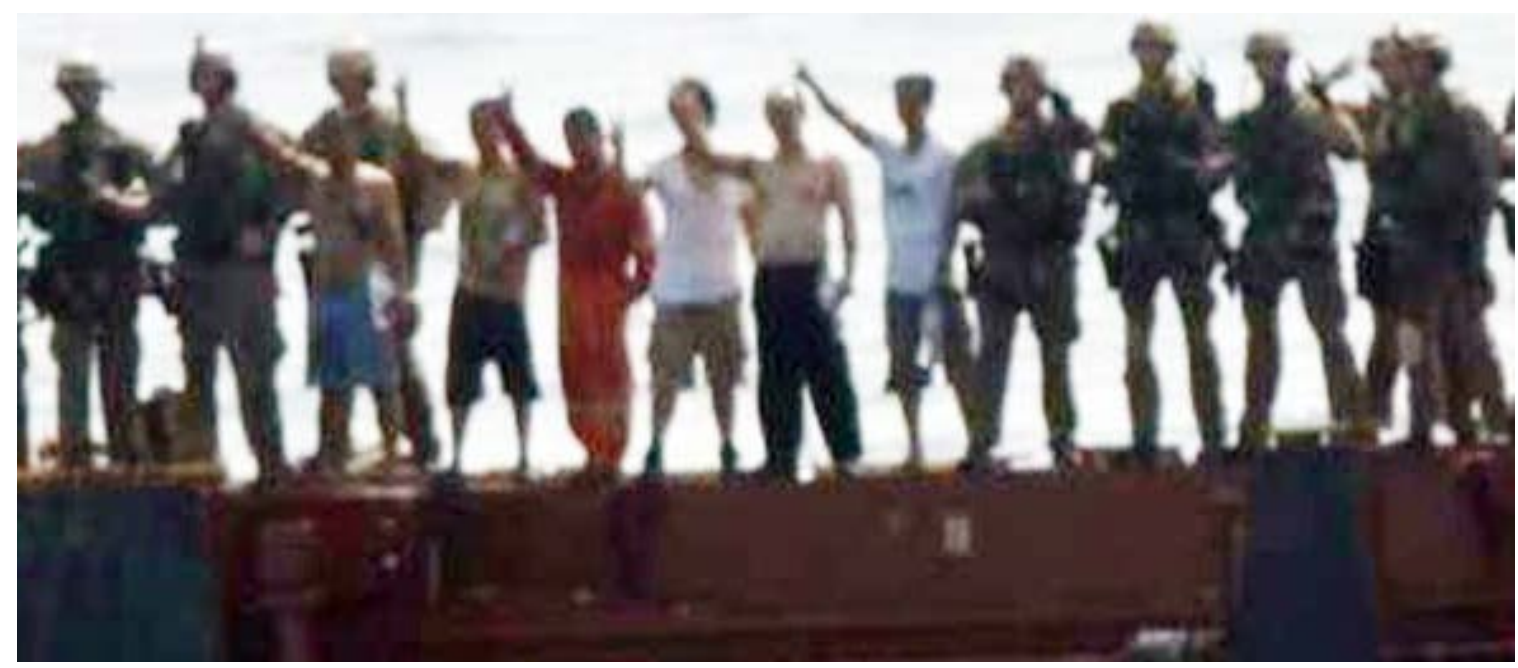

U.S. navy boards ship taken by pirates. Photo by U.S. Marine Corps, Getty Images

Mark is only one of thousands of seafarers attacked by pirates in the last fifteen years, and one of more than 3,000 seafarers captured and held hostage by Somali pirates. The details of his story are specific to him and his family, but the broad strokes of his experience and the impact it has had on him are not. Many seafarers have had similar experiences. These kinds of experiences can leave marks, both physical and behavioral. A growing body of research over the past twenty years has demonstrated the effects that intense and upsetting experiences, such as being a victim of maritime piracy, can have on survivors. This research also demonstrates that the impact is more complex than the popular understanding of post-traumatic stress disorder makes it out to be. While almost all survivors will experience some effects in the short term, the majority of people who experience a traumatic event will have no lasting impairment in ability to function in everyday life. ${ }^{2}$ Some may even show improvement in mental health and well-being. ${ }^{3}$ A minority will go on to develop lasting problems resulting from their experience. This is true for the survivors themselves as well as for their close friends and family members, who are also impacted by the threat to their loved ones.

Research by academics, ${ }^{4}$ seafarer support organizations, ${ }^{5}$ and government agencies ${ }^{6}$ has demonstrated that the negative experience of maritime piracy can lead to lasting emotional and behavioral effects on seafarers. While valuable, to date the majority of this research has been conducted through in-depth interviews with a relatively small number of seafarers known to have been directly affected by piracy. This research project was designed to add to this current research by using an indepth comparison of piracy-affected seafarers and their families to seafarers from the general population. Seafarers in this study were drawn from three countries deeply affected by piracy: India, Ukraine, and the Philippines. It was supported by the One Earth Future Foundation and the TK Foundation and executed in partnership with the Maritime Piracy Humanitarian Response Programme, with coordination and contributions from the Seamen's Church Institute of New York and New Jersey and Ateneo de Manila University.

This study shows that the negative psychological effect piracy has on seafarers is significant and long-lasting, but also demonstrates the resilience of seafarers in the face of adversity. It shows how the effects of piracy can interact with the stress of a seafaring life, including the baseline stress that comes from working at sea and being exposed to the many dangers on ships. Families in this study identify how they can also be negatively affected by piracy, and their need for targeted support and assistance. 


\section{STUDY PARTICIPANTS}

The seafarer market is a deeply internationalized one. An analysis of seafarers crewing cargo ships in 2003 found that five countries combined provided more than $50 \%$ of global seafarers: the Philippines, with a massive $27.8 \%$ of global seafarers; Russia with 7\%; India with 6.6\%; Ukraine with 6.4\%; and China with $6.1 \% .^{7}$ The distribution of people impacted by piracy reflects this diversity. Oceans Beyond Piracy's annual report on the state of maritime piracy has tracked the nationalities of seafarers impacted by piracy to the best of our ability based on publicly available data. This analysis has consistently shown that for Somali piracy, Indian and Filipino seafarers bear the brunt of the attacks and hostage-taking. ${ }^{8}$ Based on this breakdown, as well as the operational network of our research partners, this research project targeted seafarers in three countries: India, the Philippines, and Ukraine.

In each country, the study targeted an initial sample of seafarers known to have been held hostage by pirates and a sample of seafarers not known to have been attacked by pirates to serve as a comparison group. If participants gave permission, the research team contacted a member of their families as well. See Appendix I for full details about the selection process.

\section{DESCRIPTION OF PARTICIPANTS}

\section{Sample Demographics}

FIGURE 1: Sample Demographics

\begin{tabular}{|l|c|c|c|c|c|}
\cline { 2 - 6 } & $\begin{array}{c}\text { KNOWN } \\
\text { HOSTAGES }\end{array}$ & $\begin{array}{c}\text { NOT KNOWN TO } \\
\text { BE HOSTAGES }\end{array}$ & MEAN AGE (AND SD) & AGE RANGE & \% MALE \\
\hline INDIA & 44 & 101 & $31.84(9.47)$ & $20-61$ & $100 \%$ \\
\hline PHILIPPINES & 31 & 136 & $39.66(11.5)$ & $21-68$ & $99 \%$ \\
\hline UKRAINE & 26 & 127 & $36.17(11.51)$ & $20-80$ & $89 \%$ \\
\hline \multicolumn{1}{|c|}{ TOTAL } & 101 & 364 & $35.92(11.32)$ & $20-80$ & $96 \%$ \\
\hline
\end{tabular}

In total, 465 participants for this study were identified. Demographics are similar to those found in other studies of seafarers: the mean age of 35.92 (SD 11.32) is close but not identical to that found in the Global Labour Market study of 38 (SD 10.45), and the highly male-dominated sample is consistent with the demographics of seafarers overall.

\section{Maritime Experience}

Participants were asked about their level of experience in the maritime industry. On average, participants in this survey had 10 years of experience, with a fairly broad range of years spent in the maritime industry (mean=10.58, $\min =0.25, \max =50$ ).

\section{Prior Exposure To Traumatic Events At Sea}

Seafaring is a dangerous profession, and seafarers are potentially exposed to a variety of threats. A 2014 study found that the fatal accident rate for British seafarers was "21 times that in the general British workforce, 4.7 times that in the construction industry and 13 times that in manufacturing." ${ }^{10}$ This is significant when considering the long-term impact of piracy, because prior exposure to traumatic events can impair resilience and lead to more severe negative psychological impacts from later events. ${ }^{11}$ This survey asked seafarers about what negative experiences they may have had in the past, using categories

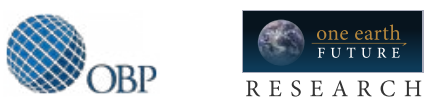


previously studied in the literature. Consistent with prior research work on how dangerous the maritime sector is, seafarers in this sample showed a high rate of having experienced prior traumatic events.

FIGURE 2: Prior Exposure to Negative Events Aboard Ships in this Sample

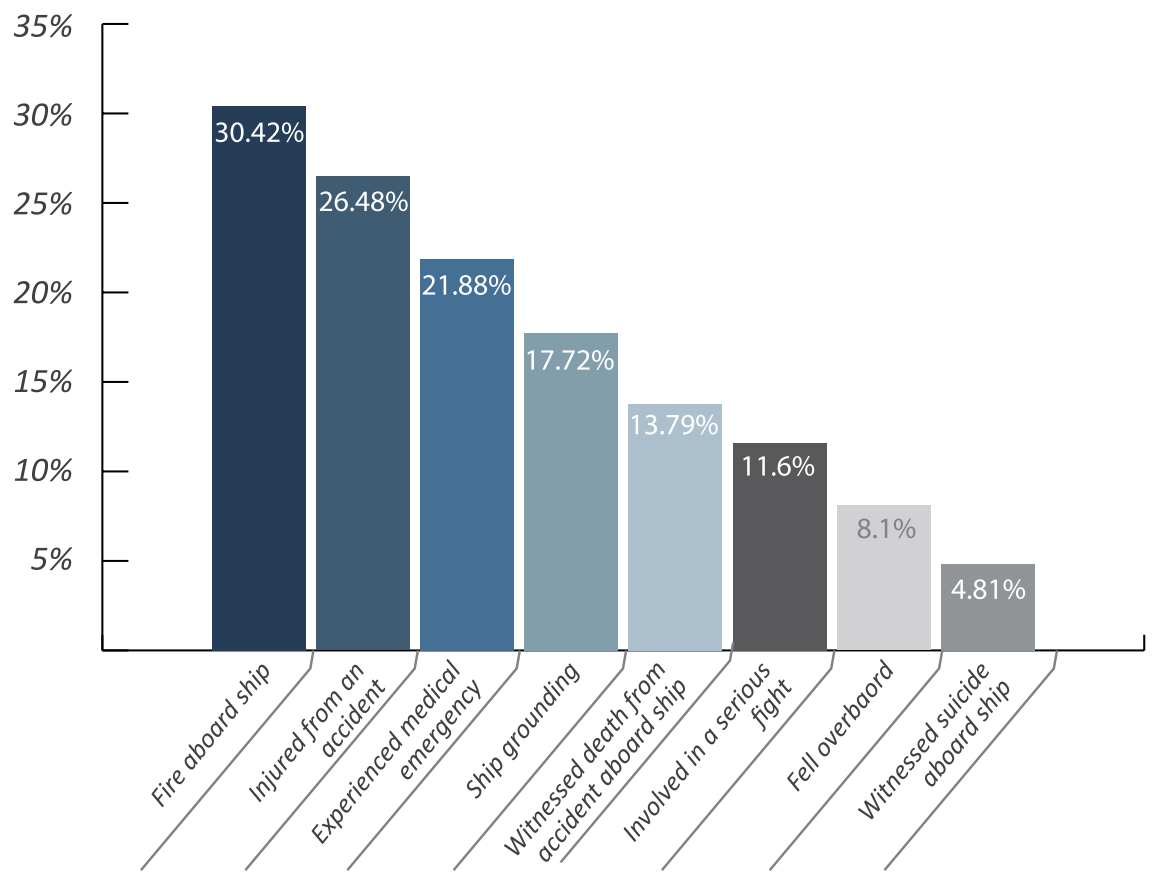

These numbers are high, but they are comparable to those found by World Maritime University student Vivek Menon, who in his Master's thesis sampled the traumatic experiences of 37 seafarers using similar categories to those in this survey. In each case, Menon's thesis found rates of exposure to traumatic events higher than those reported in this sample. ${ }^{12}$

\section{Exposure to Piracy}

In addition to other maritime traumas, this survey was specifically interested in what types of experiences seafarers have had with piracy. The survey tracked a number of different types of exposure to piracy. Table 3 below shows the rates of exposure to piracy in the seafarers who were not known to have been exposed to piracy. The former hostages and the nine seafarers from the Ukrainian sample who were approached for participation because they were known to have survived an attack were excluded from this analysis.

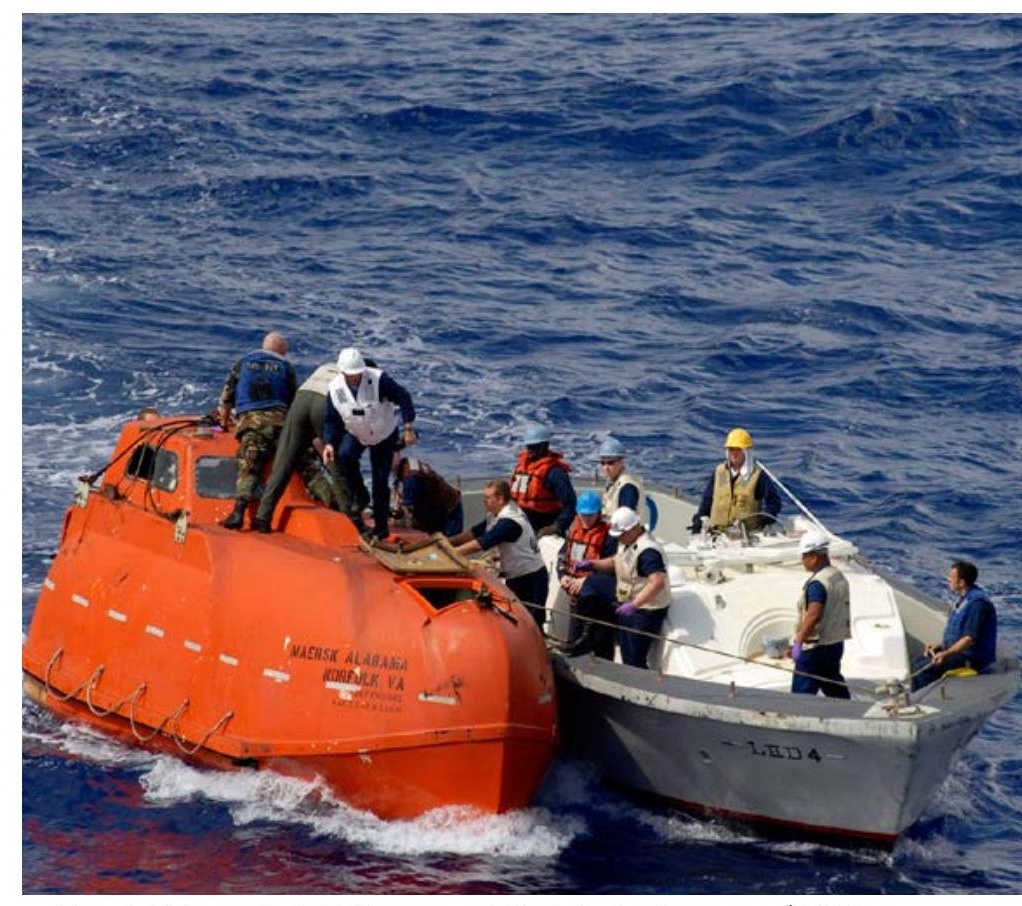

Maersk-Alabama Capt. Phillips rescued. Photo by Jon Rasmussen/U.S. Navy 
6 | The Long-Term Behavioral Impact of Piracy on Seafarers and Families

FIGURE 3: Prior Exposure To Piracy In Sample Of Seafarers Not Previously Known To Have Been Exposed

\begin{tabular}{|l|c|}
\hline \multicolumn{1}{|c|}{ TYPE OF EXPOSURE } & $\begin{array}{c}\text { PERCENT OF } \\
\text { GENERAL SAMPLE }\end{array}$ \\
\hline No exposure to piracy at all & $31.46 \%$ \\
\hline Transited piracy risk areas & $56.46 \%$ \\
\hline \multicolumn{1}{|c|}{ Transited piracy-risk areas, no other exposure } & $32.02 \%$ \\
\hline Know someone held hostage & $23.31 \%$ \\
\hline Know someone held hostage, no other exposure & $5.34 \%$ \\
\hline Witnessed an attack on another vessel & $7.02 \%$ \\
\hline Attacked, not held & $4.49 \%$ \\
\hline Attacked and pirates fired guns, but not held & $2.25 \%$ \\
\hline Attacked and boarded, but not held & $1.97 \%$ \\
\hline Attacked and sheltered in citadel, but not held & $1.12 \%$ \\
\hline
\end{tabular}

Four and a half percent of the sample reported having been attacked by pirates. The survey did not specifically define "attack," so this could include everything from a suspicious approach to a boarding. Including the additional 9 seafarers who were known survivors of attack, the majority of seafarers attacked by pirates had only been attacked once (14 out of 20 seafarers who reported the number of attacks). Four participants had been attacked twice, and one each had been attacked three and four times.

\section{LONG-TERM EFFECTS OF PIRACY}

Describing his experience reintegrating after being held as a hostage by Somali pirates, Mark talked about the long-term impact of his experiences. He said that since returning, he has struggled with controlling his emotions and that he has felt lingering effects on how he behaves:

\section{CC}

After the incident, I feel at times as if I lost any sense of fear. If I see people fighting, that would not bother me. On the other hand, I would feel extremely nervous. In those times that I feel extremely nervous, I would be extremely courteous to the point of subservience. As if I am still accustomed to the way I was subservient when we were with the pirates.

His experience is not surprising. While he was held captive, pirates physically abused him and other hostages, and showed them videos of beheadings while threatening to do the same to them if ransoms were not paid. Piracy is frequently a brutal crime, and pirates often deliberately abuse seafarers either to force them to do what the pirates want or just to amuse themselves. These kinds of traumatic events ${ }^{13}$ can trigger lasting impacts through a number of pathways. Most people want to feel safe in their day-to-day lives, and believe that bad things are unlikely to happen to them. The experience of being attacked or threatened can shatter that belief, forcing people to confront the possibility that the world is not as safe as they would like. The process of forcibly coming to terms with this can lead to long-term effects on mental health or well-being as people cope with fear and distress associated with it and develop tools to manage these emotions. ${ }^{14}$ In addition to this cognitive impact, traumatic events can also trigger lasting physiological reactions in some who experience them, leading to issues such as persistent physiological arousal or heightened reactivity. ${ }^{15}$

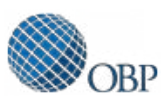




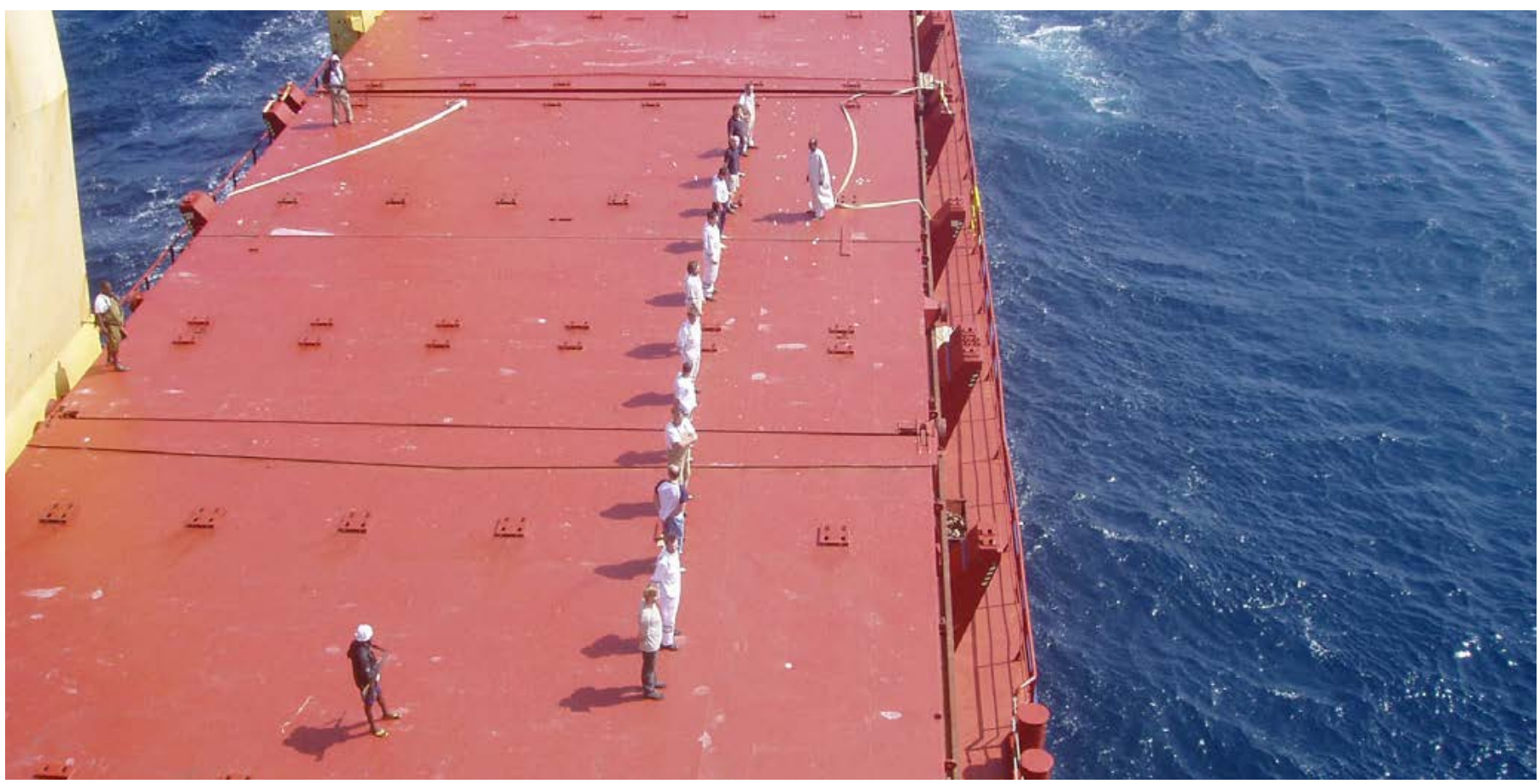

Hostages on the MV CEC Future. Photo from the Clipper Group

Almost everyone who experiences a traumatic event will have these physiological and mental reactions to some degree, but the majority of people who face them will return to normal health. ${ }^{16}$ Humans are extraordinarily resilient, and even highly traumatic and threatening events such as combat cause lasting problems in only a minority of those who go through them. A 2010 study of American combat veterans found that almost 70\% showed no significant impairment in their mental health or well-being, and found severe impairment in between $8.5 \%$ and $14 \% .{ }^{17}$ Prior research on trauma has found that there are a number of characteristics that can impact the overall risk of experiencing lasting effects. In particular, a lack of social support and high levels of overall life stress are particularly damaging to resilience, and other factors that influence recovery include a prior history of traumatic events or other medical or psychiatric issues, lower socioeconomic status, lower age, female gender, belonging to an ethnic minority, and the severity of the traumatic event itself. ${ }^{18}$ There is also evidence that physiological factors relating to individual reactivity to stress can influence long-term recovery. ${ }^{19} \mathrm{It}$ is also true that the impacts of traumatic events are not necessarily negative. In some people, confronting their traumatic experience can lead to a re-examination of what they value, deeper appreciation of the positive things in their life, and closer social ties. ${ }^{20}$ While this "post-traumatic growth" is not universal, and should not be expected following a traumatic event, there is developing research demonstrating that it does happen in some cases. ${ }^{21}$

In the case of piracy specifically, there is evidence in the existing research suggesting that piracy can have long-term effects on exposed seafarers. Two reports based on qualitative interviews with seafarers affected by piracy have documented the lasting emotional disturbances caused by piracy. A study of Filipino seafarers conducted in a partnership between the government of the Philippines and the government of Japan documented lasting emotional distress and reduced functioning in a large percentage of the seafarers interviewed. ${ }^{22}$ A 2012 report by the Seamen's Church Institute of New York and New Jersey likewise showed a number of lasting behavioral disturbances in the seafarers they interviewed. ${ }^{23}$ In addition, a small body of academic research has looked into the impact of piracy. Italian psychologist Antonio Ziello has documented diagnosable PTSD and lasting distress in a small sample of Italian seafarers and their families who have been affected by piracy. ${ }^{24}$

No current body of research is sufficiently large enough to identify the probable base rates of long-term impacts on former hostages, or to identify predictors and elements that may contribute to resilience in seafarers exposed to piracy. This research project attempted to address this with a large-scale data collection process tracking the effect of piracy on a variety of potential outcomes including post-traumatic stress symptoms, depression, well-being, and workplace-related thoughts and attitudes.
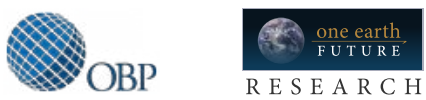


\section{RESULTS: PROBABLE POST-TRAUMATIC STRESS DISORDER}

Post-traumatic stress disorder (PTSD) is one of the long-term impacts of trauma that is most familiar to audiences of popular media. Formally, PTSD is defined as an anxiety disorder characterized by four clusters of symptoms: re-experiencing the negative event through persistent or intrusive memories of the event, avoiding negative memories and bad feelings associated with reminders of the event, lasting negative thoughts and feelings such as memory problems or feeling disconnected from people, and heightened emotional reactivity and overall physiological arousal. ${ }^{25}$ The mechanisms that link traumatic events to PTSD are still debated, but there is a clear link between both cognitive or mental elements of coping and PTSD ${ }^{26}$ and a physiological link as well. Fortunately, PTSD responds relatively well to treatment. There are several methods of therapy that are well-supported by research suggesting that they are effective in reducing the severity of PTSD. ${ }^{27}$

In this study, probable PTSD was assessed using the PCL-C questionnaire, a research-validated measure that has been found to be reliably predictive of PTSD. ${ }^{28}$ Because participants were not interviewed by a clinical psychologist or psychiatrist, they cannot be definitively diagnosed as having PTSD. Past research would suggest that there is a strong association between the scale used here and an eventual diagnosis of PTSD, however. ${ }^{29}$ See Appendix II for detailed information about the scale and scoring.

The first calculation of probable PTSD assessed the base rates of PTSD in the general seafaring population. Two hundred and fifty-five of the 356 seafarers not known to have been exposed to piracy completed the post-traumatic stress assessment. Of these 255, 10 were identified as having probable PTSD, for an overall base rate of probable PTSD of 3.92\%. When considering different categories of exposure, this rate does not vary significantly across exposure categories $\left(\chi^{2}(4, N=255)=1.643, n . s\right.$.) other than former hostages who showed rates of probable PTSD of $25.77 \%$.

FIGURE 4: Rates Of Probable PTSD By Categories Of Exposure To Piracy

\begin{tabular}{|c|c|c|c|}
\hline EXPOSURE CATEGORY & $\mathbf{N}$ & N, PROBABLE PTSD & $\begin{array}{c}\text { RATE, PROBABLE } \\
\text { PTSD }\end{array}$ \\
\hline Attacked but not boarded & 22 & 0 & $0.00 \%$ \\
\hline Transited HRA, no other exposure & 89 & 3 & $3.37 \%$ \\
\hline Other exposure, not hostages & 75 & 3 & $4.00 \%$ \\
\hline No exposure & 56 & 3 & $5.36 \%$ \\
\hline Know a hostage, no other exposure & 13 & 1 & $7.69 \%$ \\
\hline Hostage & 72 & 25 & $25.77 \%$ \\
\hline
\end{tabular}

This base rate is consistent with several estimates of PTSD prevalence in general populations. For example, a 1995 analysis of the national co-morbidity survey found overall rates of PTSD in the US population to be about $5 \%$ for men, with women showing about $10.4 \%$ and an overall average of $7.8 \%{ }^{13}$

Next, types of exposure, demographic and historical variables, and pre-departure training were all assessed for association with post-traumatic stress disorder. See Appendix II for full details of the analysis methods used. These analyses found the following key results:

- Seafarers held hostage by pirates are at higher risk for probable PTSD. Controlling for all other relevant variables, being held hostage increases the base risk of PTSD from roughly $7.8 \%$ to almost $45 \% .{ }^{30}$ No other type of exposure to piracy was related to higher risk of PTSD.

- $\quad$ Seafarers who rated pre-departure training as more useful were less likely to have PTSD.

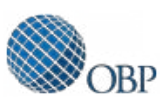


- Indian seafarers were more likely to have probable PTSD than those from the other two countries, while Ukrainians were less likely.

- However, this difference disappeared when controlling for the perceived value of pre-departure trainings. This suggests that the difference in PTSD rates between countries is due to country-related differences in the perceived value of pre-departure trainings.

See Appendix III for the full results and the statistical report. These analyses suggest that the increased rate of PTSD in former hostages compared to other groups is related to their hostage experiences. Seafarers who were held hostage are at greater risk for developing PTSD, but no other category of exposure to piracy appears to predict a significant increase in risk for PTSD.

In this sample, pre-departure training appears to have a protective effect. There is pre-existing research suggesting that survivors of traumatic events who say they felt more of a sense of helplessness during the event may have worse outcomes, ${ }^{31}$ although the actual causal role of this feeling of loss of control is debated. ${ }^{32}$ If there is, in fact, a strong link between perceived control and long-term impact, then there is a clear pathway for pre-departure training to support seafarer mental health through the potential increased sense of control it provides. However, this finding may not be reflecting a causal link but instead be due to a retroactive assessment that is influenced by the seafarer's recovery. Those seafarers who have had pre-departure training and who did not have negative reactions to piracy may retroactively be assigning value to the training specifically because they did not have negative reactions. It is difficult to tell if they would have had such reactions without the training. The relatively high rate of perceived utility of pre-departure training (see below) suggests that this latter interpretation may be the most likely: if the majority of seafarers feel that pre-departure training is useful and those who do not are also those suffering most from the impact of piracy, then it suggests that this group may be more cynical about the utility due specifically to the fact that they have more issues.

FIGURE 5: Model-Predicted Risk Of PTSD For Former Hostages And Non-Hostages By Perceived Benefit Of Pre-Departure Training

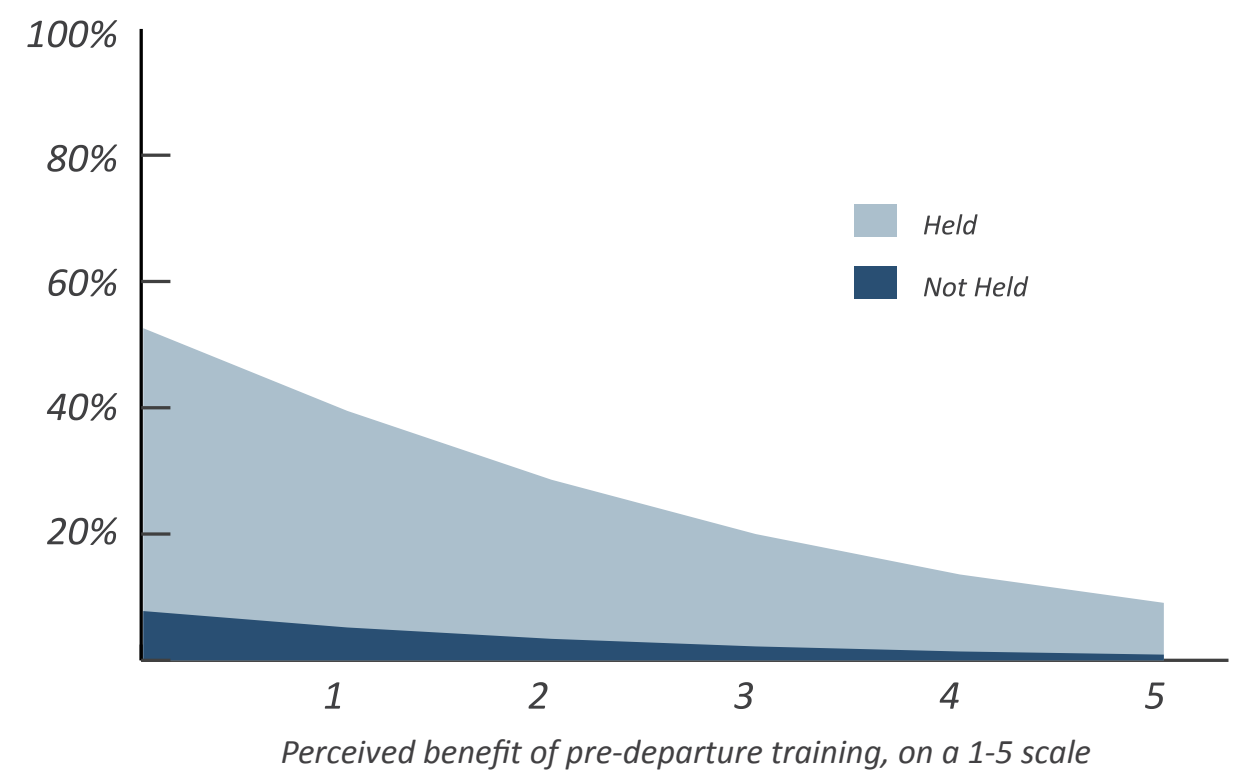

Perceived benefit of pre-departure training, on a 1-5 scale 


\section{PRE-DEPARTURE TRAINING}

Pre-departure training for seafarers transiting high-risk areas for piracy is increasingly common. This survey asked participants if they had attended pre-departure training, how valuable they felt it was, and whether there was anything they remembered from this training. Of the 446 seafarers who answered this item, $376(80.2 \%)$ had completed pre-departure training on piracy and $93(19.8 \%)$ had not. Considering only seafarers who had transited the High-Risk Area (HRA), 255 (86.1\%) had completed pre-departure training and 41 (13.9\%) had not.

Seafarers who had taken the training were asked to rate how valuable they found it on a scale from 1 (not at all useful) to 5 (very useful). Seafarers were on average very positive about the training, rating it, on average, 4.26 out of 5 .

FIGURE 6: Perceived Value Of The Training

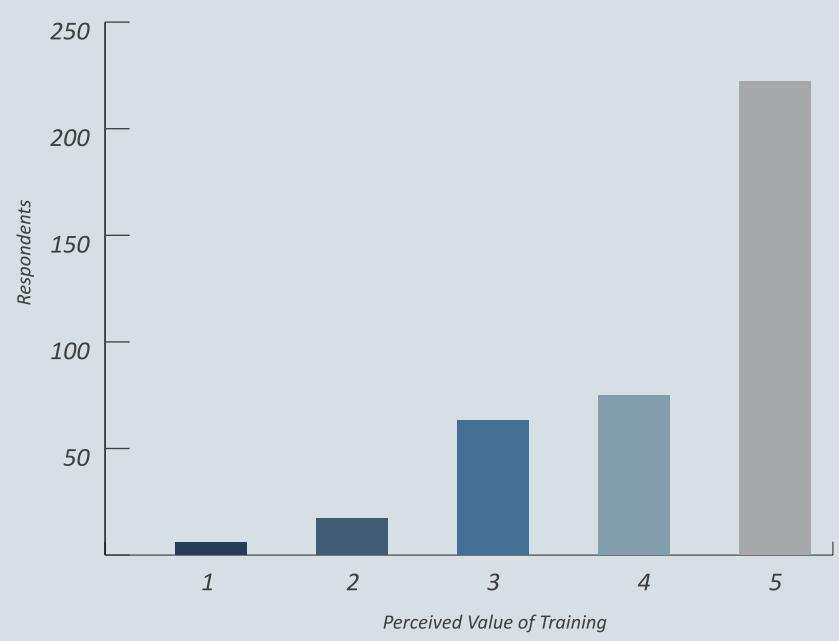

Seafarers were asked if they remembered anything specific from the training. Of the 47 seafarers who provided details about what they remembered, the most common answers $(59.6 \%)$ had to do with technical security procedures such as the use of water hoses to repel boarders, levels of alert and security, and the use of citadels. The second most-frequently remembered element was the exhortation to always remain vigilant in high-risk areas (27.6\% of seafarers included this). The third included elements relating to interacting with pirates, and in particular the idea that if seafarers were captured by pirates they should remain calm and peaceful in interacting with them $(25.5 \%$ of comments included this).

The findings in the analysis of PTSD risk suggest that this training may be a valuable tool for reducing distress. Currently, there are no existing international legal requirements for anti-piracy training for seafarers, but on a national level, some states require it for seafarers from their country or for vessels flagged in their country. In 2010, the Philippines Overseas Employment Administration enacted a legal requirement that Filipino seafarers go through anti-piracy training prior to boarding vessels. To date, no other country requires their seafarers to have similar training. Some flag registries, like Liberia's, have begun to require anti-piracy training for crew aboard their vessels, and where countries are in compliance with the International Ship and Port Facility Security code, crewmembers are required to go through a security familiarization training which may include information on antipiracy measures. There are myriad courses available through seafarer welfare organizations, and many manning agencies, recruitment centers, and private companies require participation in trainings before crews are allowed to board vessels. Nevertheless, there is no standardized, legally mandated training model across stakeholders, and requirements for crew attendance vary dramatically depending on shipping company, manning agency, recruiter, country of origin, and flag registry. Most available training programs prepare unarmed crewmembers to detect approaching pirates, conduct proper communication in the case of an attack, use evasion techniques, and manage hostage situations. Few delve into psychological coping mechanisms and strategies for psychological resilience in the face of pirate attacks and hostage situations. Extending training to address these issues may maximize the value of pre-departure training for supporting behavioral health. 


\section{POST-TRAUMATIC STRESS SYMPTOMS}

Post-traumatic stress disorder in the previous analysis was treated as a binary classification: seafarers either have PTSD or they do not. This may obscure differences within both the group with PTSD and those without. The impact of experiencing a traumatic event is better considered as a continuum, with some people showing lasting impact that does not affect their functioning at all or only moderately causes problems, and other people showing severe and lasting impairment. ${ }^{33}$ To capture this potential array of effects, a separate set of analyses looked at predictors of PTS symptoms as a continuous outcome. See Appendix II for more information about the methods. Key findings include the following:

- $\quad$ As with probable PTSD, the key risk factor for increased post-traumatic stress symptoms was having been held hostage. Hostages showed, on average, a 23\% increase in symptom severity compared to non-hostages when other predictors were controlled for. Other categories of exposure were not significant when other predictors were controlled for.

- $\quad$ Prior exposure to traumatic events aboard ships has an independent pressure on post-traumatic stress symptoms. Each traumatic experience was, on average, associated with a $4.1 \%$ increase in symptom severity.

- $\quad$ As with PTSD, seeing value in pre-departure training was predictive of lower post-traumatic stress symptoms.

See Appendix IV for the full statistical report. When considering the full spectrum of post-traumatic stress symptoms, the impact of being held hostage and the protective factor of seeing value in pre-departure training both appear a second time. In addition, prior exposure to traumatic events aboard a ship has a parallel and independent impact on probable PTSD.

FIGURE 7: Model-Predicted Symptom Severity* By Prior Traumatic Events, For High And Low Perceived Value Of Training

Low Perceived Value of Training

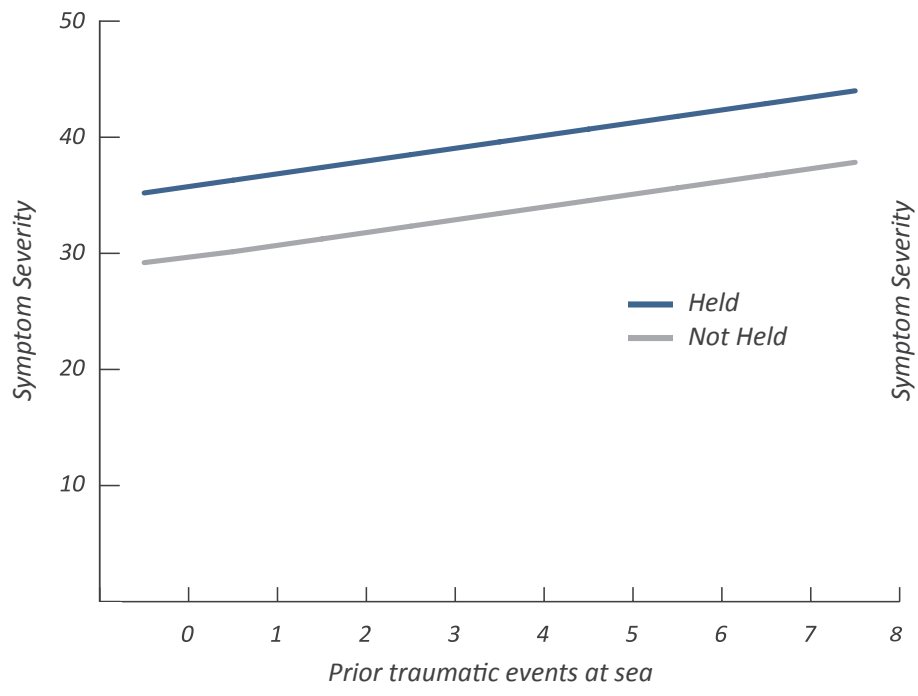

High Perceived Value of Training

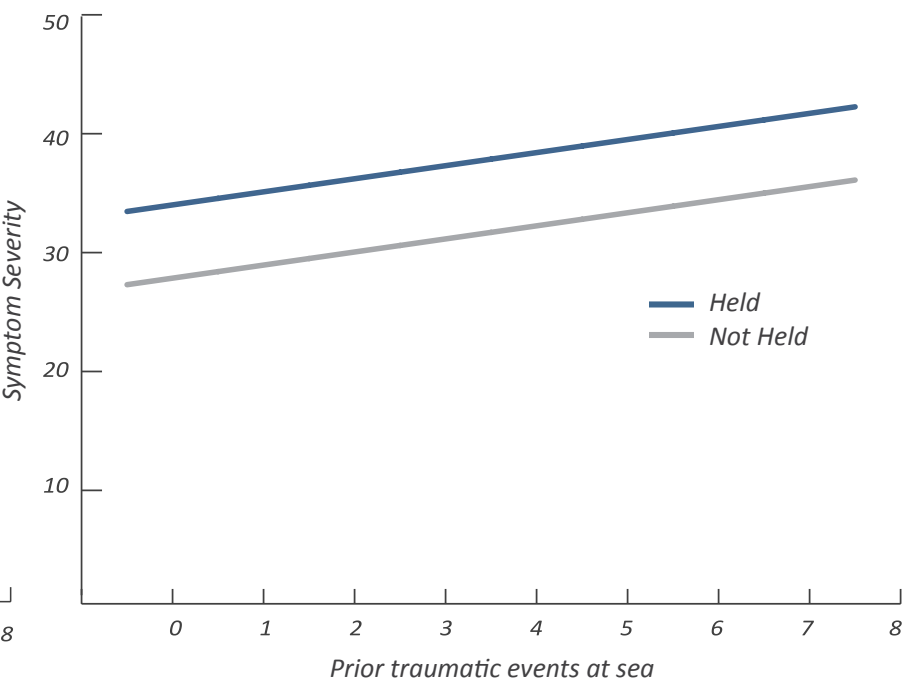

*As measured by the PCL-C standardized rating scale

\section{DEPRESSION}

Depression is a relatively common effect of experiencing traumatic events, and frequently occurs both independently of PTSD and concurrently with PTSD. ${ }^{34}$ Due to the prevalence of depression as an impact of experiencing piracy, this study looked at the impact of piracy on depressive symptoms. Key findings include the following: 
- Former hostages showed higher rates of depressive symptoms than non-hostages, but this effect was not consistent. When controlling for demographic variables including age and prior trauma, hostage experiences were not major predictors of depression.

- Prior trauma exposure was an independent pressure on depressive symptoms. This was particularly evident when country-level differences were controlled for. Each prior traumatic event was, on average, associated with a $6.4 \%$ increase in depressive symptom severity over baseline.

- Older seafarers showed fewer depressive symptoms.

See Appendix $V$ for the full description of the analysis of predictors of depression. Depression in this population appears to be more related to contextual and demographic variables than to piracy specifically. Younger seafarers and seafarers with more prior exposure to traumatic events were more likely to show depressive symptoms. The association with prior trauma suggests that depression in the seafarer population may be more related to long-term exposure to maritime stress than the specific and acute response to a single traumatic event. The finding that older seafarers show less depression may also support this interpretation: in prior research it has been found that younger people are at higher risk of lasting impact from trauma ${ }^{35}$ and depression following at least some forms of injury. ${ }^{36}$ Younger seafarers may still be developing their coping skills and abilities to deal with the challenges of a maritime career.

\section{WELL-BEING}

Traumatic events can have diverse impacts on how survivors function. While specific disorders such as PTSD and depression are relatively frequent effects of traumatic events, it is also the case that the impacts of these events can manifest in ways that don't necessarily match these specific disorders. Moreover, these disorders themselves, or symptoms of depression or post-traumatic stress, can be detrimental not just because of their primary symptoms but because of their general impact on how survivors can function. This overall sense of ability to operate in the world can be described in terms of overall well-being, and in particular how survivors feel about their physical health and ability (physical well-being), their mental health (mental well-being), and their social engagement and social networks (social well-being). This study examined all three constructs.

\section{Physical Well-Being}

Physical well-being encompasses overall health and physical ability. It is a measure of how people feel about their health and their ability to accomplish typical physical activities. See Appendix VI for full results of the analysis. Key findings for predictors of physical well-being include the following:

- Former hostages show lower levels of physical well-being, and no other categories of exposure predict well-being.

- This appears to be due to post-traumatic stress (PTS) symptomatology. When PTS symptoms are controlled for, there is no impact for being held hostage separate from this impact.

- People with higher post-traumatic stress symptoms show lower levels of physical well-being.

Photo by Geoffrey Arduini/Unsplash 
These findings suggest that the relationship between being held hostage and having lower well-being appears to specifically be because being held hostage raises post-traumatic stress symptoms. It is the presence of post-traumatic stress symptoms, not being held hostage per se, that predicts reduced well-being.

\section{Mental Well-Being}

Mental well-being is a construct that includes general mental health and overall life satisfaction. See Appendix VII for full analyses. Key findings include the following:

- Post-traumatic stress symptoms, but not depressive symptoms, are associated with lower levels of mental well-being.

- Seafarers who found more value in pre-departure training show higher rates of mental well-being.

- When controlling for post-traumatic stress, hostages show more mental well-being. That is, former hostages with lower PTS show greater mental well-being than non-hostages.

The results of these analyses duplicate the negative impact of post-traumatic stress symptoms on well-being, but also show how when this negative impact is controlled for, there is a possible association between surviving a hostage experience and positive health. This association may represent post-traumatic growth, or it may be a reflection of pre-existing resilience that led to the lower number of post-traumatic stress symptoms identified.

\section{Social Well-Being}

Social well-being is a construct including healthy social engagement and the presence of a positive and supportive social network. This is both a predictor of healthy coping and an indicator of recovery: one of the most important things supporting effective recovery following traumatic events is social support, ${ }^{37}$ and one impact of traumatic events can be relationship difficulties that complicate the ability to access this support. ${ }^{38}$ Because of this, the link between social functioning and trauma is quite important. See Appendix VIII for full results of the analyses. Key findings mirror those in the analysis of mental well-being:

- As with physical and mental well-being, the key driver of poor social well-being is post-traumatic stress. People with higher rates of post-traumatic stress symptoms show reduced social well-being.

- As with mental well-being, when rates of PTS are controlled for, hostages have higher rates of social well-being. That is, former hostages who also have less PTS show more social well-being.

\section{Overall Well-Being}

Taken as a set, the analysis of well-being shows two different key findings. Overall well-being across all three factors is impacted strongly by post-traumatic stress symptomatology. Seafarers with higher rates of PTS symptoms show reduced functioning across all areas of well-being. From prior analysis, PTS symptoms are associated with more prior maritime trauma and also with being a former hostage. This suggests that hostages, as well as those people with more prior exposure to traumatic events, may be at risk for reduced overall health and ability.

The second significant finding is that when rates of PTS are controlled for, hostages show higher mental and social well-being. To put this another way, former hostages with a given amount of post-traumatic stress symptomatology show higher rates of well-being than non-hostages with the same number of post-traumatic stress symptoms from other sources. The cause of this is unclear: this may relate to the positive support and assistance provided to former hostages, or it may reflect possible "post-traumatic growth" relating to a reassessment of priorities following a traumatic event. 

- As with well-being findings, this effect appears to be wholly driven by the impact of piracy on post-traumatic stress symptoms. Seafarers who were held hostage appear no more likely than other seafarers who have the same levels of post-traumatic stress from other sources to decline a job because of the risk of piracy.

\section{Ever Sought Out A Job Due To Pay}

The inverse of turning down a job because of risk is seeking out a job in the high-risk area because of the potential hazard pay. One item asked participants "Have you ever specifically looked for a higher-risk job to get higher pay?" Appendix XI has the full results. Key findings are:

- Filipino seafarers were significantly more likely to answer "yes" to this question.

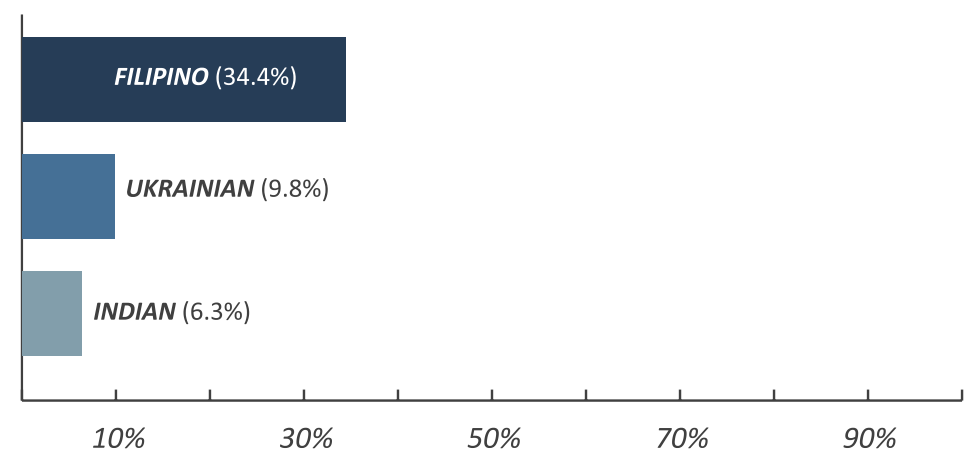

- When considering individual exposure to piracy, there is no major effect from prior exposure to piracy on people who said yes to this item.

- When considering demographic categories, the major predictor of saying yes to this question is post-traumatic stress symptoms. When controlling for predictors of PTS symptoms, including former hostages and prior traumatic events, people who have more post-traumatic stress symptoms are more likely to have said yes to this.

- This may be a retroactive relationship: people who have sought out higher-risk routes may have been more affected by traumatic events, or alternately, people who have more symptoms of post-traumatic stress may be more likely to engage in risky behaviors like seeking out higher-risk routes.

Taken as a set, these items show the impact of piracy on job-related decisions among these participants. People with more post-traumatic stress symptoms were more likely to think about piracy when taking a job, and were more likely to have turned down a job but also more likely to have sought out a job in the HRA for the higher pay. The latter finding may represent retroactive causation, with seafarers who had sought out a job for higher pay also showing more concern about piracy and more impact, or it may represent seafarers attempting to overcome concerns by seeking out threatening experiences. More research is needed on this point to clarify it. 


\section{WILLINGNESS TO TESTIFY AGAINST PIRATES}

Piracy is a crime, and pirates are as subject as any criminal to arrest and prosecution. While international naval forces and regional coast guards have the capacity to arrest pirates, there are a number of challenges to effectively prosecuting pirates - legal questions as well as practical challenges. ${ }^{39}$ One significant practical challenge is identifying seafarer witnesses and facilitating their testimony at trial. Because of the contract-based structure of maritime employment, by the time pirates face trial, many of the seafarers aboard the vessel they attacked will have moved on to other vessels and other contracts. They may be scattered across the world, and testifying against the pirates may involve passing up other employment contracts as well as potentially incurring financial costs to attend court. Because of this, one potential problem with prosecuting pirates is the willingness of seafarers to testify.

This issue was flagged by our local partners in Ukraine. To address this, an item was added to the Ukrainian survey asking "If you were invited to testify against pirate(s) in a Court, providing that all your travel and living expenses were being paid by third parties, would you agree?" One hundred and fifty seafarers responded to this question. In general, both non-hostages and former hostages were largely willing to testify if all of their expenses were covered. A relatively large minority did show unwillingness to testify at all, however.

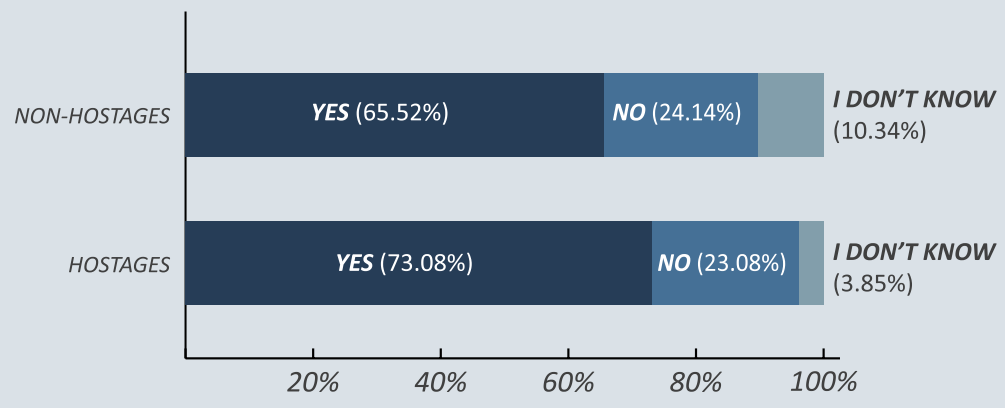

\section{HOSTAGES}

Since the rise of kidnap-and-ransom as a model for piracy in 2005 , OBP estimates that there have been more than 3,000 seafarers held hostage by Somali pirates, with more captured in other countries as well. As of this writing, there are still 41 who are currently being held in Somalia. Each of these seafarers has his or her own experience, and is coping with the longterm impact of what has happened to them.

When considering the impact of piracy, it is important to understand that what captured seafarers experience is often brutal. Pirates are regularly, even universally, abusive in both physical and mental ways ranging from carrying out beatings and forced labor to showing seafarers videos of executions and beheadings and promising it will happen to them. In particular, interviews with seafarers held hostage by Somali pirates suggest that the abuse of seafarers increased as pirates grew frustrated with the time taken by negotiations or wanted to put more pressure on companies to release their seafarers. One account noted:

Then when we reached Hobyo, after more than a month, there was no communication from the office because their negotiation seemed to be unsuccessful. After that, the word spread that every morning they will bring five members of the crew to the mainland and will chop our heads off.... It went on for two weeks until the money came. ${ }^{40}$ 
This section of the report documents the types of experiences suffered by seafarers, and explores how this may relate to longterm recovery.

\section{TYPES OF ABUSE}

To capture the rates of exposure to different kinds of abuse, the survey asked former hostages about what kinds of abuse they had suffered. Rates of abuse are listed below:

FIGURE 8: Rates Of Abuse Of Hostages

\begin{tabular}{|l|c|c|}
\hline \multicolumn{1}{|c|}{ TYPE OF ABUSE } & N & RATE \\
\hline Threatened with death or execution & 88 & $87.13 \%$ \\
\hline Given insufficient or inadequate food or water & 81 & $80.20 \%$ \\
\hline Threatened with beating or abuse & 78 & $77.23 \%$ \\
\hline Slapped, kicked, or punched by pirates & 59 & $58.42 \%$ \\
\hline Serious injury to other crew & 56 & $55.45 \%$ \\
\hline Beaten with an implement (for example a rod, stick, or gun) & 47 & $46.53 \%$ \\
\hline Ship used as "mother ship" for pirates to operate from & 39 & $38.61 \%$ \\
\hline Being hung by the tied hands or arms & 36 & $35.64 \%$ \\
\hline Other forms of extreme physical abuse & 31 & $30.69 \%$ \\
\hline Held by yourself with no other crew for long periods & 30 & $29.70 \%$ \\
\hline Death of other crew member & 27 & $26.73 \%$ \\
\hline Serious injury to self & 25 & $24.75 \%$ \\
\hline Forced to remain uncovered outside for extended periods & 20 & $19.80 \%$ \\
\hline Hung overboard & 9 & $8.91 \%$ \\
\hline Electric shock & 0 & $0.00 \%$ \\
\hline
\end{tabular}

Most former hostages experienced multiple forms of abuse. The chart below shows the distribution of the number of negative events experienced by hostages. 
18 | The Long-Term Behavioral Impact of Piracy on Seafarers and Families

FIGURE 9: Distribution Of The Number Of Types Of Abuse Experienced By Hostages

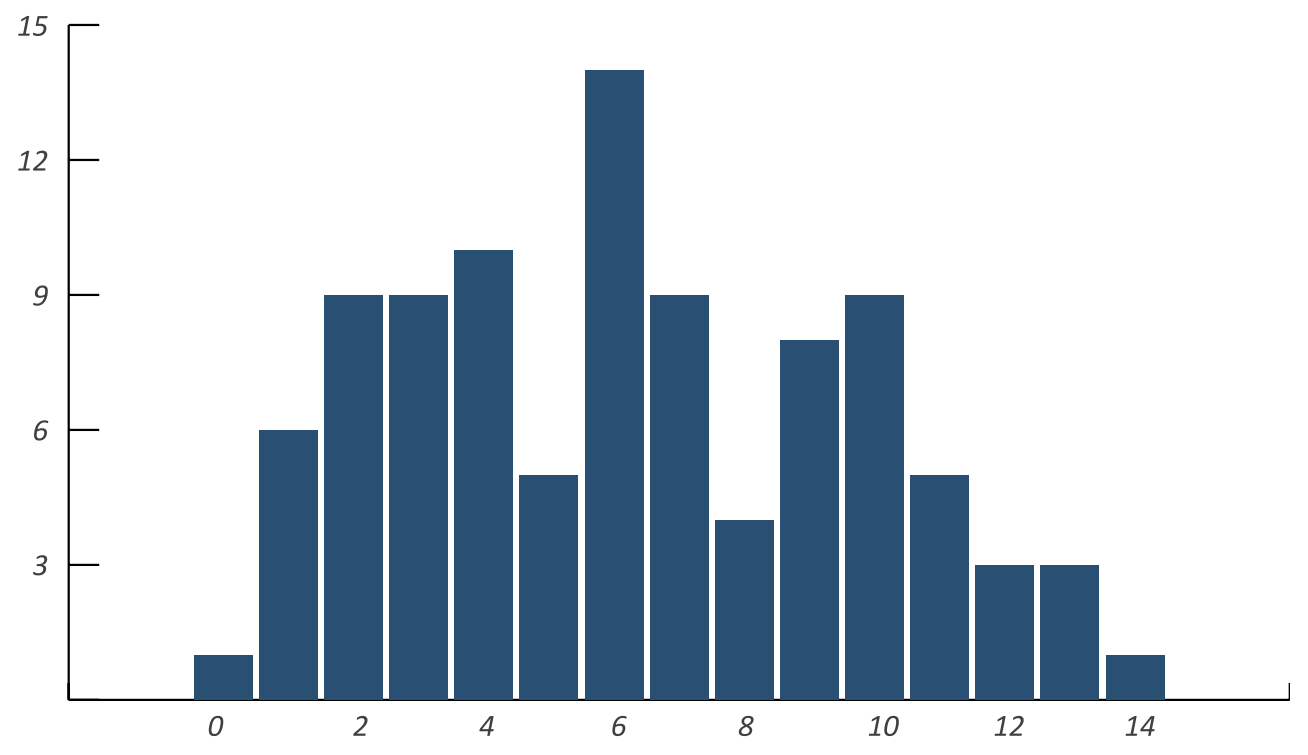

\section{PROBABLE PTSD}

Specific predictors of post-traumatic stress disorder were examined in this group, with attention to their unique experiences. While the sample size was small enough that a finding of no effect doesn't necessarily mean that there is no relationship, the key effects that were found include the following:

- No individual category of abuse is a significant predictor of distress, but the sum total of abuse is a significant predictor of probable PTSD. For each different type of abuse suffered by seafarers, the predicted probability of developing PTSD was increased by $2 \%$.

- $\quad$ No demographic variables were significant predictors of probable PTSD.

See Appendix XIII for the full analyses.

\section{POST-TRAUMATIC STRESS SYMPTOMS}

When considering post-traumatic stress symptoms overall, a different pattern emerges.

- Several individual categories of abuse show higher rates of impact on post-traumatic stress than others. Individual categories of exposure associated with higher post-traumatic stress symptoms include being beaten with a stick or object, being hung by tied arms, witnessing death and injury of other crewmembers, being threatened with death or beating, and being given insufficient food or water.

- When these are entered simultaneously into a regression, however, none remain significant. This makes it challenging to identify which of these items may be the driver of the effect: because many seafarers experienced multiple types of abuse, it is hard to say whether the increase in risk found here is related to the specific type of treatment or whether there are some links between different types of abuse. 
- The sum of abuse suffered is a significant predictor of increased post-traumatic stress symptoms.

- No demographic variable impacts this.

Full results are in Appendix XIV.

\section{DEPRESSION SYMPTOMS}

- Several categories of exposure were predictive of more depressive symptoms. Being slapped or beaten either with fists or an object, being hung by tied arms, witnessing other crewmembers being injured, being threatened with beating, and being given insufficient food were all predictive of higher numbers of depressive symptoms. When these items were entered simultaneously, the latter two items were particularly important for predicting depressive symptoms.

- The sum of different types of abuse experienced was also significant, but not when controlling for those items.

- No demographic variable was found to be predictive.

Full results are in Appendix XV.

\section{INTERPRETATION}

These data show the severity and extent of the abuse suffered by hostages. Consistent with prior work on traumatic experiences, those seafarers who suffered more abuse were also more likely to have lasting post-traumatic distress. While the

Pirates board ship. Photo from Hostage Support Partnership

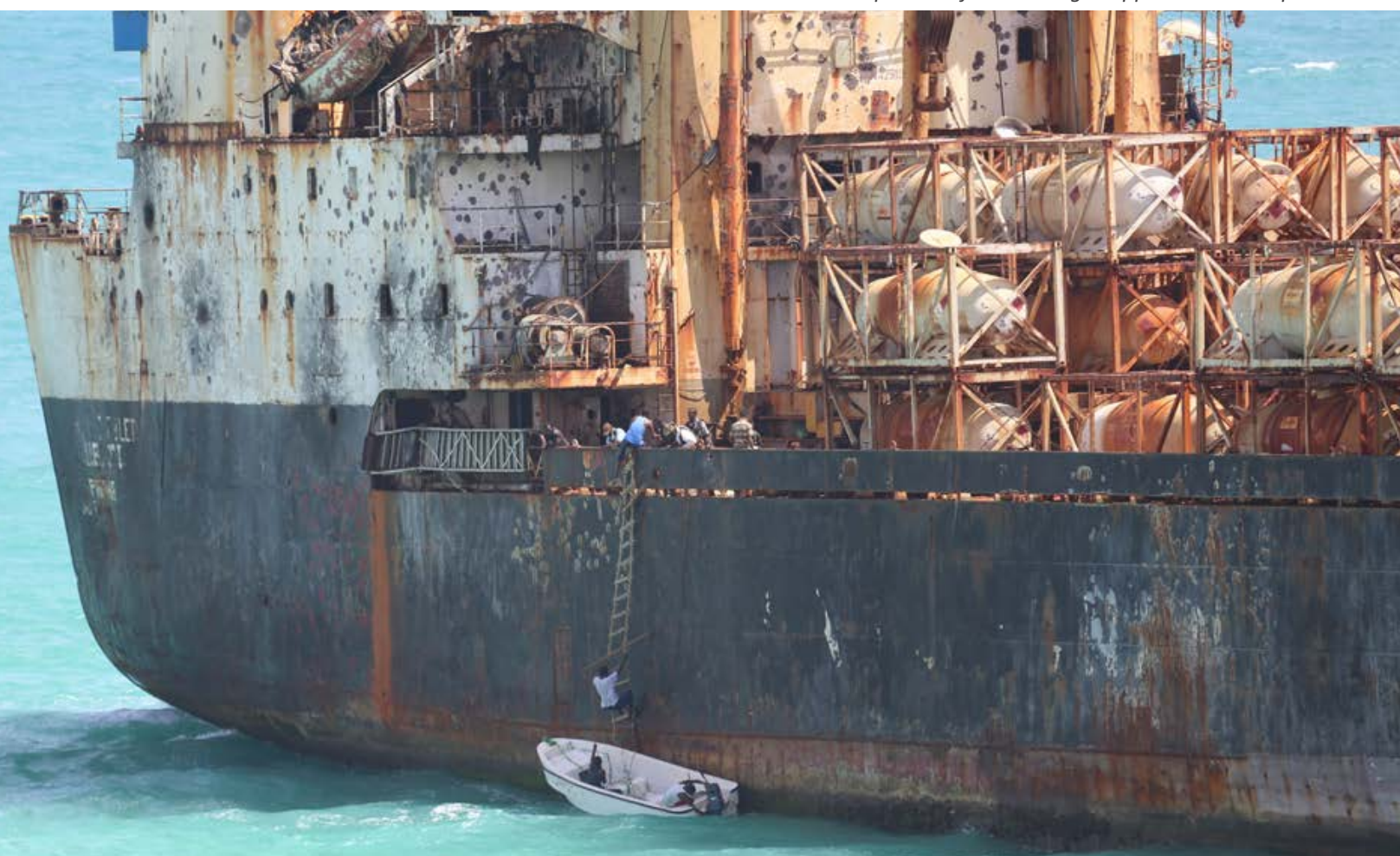


total amount of abuse experienced appears to be the element most predictive of distress, there is some evidence that some types of abuse, particularly deprivation of food and threats of beating, were particularly upsetting for seafarers in this sample.

On balance, the findings are not clear enough to argue that seafarers facing specific types of abuse should be targeted for specific support. Instead, these data suggest that it is the overall severity of their experience as a whole that is most related to long-term distress. This is consistent with other research on traumatic events, and suggests that while all former hostages may be at risk for lasting distress, this risk may be particularly strong for those who have had longer hostage experiences or who experienced more, different types of abuse.

\section{FAMILY MEMBERS}

Seafarers are not the only people affected by piracy. The families of seafarers are also impacted. In particular, the families of hostages must cope with the knowledge that their loved one has been captured while also not knowing what is happening. In some cases, pirates have even been known to contact families directly and threaten their seafarers as a way of increasing pressure on the companies for negotiation:

The pirates are the ones actually asking the captain to call his family. While he was speaking to the family, they would torture the captain. That was really upsetting. The pirate(s) would physically abuse the captain while he is speaking with his wife. In effect, the captain would beg his wife to help him and beg the ship owner to pay the ransom. ${ }^{41}$

\section{))}

In addition to the obvious distress that this situation can cause, this type of situation-in which a loved one is under threatmeets the definition of a traumatic event. ${ }^{42}$ People who experience this kind of direct knowledge that their family members are threatened may also be at risk for long-term behavioral impacts. To date there has been very little work done on how this may affect the families of seafarers captured by pirates.

This study examined rates of long-term effects among the families of seafarers. Thirty-eight family members, identified originally by participating seafarers, agreed to participate in this study. The majority of these family members were related to seafarers who had been held hostage: only 3 of the 38 family members who agreed to participate were related to seafarers who had not been held hostage.

FIGURE 10: Demographic Information, Family Members In This Sample

\begin{tabular}{|l|c|c|c|}
\hline RELATIONSHIP WITH SEAFARER & NUMBER & GENDER & $\begin{array}{c}\text { AGE RANGE AND } \\
\text { MEAN }\end{array}$ \\
\hline Spouse or cohabitating partner & 25 & $25 \mathrm{~F}$ & $23-63,41.68$ \\
\hline Parent & 7 & $4 \mathrm{M}, 3 \mathrm{~F}$ & $44-64,53.15$ \\
\hline Cousin & 3 & $3 \mathrm{M}$ & $21-28,25.67$ \\
\hline Child & 2 & $1 \mathrm{M}, 1 \mathrm{~F}$ & $18-23,20.5$ \\
\hline Sibling & 1 & $1 \mathrm{M}$ & 27 \\
\hline
\end{tabular}

Most statistical analyses with such a small group of participants are not trustworthy. However, an analysis of some basic responses yields some findings. Even with a small sample, there is a clear and lasting impact from piracy on family members. This is unsurprising when considering the experience of families of hostages. One wife of a former hostage interviewed described what it was like knowing her husband was in captivity: “My relatives brought me to churches. There wasn't much to

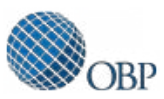


do but pray. I always went to Divine Mercy... I could not [sleep]. My stomach always ached; it was as if something was moving inside. When I was on the ship to Manila when we were called to report the first time, I was not able to directly proceed to the office because I had a fever." The impact of this experience appears to linger in families, with some showing lasting concern about seafarer wellbeing and long-term distress.

\section{CONCERN ABOUT SEAFARER WELL-BEING}

Families showed overall high levels of concern for seafarers at sea. Responding to the questions "When your seafarer is at sea, how much do you think about the risk of piracy?" and "When your seafarer is at sea, how much do you think about the risk of other things outside of piracy?" family members reported fairly high levels of concern.

FIGURE 11: Levels Of Concern About Piracy And Other Issues, Rated From 1 (None) To 5 (High)

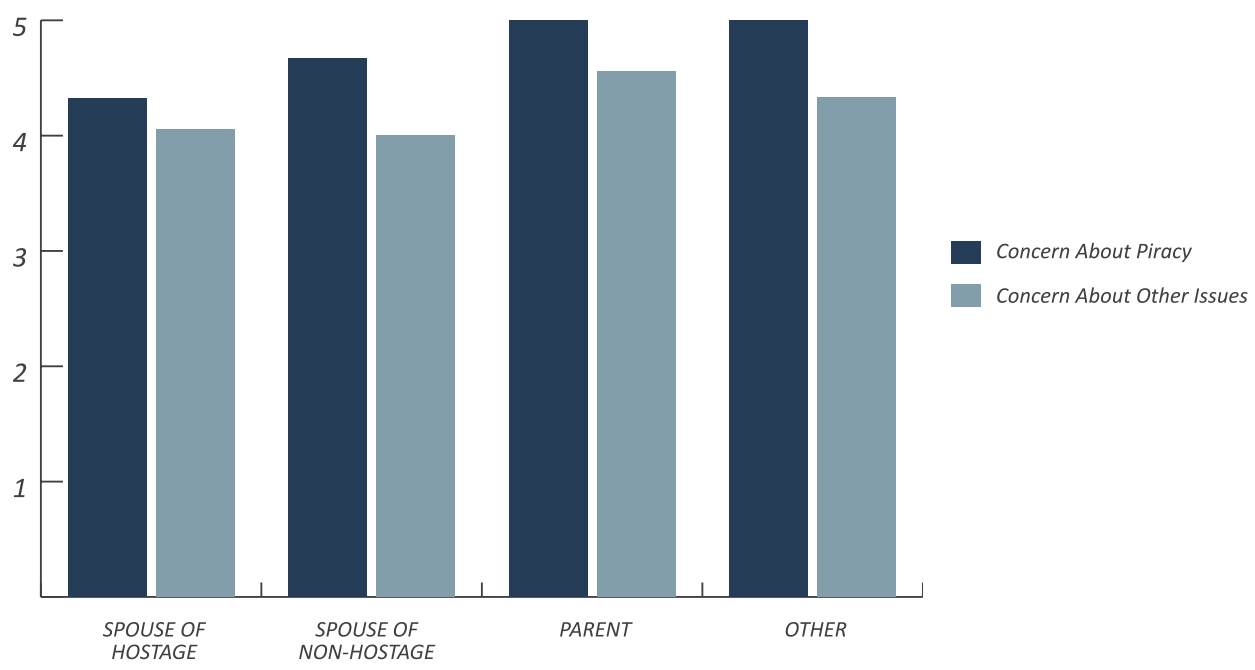

\section{KNOWLEDGE ABOUT HOW TO GET INFORMATION ABOUT SEAFARER}

For family members, one of the major issues they must cope with is the potential lack of information about what is happening to their seafarer if there is an attack or a problem. To track this, family members were asked if they had received any information from anyone about how they would be contacted if anything bad happened, and how confident they were that they would know how to get information about their seafarer in such an event. 
FIGURE 12: Percent Answering Yes, They Have Been Given Information About How They Will Be Informed If Something Happens At Sea

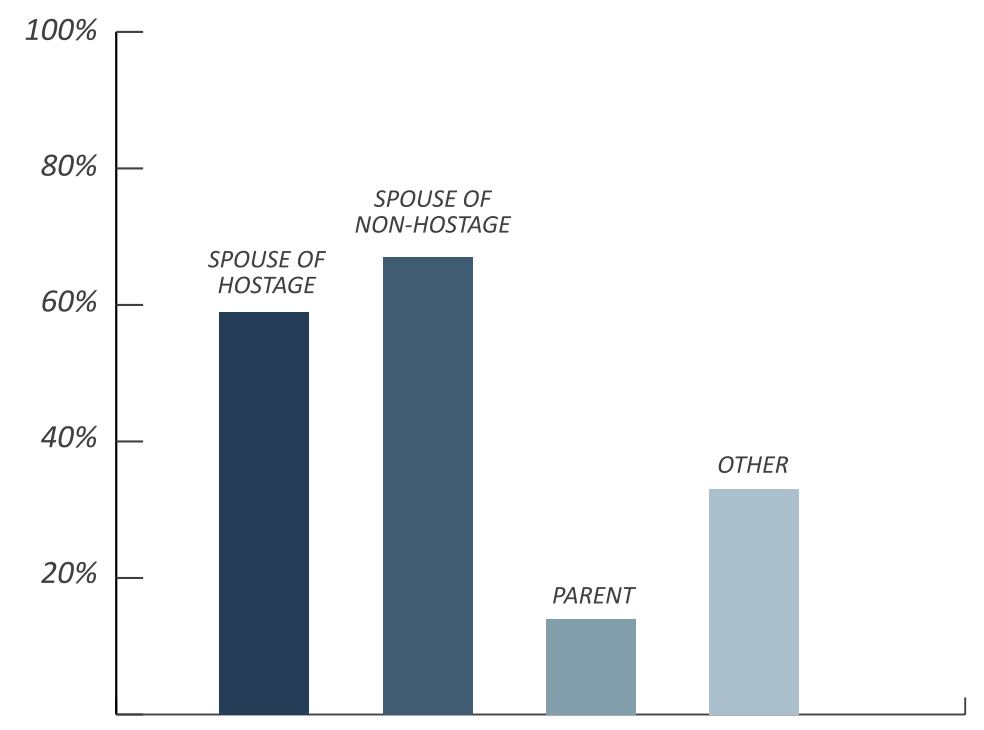

FIGURE 13: How Confident Are You That If Something Happened At Sea To Your Seafarer, You Would Know Who To Talk To In Order To Get Accurate Information?

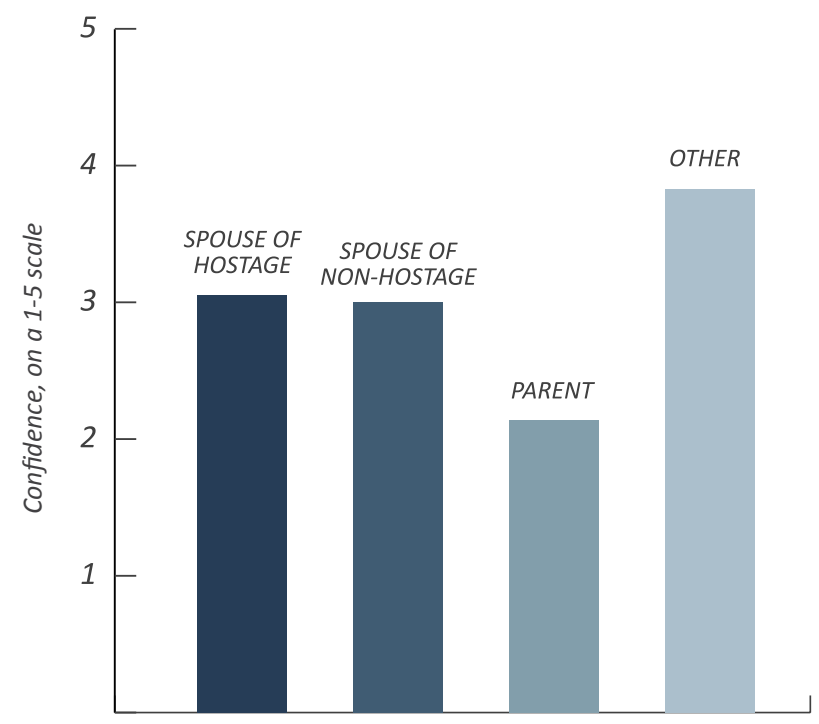

The scale used ranged from 1, "Not at all confident," through 3, "A little confident," to 5, "Extremely confident." On this basis, it suggests that family members are, on balance, not strongly confident that they know who to talk to in order to get accurate information about their seafarer.

One challenge faced by the families of seafarers is that there is not a clear and universal source for information on what is happening at sea. In a follow-up question, the survey asked family members who they thought they would approach to 
get information about things that might happen. The most common response (20 participants) was a maritime employereither a manning agency, or they would approach the ship-owning company directly. Other family members also mentioned government agencies, particularly the various ministries of foreign affairss or overseas workers' offices (6 participants). Civil society organizations, particularly in Ukraine, were mentioned by 5 participants, and other family members were mentioned by 6 participants. Other potential outlets, including the media, lawyers, seafarers' unions, and direct searches on the internet, were mentioned by 10 family members.

Overall, this suggests that family members-even spouses - are not enormously confident that they would know how to get information about the status of their seafarer in case of a negative event or pirate attack, and that there is no consensus about what the best way to get information may be. This is particularly concerning in light of the fact that more than $40 \%$ of the spouses of former hostages in this sample report that they have never been given information about how to get information about their seafarer if something bad happens.

For the family members of former hostages specifically, we explored this question directly by asking whether they felt that they had gotten "good information about what happened." Results are in Figure 14 below.

\section{FIGURE 14: Percent Of Sample Answering Yes To The Question "[If Your Seafarer Was Held Hostage] Did You Get Good} Information About What Was Happening?"

OTHER RELATIONSHIP TO HOSTAGE (50\%)

WIFE OF FORMER HOSTAGE $(45 \%)$

PARENT OF

HOSTAGE (29\%)
Less than half of the spouses in this sample whose husbands had been held by pirates reported feeling that they received good information about what happened. There is some anecdotal evidence supporting this: one seafarer interviewed in this project who had been held captive reported: "However, the company did not really communicate clearly what was happening to us. The company was reassuring our families not [to] worry though the company did not really give clear information on what was happening to us. They were telling my wife, to the effect that, 'if you hear something about your husband and his crewmates, do not worry, they are fine.' They never actually told my wife that I
mation about the well-being of their seafarer may act as was captured by pirates." This is a significant lapse; the lack of information about the well-being of their seafarer may act as a significant stressor for families.

\section{LASTING PSYCHOLOGICAL IMPACT}

The effects of the stress of piracy are apparent in the assessment of lasting post-traumatic distress in this report. As with seafarers, probable PTSD was assessed using the PCL-C scale. Results are in Figure 15.

FIGURE 15: Probable PTSD In Family Members

\begin{tabular}{|l|c|c|}
\cline { 2 - 3 } \multicolumn{1}{c|}{} & $\begin{array}{c}\text { NUMBER, } \\
\text { PROBABLE PTSD }\end{array}$ & $\begin{array}{c}\text { RATE, PROBABLE } \\
\text { PTSD }\end{array}$ \\
\hline Wife of former hostage & 6 & $27 \%$ \\
\hline Wife of non-hostage & 1 & $33 \%$ \\
\hline Parent of hostage & 2 & $29 \%$ \\
\hline Other relationship to hostage & 1 & $17 \%$ \\
\hline
\end{tabular}

Due to the small sample size, extreme caution should be taken in interpreting the rates of probable PTSD. In particular, the rate of probable PTSD in the wives of non-hostage seafarers is likely heavily distorted by the small number of family members in this category. Because of this small sample size, the base rates of 
Port Seafarers Centre and the Yuzhniy Port Seafarers Centre also have staff trained to provide connections to local psychologists and psychological assistance for seafarers who need support. Maritime trade unions are also heavily involved in promoting seafarer wellbeing and providing additional support; these include the Marine Transport Workers' Trade Union of Ukraine and the Ukrainian Maritime Trade Union Federation. Other local organizations providing support to seafarers include the Ukrainian Research Institute of Transport Medicine and a number of local law firms focusing on maritime issues and seafarer rights.

In addition to these institutions, which have some formal plans in place for addressing survivors of piracy, a number of institutions offer psychosocial support services that may be accessed by survivors of piracy. The Lab of Extreme and Crisis Psychology of the Ministry of Emergency of Ukraine is an example of an institution offering broad support that has offered outreach to seafarers affected by piracy in the past, and related organizations, such as the Volunteers' Psychological Service of Odessa, may be potential resources as well. Similarly, although engaged more at the diplomatic level, the Ukrainian Ministry of Foreign Affairs has been heavily involved in the release of Ukrainian seafarers and assisting them with accessing additional resources.

Despite the relatively broad availability of institutions offering support, psychosocial workers targeting seafarers in Ukraine report that uptake of these resources is somewhat limited. This is potentially related both to the general stigma against accessing mental health resources that is as evident in Ukraine, as it is in many other countries, and to a specific concern seafarers may have that accessing mental health services may lead to them being deemed unfit for future work at sea.

\section{IN INDIA}

In India, the overall landscape of service providers able to offer psychosocial support for seafarers includes the same basic structures found in Ukraine, but a different distribution of where the efforts are concentrated.

As in Ukraine, several international organizations in the maritime area have local programs within India targeting seafarers affected by piracy and providing other services. MPHRP has an India and South Asia chapter focusing on providing support within India, and other major seafarer support organizations, including Sailor Society, Mission to Seafarers, and Stella Maris/ Apostleship of the Sea, have staff working with seafarers in India. India also has a robust civil society sector supporting seafarers, both in general and specifically those affected by piracy. There is a large community of unions and professional associations who represent maritime industry associates or seafarers, including the National Union of Seafarers of India; the Maritime Union of India; the Forward Seamen's Union of India; the Maritime Association of Shipowners, Shipmanagers, and Agents; the Indian National Shipowners' Association; the Foreign Owners Representative and Ship Managers Association; The Company of Master Mariners of India; and the Indian chapter of the Women's International Shipping \& Trading Association. All of these institutions have some nexus to the care and support of seafarers. In addition, seafarer centers and seamen's clubs in several port cities exist to offer accommodation and support to seafarers, and have been helpful in assisting seafarers affected by piracy. These include the Kandla Seafarers' Welfare Centre, the Jarwahalal Nehru Port Trust Seafarers Centre, the Chennai Seafarers Centre, and the Prince of Wales Seamen's Club in Mumbai.

This sector is supported by several institutions specifically dedicated to providing financial support to seafarers or family members in need, all of which may be able to provide financial support to seafarers affected by piracy. The Seafarer's Welfare Fund Society was established by the National Welfare Board of Seafarers to provide support to seafarers and the families of deceased seafarers. The Maritime Floating Staff Welfare Trust Fund provides support to Indian seafarers and merchant marine officers and families. The Merchant Navy Officers' Welfare Fund assists with medical support for merchant marine officers and support for the education of officers' children. The Benevolence Fund of the Institute of Marine Engineers provides support for engineers and the families of marine engineers in need.

At the level of the government of India, the Directorate General of Shipping under the Ministry of Shipping has been the primary institution working with maritime piracy and has facilitated both the release of seafarers affected by piracy as well as support and assistance for affected seafarers and their families. The Indian Ministry of Social Justice and Empowerment is
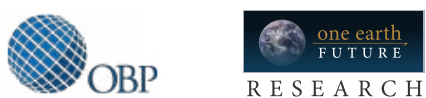
responsible for supporting welfare and social justice for disadvantaged and marginalized elements of Indian society, and as such may be an additional governmental resource for providing support.

India also has a large and active community of psychologists and behavioral health experts working in the fields of trauma and recovery. Institutions including the National Academy of Psychology, the National Institute of Mental Health and Neurosciences, and the Indian Institute of Clinical Psychologists have active programs focused on psychological assistance and support for overall mental health and resilience. Such institutions represent a significant resource for providing psychological assistance.

\section{ANALYSIS}

These two countries illustrate the fragmentation of the response to piracy's behavioral impacts but also the relatively large number of resources available. In both countries, entities including national governmental institutions, international and local civil society organizations, and private sector groups have either directly demonstrated the ability to provide support to seafarers affected by piracy or have provided support to other people coping with traumatic events. This diversity of resources offers both an opportunity for and a challenge to supporting the recovery of seafarers. The opportunity comes from the fact that there is a relatively large and active community of institutions prepared to offer support of some kind. The challenge comes when there is no central organization operating as a coordinating mechanism for documenting what resources are available and assisting seafarers and families with navigating their access to them. In the absence of such a centralizing force, there is the possibility that seafarers will get inconsistent information from several different groups, miss resources that would otherwise be available, or get duplicate offers of support in one area but potentially none in another.

\section{OVERALL ANALYSIS AND RECOMMENDATIONS}

One positive element of the response to piracy as a traumatic event is the fact that there is a large and active field of research developing best practices for dealing with large-scale traumatic events. Based on this research, it is possible to develop general guidelines for best practices for how the response to piracy should be structured.

Mark van Ommeren and colleagues argue that there is "developing consensus" on how to support communities affected by large-scale traumatic events. ${ }^{44}$ This consensus, in their description, draws a distinction between social interventions designed to support healthy social functioning and reintegration in the community and mental health interventions designed to support recovery in people experiencing specific post-traumatic distress. The former includes programs designed to restore normal social function as soon as is reasonably possible, while the latter includes targeted mental health support for people who need it. Best practices for reducing the impact of traumatic events include developing a coordinated response that builds both social interventions that reach the broader population with less intense or prolonged exposure and targeted mental health programs for those at higher risk of developing a diagnosable mental health disorder or those who function adequately but experience symptoms that are bothersome. Best practices also include, where possible, having well-developed and exercised plans in place before disasters or traumatic events occur and utilizing effective information dissemination mechanisms during the event itself, continuing through lasting recovery.

Applying this general approach to piracy suggests that a coordinated response to piracy should include good planning and information dissemination before a seafarer is exposed to threat, positive support and information exchange during captivity, planned and coordinated reintegration and support for social activity after release, and targeted mental health support for people who need it. These services should be targeted to both seafarers and their families. Given the diversity of institutions available to support seafarers, executing such a coordinated plan will also probably require cross-institutional coordination tools such as formal plans and memoranda of understanding and even annual drills or practice exercises. In addition, a coordinated response must involve a conscious plan to overcome barriers to accessing available resources, including widespread stigma around mental health issues and a deep unwillingness among some seafarers to access mental health support.
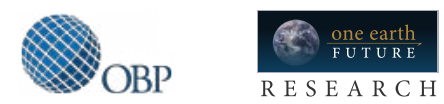


\section{PIRACY-SPECIFIC RESPONSE}

Against this general background of research on best practices, specific programs should be developed with the starting points identified in this research. Specific points relevant to the development of best practices include the following:

1. The majority of seafarers exposed to piracy did not show long-term behavioral problems rising to the level of severe impairment. In some cases, there were even some signs of improved well-being.

2. A sizeable minority of seafarers did show symptoms of experiencing lasting effects. Twenty-six percent of former hostages showed symptoms consistent with PTSD, more than double the rate for the general population. In addition, former hostages show higher rates of depressive symptoms and poorer overall well-being than non-hostages. Their family members show significant effects as well.

3. Prior maritime trauma may have an independent impact on seafarer well-being. Post-traumatic stress symptoms were independently related to exposure to negative events in the maritime environment and to being held hostage.

Based on these overall findings, any response to the long-term impact of piracy should be built around the following basic pillars:

1. The response to maritime piracy should be an integrated response including pre-event planning and training, reduction of stigma around the use of psychological support, during-event management, and post-event support and care. Care for the families should be considered an integral part of the response.

2. Post-event care should include social integration and support as well as targeted mental health support. All hostages will benefit from the former, and a minority will need the latter.

3. Programs designed to mitigate the long-term impact of piracy should also, if possible, support resilience in the face of other maritime-related traumatic events.

More detail on each point follows.

The long-term impact of traumatic events can be significantly mitigated by prior preparation and training, as well as information management and support during the traumatic event. Because of this, mitigating the long-term impact of piracy should be considered a project that includes pre-departure training and preparation, during-event support, and post-event interventions. These activities should include elements designed to reach families as well as seafarers, and reduce barriers to access, such as perceived stigma around mental health issues.
The response to maritime piracy should be an integrated response including preevent planning and training, reduction of stigma around the use of psychological support, during-event management, and post-event support and care. Care for the families should be considered an integral part of the response. 


\section{Pre-Departure Training}

This research suggests that pre-departure training for seafarers transiting high-risk areas can be a valuable tool for reducing the long-term impact of experiencing piracy. The current focus of pre-departure training received by seafarers in this study

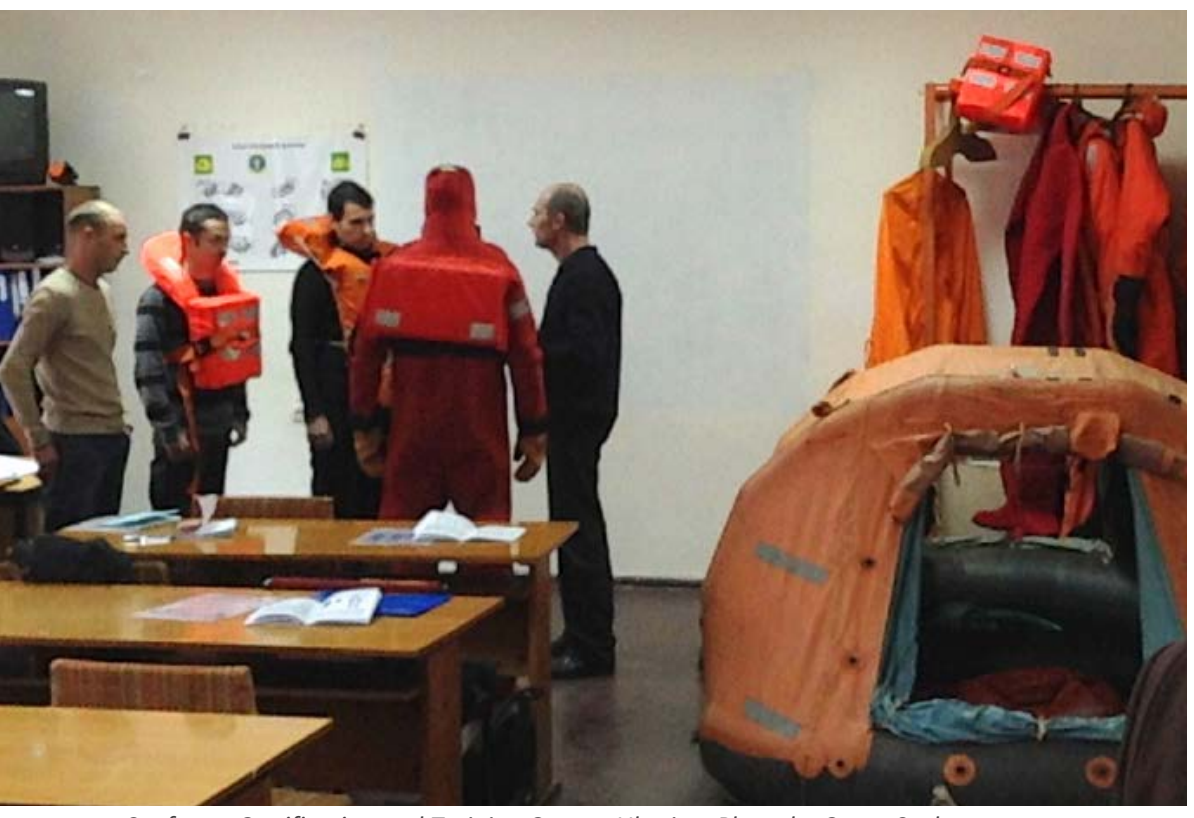

Seafarers Certification and Training Centre, Ukraine. Photo by Conor Seyle is heavily weighted towards harm mitigation through an emphasis on practical elements addressing specific threats associated with piracy. This is valuable for two reasons. Such training may actually reduce the threat of piracy by providing seafarers with more effective tools for response. In addition, by providing seafarers with a plan for how to respond, it may provide additional perceived control during the traumatic event.

One possible extension of pre-departure training would be the development of a module specifically focused on basic psychoeducation, including positive stress-management techniques for highintensity events such as piracy. Basic coping techniques, such as breathing exercises to manage physiological stress, can be effective in reducing acute stress and improving functioning during traumatic events. Reducing physiological stress responses during the traumatic event can improve longterm functioning. Several institutions, including the Seamen's Church Institute of NY \& NJ, the Maritime Piracy Humanitarian Response Programme, and the Crisis Response Centre of the Sailors' Society have already developed initial trainings or familiarity with these issues. In addition, models for this kind of training have been developed by responders to other forms of trauma and may be valuable resources for agencies or governments interested in adding this component. Some examples include "Psychological First Aid," 45 "Skills for Psychological Recovery," ${ }^{46}$ and "Trauma Risk Management (TRiM)." 47

Pre-departure training on piracy is not available for family members, but a corresponding program focused on providing information about piracy risk and the support available to seafarers' family members would be a valuable addition to the current system. One possibility is for state institutions focused on piracy as a part of their mandate to consider the development of basic outreach and information tools to provide specific information about piracy and the current systems in place for response to families. Another option is for pre-departure training to include an information sheet specifically targeted to families including the shipping company's points of contact for piracy, which can be sent to families via post or e-mail. This may also include information about how to access seafarer pay due them while a seafarer is in captivity, a listing of other resources for support, and recommendations for how to respond to pirates if they reach out to families directly.

\section{During-Event Response}

Transparent, timely, and accurate information exchange during large-scale traumatic events is an important part of reducing the negative long-term impact. In many cases, not knowing what is happening is worse for family members than having specific information. This is significant because of the direct impact on families and because of the possibility that when family members have more significant distress, the impact on seafarers will be profound. A basic assumption of disaster psychology in the current research is that maximizing transparency about information that can be verified as true is the best approach, as it maximizes trust between response organizations and families, reassures families when the news is positive, and allows families to begin to cope with the situation when the news is negative. It also may avoid creating oppositional dynamics: in some cases, families who feel that they have not been treated well may use public, media, and legal avenues to put pressure 
on the companies, which could complicate the negotiation process. Direct engagement with families and building more trust can help prevent families from feeling that this is necessary.

While seafarers are being held hostage, international support organizations tasked with supporting the hostages, including seafarer support institutions, shipping companies, or international organizations, should specifically develop outreach to family members. This outreach should strive to provide families with accurate and timely information, as long as the information passed along is verified. Where possible, this outreach should be coupled with access to social and mental health support. As with post-event care, support for families should include connection with pre-existing social supports, information about what to expect in terms of traumatic stress responses, and basic information about positive coping skills, in addition to cautions about negative coping activities such as self-isolation or substance misuse. This may not be sufficient to mitigate long-term negative impact, however. During the time when a seafarer is under threat, the family will likely be under continuous stress. As a result, the connection with social support and coping skills, while valuable, is likely to result primarily in the mitigation of acute distress. More targeted crisis interventions and mental health support may still be needed in a small but significant number of people once the situation has resolved and the family members have moved on to more systematic processing of the event or have emerged from a protective denial. In addition, many families suffer a practical impact in the form of financial stress from the loss of the wages of their seafarer, which can cause significant hardship. Financial concerns compound the stress on families - which is often suppressed while family members focus on taking care of basic needs like paying for shelter and food and planning for safety. Companies responsible for paying seafarers should ensure that payments are made to the families of hostages during the period of captivity, and social support organizations assisting families should prioritize financial support for families who do not receive funding from their employers.

Following the release of a hostage, programs for support should be developed that include re-integration with social support systems, re-establishment of engagement in routine behaviors as soon as possible, and targeted crisis intervention that includes information on what types of responses to expect after involvement in a traumatic event; practical, tailored coping skills development; and formal, targeted mental health interventions when necessary.

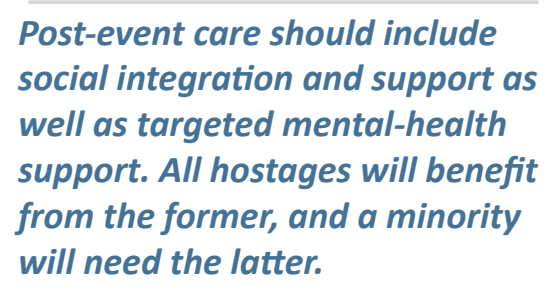

Post-event care should include social integration and support as well as targeted mental-health support. All hostages will benefit will need the latter.

\section{Social Support}

Hostage experiences are intense and difficult. This study suggests that their lasting impact is relatively high when compared to the effects of other traumatic events. However, in absolute terms, it is still the case that a strong majority of seafarers who have been held hostage show no signs of having lasting post-traumatic stress rising to the level of functional impairment.

Humans are generally resilient: most people bounce back from negative events with no lasting negative impact. Social support and re-integration is a critical part of this resilience. Some researchers have argued that "The best immediate therapy for acute stress is social," and that the re-establishment of social bonds and normal social functioning is the foundation of effective recovery from large-scale traumatic events. ${ }^{48}$ In the case of maritime piracy, this should take the form of speedy re-integration of seafarers into their normal lives and communities. This can also include, if the seafarer is interested in continuing to work at sea and is ready to re-engage, a speedy re-integration into professional life.

Such re-integration is a challenge for a variety of practical and bureaucratic reasons. Piracy is a crime, and seafarers released from captivity may experience delays in repatriation and reintegration with their families while they are debriefed by law enforcement agencies. There may also be delays associated with visas and travel documents, as former hostages are often released far from their home countries without their passports or other documentation. This delay is not necessarily bad; it allows state and company institutions to provide immediate medical and emotional care, and the law enforcement need for effective documentation of the case is real. However, re-establishing normal social engagement should be considered an important part of recovery, and delays should be minimized wherever possible.

During the delay before seafarers are repatriated or united with their families, attempts should be made to maximize social support for seafarers. Communication with family and friends should be allowed if possible, and seafarers should be afforded

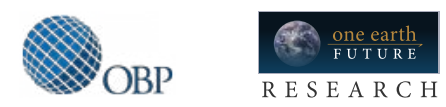


the maximum possible freedom of movement and engagement with each other. Visits from bona-fide seafarers' welfare organizations dedicated to the care of the seafarer and the provision of assistance and welfare services at no cost should be encouraged and facilitated. Institutions involved in hostage release and repatriation should have the contact details of suitable people from these organizations as part of their contingency planning. Additionally, family members need to be informed of and prepared for what to expect in terms of the physical and medical status of their loved one and their appearance and mental condition, especially if the seafarer was held for a significant period of time. Family members should be given recommendations on how to approach to the seafarer, their expectations, limitations, recovery timeframes, and practical ways to ease integration.

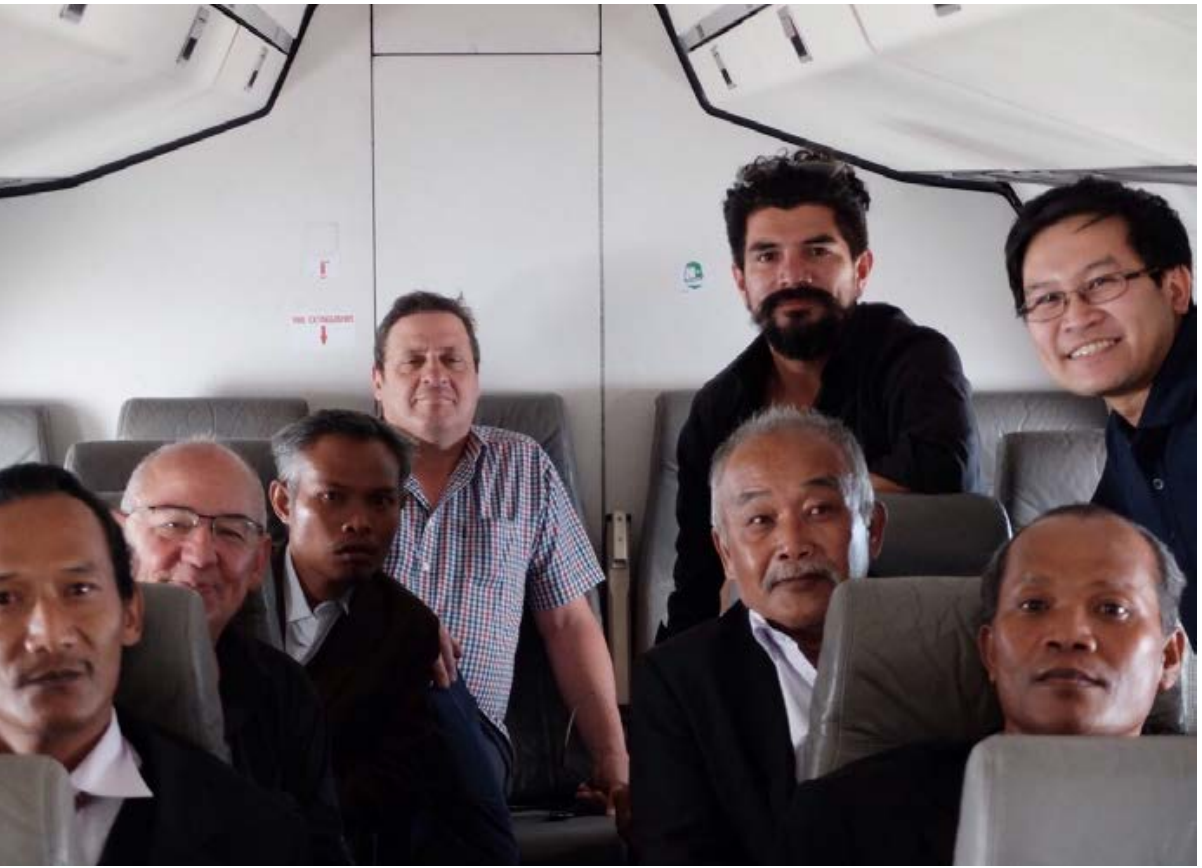

Released hostages from the FV Prantalay and their negotiators. Photo from Hostage Support Partnership
During the immediate response, seafarers will interact with a large number of people from a variety of different law enforcement, legal, state, and private company institutions. Wherever possible, the people designated by these institutions to work with released hostages should be provided with basic training on maximizing social support and working with trauma survivors. There are some basic tools that can provide important support for healthy recovery and reintegration that institutional points of contact should be familiar with. These include, but are not limited to, training in things such as empathetic and active listening, both respecting the privacy of the survivor if they do not want to talk and supporting their possible desire to "ventilate" or share their experiences, and working with the seafarer to encourage a return to control over their own life. ${ }^{49}$ Formal training for designated points of contact working with seafarers should be considered. As discussed, several seafarer support institutions have already begun to develop tools that could be adapted for this purpose, and there are some widely available models for trauma response that may be appropriate for such training.

After release and repatriation, social interventions should focus on encouraging a return to normal social and community engagement as soon as possible. Maximizing these opportunities is in part an issue of minimizing the demands on the seafarer and allowing the seafarer to spend as much time with family as possible, and in part an issue of managing larger social, company, and community perceptions of seafarers and returned hostages. Previous reports by Oceans Beyond Piracy have documented how returned seafarers are sometimes treated by other crewmembers. Some seafarers report that other seafarers or friends in their community treat them differently, expecting them to engage in the angry outbursts or emotional instability popularly associated with PTSD. ${ }^{50}$ This leads to double victimization of seafarers: in addition to coping with the impact of their experiences, they must also cope with the reactions of their co-workers and the associated challenges with reintegration.

Where possible, reintegration programs carried out by the state or by companies should prepare the seafarer for the possibility of such reactions. In addition, a better appreciation among seafarers of the actual likelihood of PTSD may support effective reintegration. Research including this report confirms the larger understanding in trauma research that the majority of former hostages will not have lasting distress or a diagnosable mental condition as a result of being a victim of piracy. Pre-departure training that includes basic psychoeducation should consider including this finding. In addition to its value as a part of the 
training, it may assist in spreading this understanding across the larger community. State institutions tasked with supporting seafarers may also consider targeted information campaigns aimed at manning and training agencies and officers aboard ships and showing that this double victimization is both unfair and inaccurate.

All of these recommendations assume a genuine interest in supporting seafarers on the part of companies and state institutions. It is important to acknowledge that this is not always the case, and some states and companies have functionally abandoned seafarers they are responsible for while others have expressed concern but provided little in the way of actual support. More broadly, in the past, many organizations believed that acknowledging concerns for their employees raised risk management red flags that would make the organization financially responsible for the "damage" to their employees. The research is clear at this point that the opposite is likely true: transparency, information-sharing, and support are best practices for mitigating harm, and hence also help decrease risk management concerns. It is important that companies and governments follow best practice and emulate those who have developed and disseminated materials to assist those who want to provide the best for their citizens and employees, and international mechanisms to promote this should be encouraged.

\section{Mental Health Interventions}

In addition to larger programs focused on social support and reintegration, targeted mental health support is an important part of reducing the long-term impact of being a victim of piracy. This can include providing basic psychoeducation and information to every survivor of piracy along with more targeted support and interventions designed to help seafarers with more specific distress.

One challenge in addressing trauma is destigmatizing seeking mental health support. In many countries internationally, including the United States, there is a stigma associated with accessing mental health services. In the case of seafarers, stories of stigma being attached to people who are seen as having issues such as those above suggest that even if a seafarer is willing to access support, he or she may be unwilling to face the associated negative public perceptions. One way of minimizing this stigma is to provide mental health support as a part of primary medical care. ${ }^{51}$ People are, in general, already used to talking openly to their medical health provider, and approaching mental health care as part of the larger medical support provided after exposure to piracy can be a way of reducing stigma. Developing this approach means consciously working with the institutions providing physical health care and support following release and reintegration to make sure that mental health elements are included in this support and tracking.

Research suggests that the kind of direct mental health support that will be most helpful is a layered approach starting with basic information about coping and resilience and moving to assessments for more serious effects, targeted therapy for people who need more direct engagement, and longer-term access to support for those with delayed-onset issues. In terms of information about coping and resilience, there is some debate over the most appropriate content. Many programs suggest providing "psychoeducation," or basic information on the most likely impact of traumatic events, as a way of normalizing symptoms and providing information about what kinds of symptoms require additional support. The value of this is somewhat contested: several experimental studies on psychoeducation have found little impact, ${ }^{52}$ only modest positive impacts, ${ }^{53}$ or even negative impacts. ${ }^{54} \mathrm{~A}$ recent review of evidence around psychoeducation concluded that on balance, there is little evidence for significant positive impact, but psychoeducation for trauma survivors may be most useful when the emphasis is on healthy coping mechanisms and positive recovery trajectories rather than on negative impacts and trauma symptoms. ${ }^{55}$ Applying this to piracy survivors suggests that initial mental health support should focus on providing positive information about stress relief and basic tools that can be used to support recovery.

In addition to the initial support, specific screening for possible long-term trauma should be conducted in order to identify seafarers who are at higher risk for long-term negative impact. Entities responsible for addressing the medical impact of experiencing piracy, whether state or private, should not assume that an initial screening immediately after release will effectively capture those seafarers who need assistance: many symptoms of the long-term effects of a traumatic event may develop weeks or longer after the event has taken place. Seafarers who are assessed only in the immediate aftermath of an

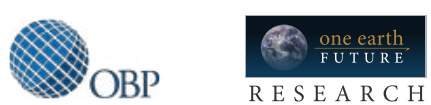


event may not initially show symptoms that will later develop, or alternately may show significant symptoms that resolve over time by themselves. Research on acute predictors suggests that while there are some biological markers that distinguish the response of people more likely to develop PTSD, ${ }^{56}$ based on behavioral data, "in the acute aftermath of a traumatic event, it is not really possible to differentiate between individuals who will subsequently develop a PTSD and those who will it not." 57 While mental health assessments should be integrated into the primary health care provided to seafarers after release to help those experiencing immediate distress, this is not sufficient in and of itself. Ideally, seafarers will be provided with physical and mental health screenings again at least three and six months after the event and annually thereafter. This will help identify those who need additional targeted support to assist with recovery.

There are a number of therapeutic interventions that have been shown to assist people dealing with the long-term impact of trauma. Both PTSD and depression, as well as reduced overall well-being, can be mitigated by appropriate support and, in some cases, medication. Targeted clinical interventions including Trauma-Focused Cognitive Behavioral Therapy, Eye Movement Desensitization and Response, and stress management interventions have been shown to be effective in reducing symptoms of PTSD. ${ }^{58}$ Which specific method is most appropriate for the affected seafarer is dependent on the tools available to the therapists able to provide the therapy.

Because of the potential for delayed onset for symptoms, it is important that whichever therapeutic intervention is used, mental health support offered to seafarers should include some component of lasting support. Seafarers may appear fine for several months, only to develop issues later. If the entire support system is focused on the immediate release and reintegration period, these seafarers will be left out of the system. One way to mitigate this would be to directly target released hostages for assessment and support at three, six, or twelve months after the release, as discussed. Another would be to ensure that former hostages have a specific mental health provider they can access as needed if they develop specific issues.

\section{NOVEL APPROACHES FOR PROVIDING SOCIAL SUPPORT AND MENTAL HEALTH CARE}

The current system in place for providing support to seafarers is built around the institutions that already exist, including port chaplains and social institutions, state organizations, and the maritime industry. In addition to these institutions, some elements of how the maritime industry is structured suggest that there may be room for novel tools to support post-piracy recovery and reintegration. One potentially promising tool is the developing field of e-therapy, where therapy is provided through online media that may include static websites, email or text interactions with therapists, or video chat. There is some developing evidence that e-therapy can be effective as a mental health intervention for both general mental health issues ${ }^{59}$ and PTSD specifically. ${ }^{60}$ The highly mobile nature of the seafarer's profession suggests that e-therapy tools may be particularly valuable for supporting seafarer resilience and recovery. The development of web-based or even smartphone app-based tools for psychoeducation, self-administered screening tools, and direct psychological assistance may be particularly valuable for the seafarer population. There is already some experimentation in this area: the seafarer support organization Sailors' Society has recently released the "Wellness at Sea" app intended to support seafarer well-being across "social, emotional, physical, intellectual, and spiritual" dimensions ${ }^{61}$.

This study demonstrates that piracy has a lasting impact on at least some seafarers, but also demonstrates how other maritime events and overall stress can impact seafarers. Overall levels of post-traumatic stress, whether from prior traumatic events at sea or from piracy specifically, had a significant impact on seafarers' physical and mental well-being.

The aggregate impact of mental health issues on workplace performance can be significant. A 2008 study by the RAND Corporation looked at the long-term impact of war-related trauma in American servicemen and women. The analysis found that in that population, the cost of mental health-related slowdowns or lost work was so high that the delivery of best-practice mental health support to veterans would "pay for itself within two years, or even save money, by improving productivity and reducing medical and mortality costs." ${ }^{12}$ In the case of seafarers, it is likely that a similar improvement in workplace
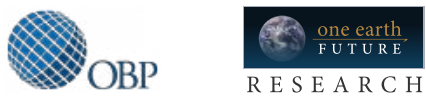


\section{Programs designed to mitigate the long- term impact of piracy should also, if possible, support resilience in the face of other traumatic maritime events.}

effectiveness may result from better support, although the question of what entity is responsible for paying for this care is more open.

The topic of seafarer mental health has been addressed by other seafarer institutions, including the Seamen's Church Institute of NY \& $\mathrm{NJ},{ }^{63}$ and how to develop these systems and encourage their use remains a point of debate. This research suggests that some system

addressing stress management and allowing seafarers to access systematic mental health support may be an important tool for improving seafarer well-being and workplace performance. The development of such a system could contribute significantly to the overall well-being of seafarers.

Currently, there is no comprehensive model for supporting seafarer mental health, but several institutions are aware of the potential need for such a model or are working to provide specific and targeted support to seafarers who request it. Given the clear association between mental health and experiencing piracy-related trauma, there is the potential for piracyspecific programs to contribute to the overall "patchwork quilt" of mental health services and support for seafarers. While some elements of programs designed to support resilience in the face of piracy must necessarily address piracy-specific issues, broader issues of mental health and resilience can be addressed as well. The tools for coping and positive emotion management that can be a valuable part of psychoeducation are not limited to piracy-specific threats. In particular, the recommendations here for pre-departure training about piracy for both seafarers and maritime industry representatives open the door for engagement with elements that can support awareness of mental health and trauma issues outside of piracy. If pre-departure training is expanded to include psychoeducation and coping tools, seafarers can be encouraged to use these tools to address other issues such as isolation, separation from loved ones, and loss and grief for both themselves and other seafarers they interact with. Sensitization and psychoeducation training aimed at maritime industry figures should also address larger issues of mental health as well as the potential specific impact of piracy. If officers or senior crew are more familiar with the symptoms and impact of mental health issues, they may be able to proactively identify issues in their crewmembers and help seafarers mitigate the development of a serious mental health concern or problem on board. Doing this could help provide the maritime industry with better tools for stress management and support, and potentially decrease the stigma associated with mental health issues and accessing help and support. While this is only part of a larger and more comprehensive approach to providing mental health support to seafarers, the necessity of providing this kind of resource as a part of mitigating the negative psychological impact of piracy suggests that there is a clear opportunity to support the overall engagement of seafarers with mental health issues.

This training may also support a greater appreciation for the human cost of piracy and other traumatic events at sea as a valuable element of improving seafarer well-being and resilience among seafarers. Encouraging seafarers to access mental health resources in general will help provide support for those affected by piracy, and would also help address issues unrelated to piracy, such as substance misuse, depression, or other mental health issues. Other tools supporting this general awareness may be valuable. One such tool is a greater focus within public reporting on the psychological and behavioral impacts of maritime events. Institutions tasked with reporting on seafarer well-being may consider adding reporting on seafarer mental and behavioral health and promoting open discussion about seafarer well-being. Reporting tools that allow seafarers to report other traumatic

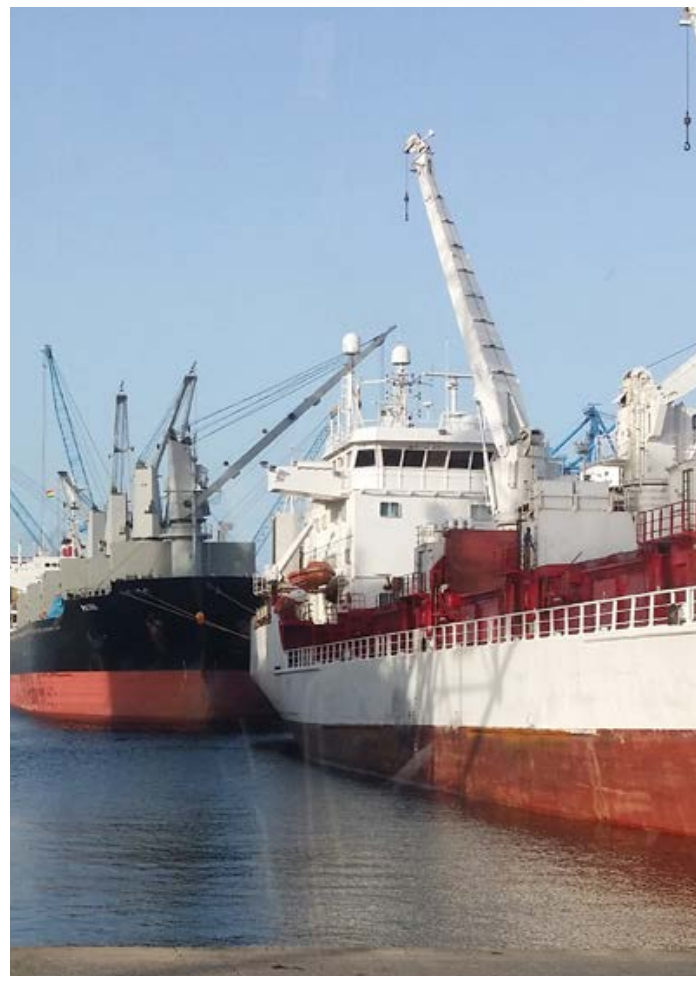

Port in Ghana. Photo by Greg Clough events and their impact may be valuable in that sphere. 


\section{POTENTIAL MODEL FOR RESPONSE}

The full development of these proposed interventions should be left to the specific institutions tasked with supporting seafarer mental health internationally. However, the potential model below shows one way that these recommendations may be integrated into a holistic and layered approach to supporting seafarers, and identifies potential actors who could support each step. For an alternative perspective which is also consistent with these recommendations, see the ISWAN/MPHRP good practice guide for shipping companies and manning agencies. This guide includes specific information about how shipping companies and manning agencies can work with seafarers and families directly. ${ }^{64}$

\section{Prior To Pirate Attack}

1. Seafarer support institutions interested in mental health issues should develop packaged psychoeducational training elements to be included in trainings tailored to the seafaring culture and aimed at companies and manning agencies, maritime industry figures, seafarers themselves, or government representatives.

2. Shipowners should develop specific plans for responding to incidents of piracy, including designated focal points for piracy issues and plans for identifying and sharing information with families. Designated focal points should be provided with brief psychoeducational training on the possible impacts of piracy on seafarers and families.

3. Pre-departure training should be offered to seafarers transiting piracy risk areas. Ideally, this training would be standardized across different institutions and states supporting the delivery of this training, and would include basic stress management tools and some mechanism for providing basic content to families as well.

a. A version of such training is already offered by many manning agencies internationally, and is a legally mandated part of the pre-departure orientation in some countries. This should be considered a best practice, and the training should be expanded to specifically include coping tools.

b. Contact details of agencies that can provide appropriate support in case of a crisis, including charities and NGOs, should be made available to seafarers and families.

4. Any institution that is likely to be involved in the release and repatriation of former hostages, including UN and international agencies, state ministries of foreign affairs or other relevant directorates, and civil society organizations, should ensure that staff who may interact with former hostages are provided with basic psychoeducation about interacting with and supporting survivors of traumatic events, basic assessment skills to identify seafarers who are experiencing symptoms indicative of major depression or PTSD, and knowledge of local agencies who would be able to deal with referrals.

a. This is critical in particular for those staff members who debrief or interrogate released hostages, where the methods used may contribute to the development of a serious mental disorder or the triggering of distress symptoms, or alternately be used to empower the seafarer to move in the direction of long-term recovery.

\section{During Hostage-Holding}

1. Mechanisms for providing validated information to families should be established. An active effort should be made to be open and transparent, timely, and accurate in the information released. Institutions involved in the negotiation, including companies, state, and international organizations, should establish information-sharing mechanisms internally that ensure that there is a clear pathway for information to be vetted and then shared directly with families.

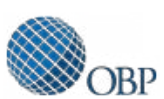


2. Psychosocial support, including coping tools, should be shared with families. This could be executed through state social support institutions or by the ship or manning agency.

\section{After Release}

1. During the initial release phase, when seafarers are being debriefed and arrangements are being made for repatriation, seafarers should be provided with basic information about coping tools and trauma. If possible, assessment for mental health should be integrated with the physical health assessment provided by the institutions arranging their repatriation.

a. Any representative from industry, law enforcement, or a state agency charged with information-gathering or debriefing should be sufficiently familiar with psychological trauma and the impact of traumatic events to know the best practices in interacting with survivors of trauma.

b. During this phase, seafarers should be provided with the maximum possible access to social support and assistance. Seafarer welfare organizations or other social support entities responsible for the well-being of seafarers should be allowed to support seafarers in this period.

2. Seafarers should be provided with long-term access to physical and mental health resources. Under the general maritime law and the ILO's Maritime Labour Convention of 2006, the provision of health care related to work at sea is the responsibility of the shipowner, and case law suggests that this extends to mental health care as well as physical.65 State agencies charged with social support and the provision of mental health care may also be implicated in this. In addition to ensuring access, conscious efforts to address the stigma associated with seeking mental health care may be important in allowing seafarers to use the systems in place. One approach that may ensure access and effective screening for long-term effects is for shipowners to specifically schedule a follow-up assessment six months after release and again at twelve months; effective screening for long-term impact is possible at such time. 


\section{NOTES}

1. Not his real name. Data from an interview conducted 26 April 2012

2. Rachel Yehuda, "Risk and Resilience in Posttraumatic Stress Disorder," The Journal of Clinical Psychiatry 65 Suppl 1 (December 2003): 29-36.

3. Richard G. Tedeschi and Lawrence G. Calhoun, "Posttraumatic Growth: Conceptual Foundations and Empirical Evidence," Psychological Inquiry 15, no. 1 (January 1, 2004): 1-18, doi:10.1207/s15327965pli1501_01.

4. Antonio Rosario Ziello, Rolando Degli Angioli, et al., "Psychological Consequences in Victims of Maritime Piracy: The Italian Experience," International Maritime Health 64, no. 3 (2013): 136-41. \|uc0\|u8221\{\} \{\\i\{\}International Maritime Health\} 64, no. 3 (2013

5. Michael Stuart Garfinkle, Craig L. Katz, and Janaka Saratchandra, "The Psychological Impact of Piracy on Seafarers" (New York: The Seamen's Church Institute of New York \& New Jersey, 2012).

6. Philippine Overseas Employment Administration and Ministry of Land, Infrastructure, Transport and Tourism, Government of Japan, “In Their Own Words: Filipino Seafarers' Experiences of Maritime Piracy" (Manila, 2012).

7. Neil Ellis and Helen Sampson, "The Global Labour Market for Seafarers Working Aboard Merchant Cargo Ships 2003" (Cardiff: Seafarers International Research Centre, 2008).

8. Kaija Hurlburt et al., "Human Cost of Maritime Piracy 2012" (Broomfield, CO: One Earth Future Foundation, 2013), http://oceansbeyondpiracy.org/publications/human-cost-maritime-piracy-2012; Jens Vestergaard Madsen et al., "The State of Maritime Piracy 2013" (Broomfield, CO: One Earth Future Foundation, 2014); Matthew R Walje et al., "The State of Maritime Piracy 2014" (Broomfield, CO: One Earth Future Foundation, 2015).

9. Ellis and Sampson, "The Global Labour Market for Seafarers Working Aboard Merchant Cargo Ships 2003."

10. Stephen Roberts et al., "Fatal Accidents and Injuries among Merchant Seafarers Worldwide," Occupational Medicine 64, no. 4 (June 1, 2014): 259-66, doi:10.1093/occmed/kqu017.

11. Axel Perkonigg et al., "Traumatic Events and Post-Traumatic Stress Disorder in the Community: Prevalence, Risk Factors and Comorbidity," Acta Psychiatrica Scandinavica 101, no. 1 (January 1, 2000): 46-59, doi:10.1034/j.1600-0447.2000.101001046.x.

12. Vivek Menon, "Iron Men Manned Wooden Ships! Vs. Iron Ships Manned by Wooden Men?: Socio-Psychological Impact on Seafarers due to Accidents/Incidents" (Malmö, Sweden: World Maritime University, 2011).

13. American Psychiatric Association, Diagnostic and Statistical Manual of Mental Disorders, 5th Edition: DSM-5, 5 edition (Washington, D.C: American Psychiatric Publishing, 2013).

14. Anke Ehlers and David M Clark, "A Cognitive Model of Posttraumatic Stress Disorder," Behaviour Research and Therapy 38 , no. 4 (n.d.): 319-45.

15. Rachel Yehuda and Joseph LeDoux, "Response Variation Following Trauma: A Translational Neuroscience Approach to Understanding PTSD," Neuron 56, no. 1 (October 4, 2007): 19-32, doi:10.1016/j.neuron.2007.09.006.

16. Yehuda, "Risk and Resilience in Posttraumatic Stress Disorder."

17. J.L. Thomas et al., "Prevalence of Mental Health Problems and Functional Impairment among Active Component and National Guard Soldiers 3 and 12 Months Following Combat in Iraq," Archives of General Psychiatry 67, no. 6 (June 1, 2010): 614-23, doi:10.1001/archgenpsychiatry.2010.54.

18. Chris R. Brewin, Bernice Andrews, and John D. Valentine, "Meta-Analysis of Risk Factors for Posttraumatic Stress Disorder in Trauma-Exposed Adults," Journal of Consulting and Clinical Psychology 68, no. 5 (2000): 748-66, doi:10.1037/0022-006X.68.5.748.

19. Yehuda and LeDoux, "Response Variation Following Trauma."

20. Tedeschi and Calhoun, "Posttraumatic Growth: Conceptual Foundations and Empirical Evidence."

21. de Sales Turner and Helen Cox, “Facilitating Post Traumatic Growth," Health and Quality of Life Outcomes 2 (2004): 34, doi:10.1186/1477-7525-2-34.

22. "In Their Own Words: Filipino Seafarers' Experiences of Maritime Piracy."

23. Garfinkle, Katz, and Saratchandra, "The Psychological Impact of Piracy on Seafarers."

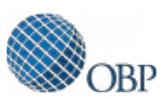


24. Antonio Rosario Ziello, Rolando Degli Angioli, et al., "Psychological Consequences in Victims of Maritime Piracy: Evaluation of Experiences of Kidnapped Seafarers and Their Families," Archives Des Maladies Professionnelles et de l'Environnement 74, no. 5 (2013): 538-539; Ziello, Angioli, et al., "Psychological Consequences in Victims of Maritime Piracy."

25. American Psychiatric Association, Diagnostic and Statistical Manual of Mental Disorders, 5th Edition.

26. Ehlers and Clark, "A Cognitive Model of Posttraumatic Stress Disorder"; Yehuda and LeDoux, "Response Variation Following Trauma."

27. Jonathan I. Bisson et al., "Psychological Treatments for Chronic Post-Traumatic Stress Disorder," The British Journal of Psychiatry 190, no. 2 (2007): 97-104.

28. Scott D. McDonald and Patrick S. Calhoun, "The Diagnostic Accuracy of the PTSD Checklist: A Critical Review," Clinical Psychology Review 30, no. 8 (December 2010): 976-87, doi:10.1016/j.cpr.2010.06.012.

29. Ibid.; Artin Terhakopian et al., "Estimating Population Prevalence of Posttraumatic Stress Disorder: An Example Using the PTSD Checklist," Journal of Traumatic Stress 21, no. 3 (June 1, 2008): 290-300, doi:10.1002/jts.20341.

30. Calculated from the regression output from Appendix III with log odds transformed to probability.

31. Anke Ehlers et al., "Predicting Response to Exposure Treatment in PTSD: The Role of Mental Defeat and Alienation," Journal of Traumatic Stress 11, no. 3 (July 1, 1998): 457-71, doi:10.1023/A:1024448511504.

32. Maria Livanou et al., "Beliefs, Sense of Control and Treatment Outcome in Post-Traumatic Stress Disorder," Psychological Medicine 32, no. 1 (January 2002): 157-165, doi:10.1017/S0033291701004767.

33. J.L. Thomas et al., "Prevalence of Mental Health Problems and Functional Impairment among Active Component and National Guard Soldiers 3 and 12 Months Following Combat in Iraq"; Yehuda, "Risk and Resilience in Posttraumatic Stress Disorder."

34. Meaghan L. O’Donnell, Mark Creamer, and Philippa Pattison, "Posttraumatic Stress Disorder and Depression Following Trauma: Understanding Comorbidity.," The American Journal of Psychiatry 161, no. 8 (2004): 1390-96.

35. Brewin, Andrews, and Valentine, "Meta-Analysis of Risk Factors for Posttraumatic Stress Disorder in Trauma-Exposed Adults."

36. Mark J. Rapoport et al., "Age and Major Depression After Mild Traumatic Brain Injury," The American Journal of Geriatric Psychiatry 11, no. 3 (May 2003): 365-69, doi:10.1097/00019442-200305000-00015.

37. Brewin, Andrews, and Valentine, "Meta-Analysis of Risk Factors for Posttraumatic Stress Disorder in Trauma-Exposed Adults."

38. Jack Tsai et al., "The Role of Coping, Resilience, and Social Support in Mediating the Relation between PTSD and Social Functioning in Veterans Returning from Iraq and Afghanistan," Psychiatry 75, no. 2 (2012): 135-149.

39. Eugene Kontorovich, "'A Guantánamo on the Sea': The Difficulty of Prosecuting Pirates and Terrorists," California Law Review 98, no. 1 (2010): 243-75.

40. Interview with former hostage conducted February 2012.

41. Interview with former hostage conducted 26 April 2012.

42. American Psychiatric Association, Diagnostic and Statistical Manual of Mental Disorders, 5th Edition.

43. These two countries were selected because the Philippines, as the dominant provider of seafarers for the global market, has a significantly more developed system for engaging with seafarers. This means that seafarers in the Philippines may have access to more support, but that the system is not typical for other countries. Information about support available for seafarers was collated by project team members working in these two countries.

44. Mark van Ommeren, Shekhar Saxena, and Benedetto Saraceno, "Mental and Social Health During and After Acute Emergencies: Emerging Consensus?," Bulletin of the World Health Organization 83, no. 1 (January 2005): 71-75, doi:10.1590/S004296862005000100017.

45. Josef I. Ruzek et al., "Psychological First Aid," Journal of Mental Health Counseling 29, no. 1 (January 2007): 17-49; Melissa Brymer et al., "Psychological First Aid Field Operations Guide" (National Child Traumatic Stress Network, 2006), http://eric.ed.gov /?id=ED542874.

46. Steve Berkowitz et al., "Skills for Psychological Recovery: Field Operations Guide" (Washington, D.C: National Center for PTSD and National Child Traumatic Stress Network, 2010). 
47. Neil Greenberg, Victoria Langston, and Norman Jones, "Trauma Risk Management (TRiM) in the UK Armed Forces," Journal of the Royal Army Medical Corps 154, no. 2 (June 1, 2008): 124-27, doi:10.1136/jramc-154-02-11; Neil Greenberg et al., "A Cluster Randomized Controlled Trial to Determine the Efficacy of Trauma Risk Management (TRiM) in a Military Population," Journal of Traumatic Stress 23, no. 4 (August 1, 2010): 430-36, doi:10.1002/jts.20538.

48. Derrick Silove, "The Best Immediate Therapy for Acute Stress Is Social," Bulletin of the World Health Organization 83, no. 1 (January 2005): 75-76, doi:10.1590/S0042-96862005000100017.

49. Kiran Rao, "Psychosocial Support in Disaster-Affected Communities," International Review of Psychiatry 18, no. 6 (January 1, 2006): 501-5, doi:10.1080/09540260601038472.

50. Hurlburt et al., "Human Cost of Maritime Piracy 2012."

51. World Health Organization, The World Health Report 2001: Mental Health: New Understanding, New Hope (Genève: World Health Organization, 2001); van Ommeren, Saxena, and Saraceno, "Mental and Social Health During and After Acute Emergencies."

52. Eunice C. Wong, Grant N. Marshall, and Jeremy NV Miles, "Randomized Controlled Trial of a Psychoeducational Video Intervention for Traumatic Injury Survivors," Journal of Traumatic Stress Disorders \& Treatment 2, no. 2 (2013), http://www.rand.org/pubs/external_publications/EP50363.

53. Kathleen Mulligan et al., "Psycho-Educational Interventions Designed to Prevent Deployment-Related Psychological III-Health in Armed Forces Personnel: A Review," Psychological Medicine 41, no. 4 (April 2011): 673-686, doi:10.1017/S003329171000125X.

54. Mark J. D. Jordans et al., "A Controlled Evaluation of a Brief Parenting Psychoeducation Intervention in Burundi," Social Psychiatry and Psychiatric Epidemiology 48, no. 11 (December 9, 2012): 1851-59, doi:10.1007/s00127-012-0630-6.

55. Simon Wessely et al., "Does Psychoeducation Help Prevent Post Traumatic Psychological Distress?," Psychiatry 71, no. 4 (December 1, 2008): 287-302, doi:10.1521/psyc.2008.71.4.287.

56. Rachel Yehuda, Alexander C. McFarlane, and Arieh Y. Shalev, "Predicting the Development of Posttraumatic Stress Disorder from the Acute Response to a Traumatic Event," Biological Psychiatry 44, no. 12 (December 15, 1998): 1305-13, doi:10.1016/S00063223(98)00276-5; Thomas Ehring et al., "Do Acute Psychological and Psychobiological Responses to Trauma Predict Subsequent Symptom Severities of PTSD and Depression?," Psychiatry Research 161, no. 1 (October 30, 2008): 67-75, doi:10.1016/j.psychres.2007.08.014.

57. Yehuda, McFarlane, and Shalev, "Predicting the Development of Posttraumatic Stress Disorder from the Acute Response to a Traumatic Event."

58. Bisson et al., "Psychological Treatments for Chronic Post-Traumatic Stress Disorder."

59. Gerhard Andersson, "Using the Internet to Provide Cognitive Behaviour Therapy," Behaviour Research and Therapy 47, no. 3 (March 2009): 175-80, doi:10.1016/j.brat.2009.01.010.

60. Britt Klein et al., "A Therapist-Assisted Cognitive Behavior Therapy Internet Intervention for Posttraumatic Stress Disorder: Pre-, Post- and 3-Month Follow-up Results from an Open Trial," Journal of Anxiety Disorders 24, no. 6 (August 2010): 635-44, doi:10.1016/j.janxdis.2010.04.005.

61. Sailors' Society, "Wellness at Sea," Sailors' Society, 2016, http://www.sailors-society.org/ourprojects/wellness/.

62. Terri Tanielian et al., "Invisible Wounds of War" (Santa Monica, CA: RAND Corporation, 2008).

63. Douglas Stevenson, "Seafarers' Rights to Mental Health Care," September 8, 2009, http://seamenschurch.org/article/seafarersrights-mental-health-care.

64. Maritime Piracy Humanitarian Response Programme, "Good Practice Guide for Shipping Companies and Manning Agents: Humanitarian Support of Seafarers and their Families in Cases of Armed Robbery and Pirate Attack" (International Seafarers Welfare and Assistance Network, 2016), http://seafarerswelfare.org/news-and-media/latest-news/iswan-launches-good-practice-guide-on-the-humanitarian-response-to-piracy.

65. Stevenson "Seafarers' Rights to Mental Health Care".

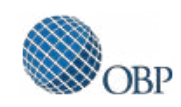




\section{APPENDIX I: SAMPLE INFORMATION AND METHODS}

Data collection targeted two groups: seafarers known to have been held hostage by pirates and a comparison group of seafarers not known to have been exposed. These two groups were sought out in three countries: the Philippines, India, and Ukraine.

\section{DATA COLLECTION IN THE PHILIPPINES}

Based on pre-existing work with returned seafarers, media reports, and discussions with the Philippine government, a list of known hostages was developed by project partners Ateneo de Manila University and Maritime Piracy Humanitarian Response Programme (MPRHP) Philippines. Returned hostages were contacted by telephone and email and asked to participate in the study.

Seafarers not known to have been exposed to attack were approached through training centers and seafarer welfare organizations. Seafarers present at these locations were approached for participation.

\section{DATA COLLECTION IN INDIA}

Project partner MPHRP India has been working with returned hostages in India and the Indian government, and through this work had a list of 94 known hostages. These former hostages were approached via email and phone calls and asked to participate. Of the 94 former hostages, 44 participated in the study (46.8\%).

Seafarers not known to have been exposed to attack were approached through the contact list of the National Union of Seafarers of India and invited to participate.

\section{DATA COLLECTION IN UKRAINE}

Project partner MPHRP Ukraine has been working with returned hostages in Ukraine, as well as with Ukrainian civil society groups supporting survivors of piracy. Through this work, MPHRP had a list of 82 known hostages and previously attacked seafarers. These seafarers were approached via e-mail and phone calls and through their colleagues and friends; media channels were also used to draw attention to the project and invite piracy survivors to participate. Of the 82 survivors, 35 (41.5\% agreed to participate).

The comparison sample was collected through a partnership with the Seafarers' Training and Certification Center in Odessa. Seafarers participating in training courses were invited to participate in the survey.

\section{POWER ANALYSIS}

The sample size was based on a target sample of 50 piracy-exposed seafarers and 100 non-exposed seafarers in each country. This target was identified in advance through a statistical power analysis conducted in R using the "pwr" package. This analysis assumed a basic analytical approach of an unbalanced two-sample t-test representing a comparison of piracy-exposed and unexposed seafarers within each country, relatively strong effect size $(d=.80)$, and a significance level of $p<.05$. Under these assumptions, the resulting power calculation for within-country comparisons at a sample size of 150 per country is .996. With the actual sample size identified, within-country power ranges from .958 (Ukraine) to .993 (India) with the Philippines in between at 979 . 


\section{APPENDIX II: OUTCOME MEASURES SCORING METHODS AND ANALYSIS DETAILS}

\section{POST-TRAUMATIC STRESS DISORDER}

PTSD was assessed using the Posttraumatic Checklist-Civilian $(\mathrm{PCL}-\mathrm{C})^{1}$ with the traumatic event specified as piracy rather than negative experience more broadly. The study was launched before the DSM- $V$ was released, and the presence of probable PTSD was coded using DSM-IV criteria. In order to be coded as having probable PTSD, participants must have endorsed items associated with at least 1 symptom from Axis $B, 2$ from Axis $D$, and 3 from Axis $C$ and also have a total sum score on the PCL greater than 44 . The cutoff of 44 has been shown to be an inflection point in the accuracy of the PCL, with scores lower than 44 leading to an over-estimation of PTSD prevalence when the true base rate is less than 15\%, and 44 or higher leading to an under-estimation when base rates are higher than $35 \% .{ }^{2}$ Based on the expected base rate of PTSD, 44 was selected as the cutoff.

\section{DEPRESSION}

Depression was assessed using the Center for Epidemiological Studies Depression Scale (CES-D). ${ }^{3}$ The CES-D can be used as a continuous measure and also can be coded for the presence of serious depression. Due to fairly significant cultural differences in what constitutes appropriate cutoffs for serious depression, ${ }^{4}$ the CES-D was used as a sum score for assessing symptom severity.

\section{WELL-BEING}

Well-being was assessed using the Duke Health Profile, ${ }^{5}$ a multi-faceted scale including subscales tracking a number of different facets of well-being. Specific subscales used were those tracking physical, mental, and social well-being. All three subscales were coded according to standardized coding metrics, except the subscale for physical health. On the advice of partner organizations, two items relating to physical ability to work were removed; advisors felt that such items would raise concerns in seafarers who might perceive the items as implying they were not fit to continue to work. As such, the physical well-being subscale was calculated on the basis of three items rather than five.

\section{ANALYSES}

Participants were nested within country. This is significant because while trauma has a strong physiological component, its impact on behavior is strongly affected by culture. ${ }^{6}$ As a result, the impact of traumatic events in this study will be affected by both culture and the generic impact of the type of event experienced. This poses a challenge for statistical analysis: typical statistical analyses used for large datasets assume that each individual in the data is independent of the other individuals. To address this concern, analyses were conducted using hierarchical linear modeling (HLM). ${ }^{7}$ HLM models explicitly incorporate intra-class correlation in the calculation of effect sizes, accounting for the violation of independence. The analyses were conducted using the "multilevel" package in R (using Rstudio v0.98.945). For continuous variables, each outcome was modeled with individual-level variables at level 1 and country variables at level 2 . For binary outcome variables, a binomial link function was used to enable the analysis, using the "family=binomial" argument in the "Imer" command.

\section{ISSUE: MISSING DATA}

A relatively high number of participants, particularly those in the comparison group, failed to complete all of the items. This was the case particularly in the Ukranian non-hostage group, where $68 \%$ of the group failed to complete more than a third of at least one of the three key dependent variable scales. During the analyses, cases with missing data were deleted casewise per-analysis. Due to the use of this approach, the number of cases included in each analysis shifts as variables were included or deleted. The results below report the number of cases included as well as the results of analyses.

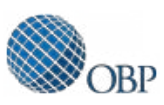


APPENDIX III: HLM REGRESSION MODELS RESULTS FOR PROBABLE PTSD

\begin{tabular}{|c|c|c|c|c|c|c|c|c|c|c|c|c|c|}
\hline & Model 1 & 2 & 3 & 4 & 5 & 6 & 7 & 8 & 9 & 10 & 11 & 11 & 12 \\
\hline Intercept & $\begin{array}{l}-2.07 \\
* * *\end{array}$ & $\begin{array}{l}2.34 \\
* * *\end{array}$ & \begin{tabular}{|l}
-2.32 \\
$* * *$
\end{tabular} & & \begin{tabular}{|l}
-3.38 \\
$* * *$
\end{tabular} & $\begin{array}{l}-3.26 \\
* * *\end{array}$ & \begin{tabular}{|l}
-2.06 \\
$*$
\end{tabular} & $\begin{array}{l}-2.47 \\
* * *\end{array}$ & $\begin{array}{l}-3.71 \\
* * *\end{array}$ & \begin{tabular}{|l}
-3.20 \\
$* * *$
\end{tabular} & \begin{tabular}{|l}
-3.30 \\
$* * *$
\end{tabular} & $\begin{array}{l}-3.90 \\
* * *\end{array}$ & $\begin{array}{l}-2.46 \\
* * *\end{array}$ \\
\hline \multicolumn{14}{|c|}{ Exposure } \\
\hline Transit only & $-1.40^{*}$ & & & & & n.s. & & & & & & & \\
\hline $\begin{array}{l}\text { Know hst } \\
\text { only }\end{array}$ & & n.s. & & & & & & & & & & & \\
\hline $\begin{array}{l}\text { Viewed } \\
\text { attack only }\end{array}$ & & & n.s. & & & & & & & & & & \\
\hline $\begin{array}{l}\text { Attacked, } \\
\text { not held }\end{array}$ & & & & $\begin{array}{l}\text { See } \\
\text { below }\end{array}$ & & & & & & & & & \\
\hline Held & & & & & $\begin{array}{l}2.17 \\
* * *\end{array}$ & $\begin{array}{l}2.05 \\
* * *\end{array}$ & \begin{tabular}{|l|}
1.98 \\
$*$
\end{tabular} & \begin{tabular}{|l|}
2.26 \\
$* * *$
\end{tabular} & \begin{tabular}{|l|}
2.13 \\
$* * *$
\end{tabular} & $\begin{array}{l}2.30 \\
* * *\end{array}$ & $\begin{array}{l}2.16 \\
* * *\end{array}$ & $\begin{array}{l}2.25 \\
* * *\end{array}$ & $\begin{array}{l}2.37 \\
* * *\end{array}$ \\
\hline \multicolumn{14}{|c|}{ Demographics } \\
\hline $\begin{array}{l}\text { Age } \\
\text { (Ctr) }\end{array}$ & & & & & & & n.s. & & & & & & \\
\hline Religious & & & & & & & n.s. & & & & & & \\
\hline $\begin{array}{l}\text { Prior trau- } \\
\text { ma }\end{array}$ & & & & & & & n.s. & & & & & & \\
\hline \multicolumn{14}{|c|}{ Pre-departure training } \\
\hline Had PTD & & & & & & & & n.s. & & n.s. & & & n.s. \\
\hline $\begin{array}{l}\text { Usefulness } \\
\text { of PTD }\end{array}$ & & & & & & & & \begin{tabular}{|l|}
-0.44 \\
$* * *$
\end{tabular} & & $\begin{array}{l}-0.43 \\
*\end{array}$ & & & $\begin{array}{l}.43 \\
*\end{array}$ \\
\hline \multicolumn{14}{|c|}{ Country } \\
\hline India & & & & & & & & & \begin{tabular}{|l|}
1.03 \\
$* *$
\end{tabular} & n.s. & & & \\
\hline $\mathrm{Phi}$ & & & & & & & & & & & n.s. & & \\
\hline Ukr & & & & & & & & & & & & -1.3. & n.s. \\
\hline $\mathrm{N}$ & 348 & 358 & 355 & & 352 & 344 & 257 & 327 & 352 & 327 & 352 & 352 & 327 \\
\hline
\end{tabular}

Note: Because no seafarers who were attacked but not held hostage had PTSD in this sample, there is no variability in the dependent variable associated with the predictor "attacked," hence its effect cannot be modeled.

$* * *<0.001, * *<0.01, *<0.05,0.05>.<0.6$ 


\section{APPENDIX IV: PCL-C SUM}

\begin{tabular}{|c|c|c|c|c|c|c|c|c|c|c|c|}
\hline & Model 1 & 2 & 3 & 4 & 5 & 6 & 7 & 8 & 9 & 10 & 11 \\
\hline Intercept & $\begin{array}{l}28.26 \\
* * *\end{array}$ & $\begin{array}{l}27.12 \\
* * *\end{array}$ & $\begin{array}{l}27.32 \\
* * *\end{array}$ & \begin{tabular}{|l|}
33.34 \\
$* * *$
\end{tabular} & $\begin{array}{l}24.68 \\
* * *\end{array}$ & $\begin{array}{l}24.83 \\
* * *\end{array}$ & $\begin{array}{l}25.89 \\
* * *\end{array}$ & $\begin{array}{l}26.84 \\
* * *\end{array}$ & $\begin{array}{l}23.07 \\
* * *\end{array}$ & $\begin{array}{l}24.85 \\
* * *\end{array}$ & $\begin{array}{l}26.11 \\
* * *\end{array}$ \\
\hline \multicolumn{12}{|c|}{ Exposure } \\
\hline Transit only & $\begin{array}{l}-3.95 \\
* *\end{array}$ & & & & & n.s. & & & & & \\
\hline $\begin{array}{l}\text { Know hst } \\
\text { only }\end{array}$ & & n.s. & & & & & & & & & \\
\hline $\begin{array}{l}\text { Viewed } \\
\text { attack, not } \\
\text { attacked }\end{array}$ & & & n.s. & & & & & & & & \\
\hline $\begin{array}{l}\text { Attacked, } \\
\text { not held }\end{array}$ & & & & n.s. & & & & & & & \\
\hline Held & & & & & $\begin{array}{l}8.79 \\
* * *\end{array}$ & $\begin{array}{l}8.64 \\
* * *\end{array}$ & $\begin{array}{l}6.75 \\
* * *\end{array}$ & $\begin{array}{l}6.16 \\
* * *\end{array}$ & $\begin{array}{l}6.76 \\
* * *\end{array}$ & $\begin{array}{l}6.88 \\
* * *\end{array}$ & $\begin{array}{l}6.78 \\
* * *\end{array}$ \\
\hline \multicolumn{12}{|c|}{ Demographic } \\
\hline $\begin{array}{l}\text { Age } \\
\text { (Ctr) }\end{array}$ & & & & & & & n.s. & & & & \\
\hline Religious & & & & & & & n.s. & & & & \\
\hline $\begin{array}{l}\text { Prior } \\
\text { trauma }\end{array}$ & & & & & & & $\begin{array}{l}1.27 \\
* *\end{array}$ & $\begin{array}{l}1.10 \\
* *\end{array}$ & $\begin{array}{l}1.13 \\
* *\end{array}$ & $\begin{array}{l}1.10 \\
* *\end{array}$ & $\begin{array}{l}1.13 \\
* *\end{array}$ \\
\hline \multicolumn{12}{|c|}{ Pre-dep training } \\
\hline Had PTD & & & & & & & & n.s. & & & \\
\hline $\begin{array}{l}\text { Usefulness } \\
\text { of PTD }\end{array}$ & & & & & & & & $\begin{array}{l}-1.46 \\
*\end{array}$ & & & \\
\hline \multicolumn{12}{|c|}{ Country } \\
\hline India & & & & & & & & & n.s. & & \\
\hline Ukr & & & & & & & & & & n.s. & \\
\hline Phi & & & & & & & & & & & n.s. \\
\hline $\mathrm{N}$ & 342 & 343 & 346 & 352 & 352 & 344 & 250 & 238 & 255 & 255 & 255 \\
\hline
\end{tabular}

$* * *<0.001, * *<0.01, *<0.05,0.05>$. $<0.6$ 


\section{APPENDIX V: CES-D SUM ANALYSES}

\begin{tabular}{|c|c|c|c|c|c|c|c|c|c|c|c|}
\hline & Model 1 & 2 & 3 & 4 & 5 & 6 & 7 & 8 & 9 & 10 & 11 \\
\hline Intercept & $\begin{array}{l}15.04 \\
* * *\end{array}$ & $\begin{array}{l}14.46 \\
* * *\end{array}$ & $\begin{array}{l}14.53 \\
* * *\end{array}$ & $\begin{array}{l}14.55 \\
* * *\end{array}$ & $\begin{array}{l}13.50 \\
* * *\end{array}$ & $\begin{array}{l}13.88 \\
* * *\end{array}$ & $\begin{array}{l}11.26 \\
* * *\end{array}$ & $\begin{array}{l}15.31 \\
* * *\end{array}$ & $\begin{array}{l}12.09 \\
* * *\end{array}$ & $\begin{array}{l}12.46 \\
* * *\end{array}$ & $\begin{array}{l}14.06 \\
* * *\end{array}$ \\
\hline \multicolumn{12}{|c|}{ Exposure } \\
\hline Transit only & $\begin{array}{l}-2.15 \\
*\end{array}$ & & & & & n.s. & & & & & \\
\hline $\begin{array}{l}\text { Know hst } \\
\text { only }\end{array}$ & & n.s. & & & & & & & & & \\
\hline $\begin{array}{l}\text { Viewed } \\
\text { attack, not } \\
\text { attacked }\end{array}$ & & & n.s. & & & & & & & & \\
\hline $\begin{array}{l}\text { Attacked, } \\
\text { not held }\end{array}$ & & & & n.s. & & & & & & & \\
\hline Held & & & & & $\begin{array}{l}3.22 \\
* *\end{array}$ & $\begin{array}{l}2.84 \\
* *\end{array}$ & n.s. & n.s. & n.s. & n.s. & n.s. \\
\hline \multicolumn{12}{|c|}{ Demographic } \\
\hline $\begin{array}{l}\text { Age } \\
\text { (Ctr) }\end{array}$ & & & & & & & $\begin{array}{l}-0.13 \\
* *\end{array}$ & $\begin{array}{l}-0.16 \\
* *\end{array}$ & $\begin{array}{l}-0.13 \\
*\end{array}$ & $\begin{array}{l}-0.14 \\
*\end{array}$ & $\begin{array}{l}-0.15 \\
* *\end{array}$ \\
\hline Religious & & & & & & & n.s. & & & & \\
\hline $\begin{array}{l}\text { Prior } \\
\text { trauma }\end{array}$ & & & & & & & 0.63 & $\begin{array}{l}0.62 \\
\end{array}$ & \begin{tabular}{|l}
0.84 \\
$* *$
\end{tabular} & $\begin{array}{l}0.83 \\
*\end{array}$ & $\begin{array}{l}0.81 \\
*\end{array}$ \\
\hline \multicolumn{12}{|c|}{ Pre-dep training } \\
\hline Had PTD & & & & & & & & n.s. & & & \\
\hline $\begin{array}{l}\text { Usefulness } \\
\text { of PTD }\end{array}$ & & & & & & & & n.s. & & & \\
\hline \multicolumn{12}{|c|}{ Country } \\
\hline India & & & & & & & & & n.s. & & \\
\hline Phi & & & & & & & & & & n.s. & \\
\hline Ukr & & & & & & & & & & & n.s. \\
\hline $\mathrm{N}$ & 314 & 322 & 321 & 324 & 324 & 316 & 234 & 224 & 241 & 241 & 241 \\
\hline
\end{tabular}

$* * *<0.001, * *<0.01, *<0.05,0.05>$. $<0.6$ 


\section{APPENDIX VI: PHYSICAL WELL-BEING}

\begin{tabular}{|c|c|c|c|c|c|c|c|c|c|c|c|c|}
\hline & \begin{tabular}{|l} 
Model \\
1
\end{tabular} & 2 & 3 & 4 & 5 & 6 & 7 & 8 & 9 & 10 & 11 & 12 \\
\hline Intercept & $\begin{array}{l}5.00 \\
* * *\end{array}$ & $\begin{array}{l}5.02 \\
* * *\end{array}$ & $\begin{array}{l}5.03 \\
* * *\end{array}$ & $\begin{array}{l}5.01 \\
* * *\end{array}$ & $\begin{array}{l}5.21 \\
* * *\end{array}$ & $\begin{array}{l}5.34 \\
* * *\end{array}$ & $\begin{array}{l}5.25 \\
* * *\end{array}$ & $\begin{array}{l}6.63 \\
* * *\end{array}$ & $\begin{array}{l}6.62 \\
* * *\end{array}$ & $\begin{array}{l}6.79 \\
* * *\end{array}$ & $\begin{array}{l}6.35 \\
* * *\end{array}$ & $\begin{array}{l}6.59 \\
* * *\end{array}$ \\
\hline \multicolumn{13}{|c|}{ Exposure } \\
\hline Transit only & n.s. & & & & & & & & & & & \\
\hline $\begin{array}{l}\text { Know hst } \\
\text { only }\end{array}$ & & n.s. & & & & & & & & & & \\
\hline $\begin{array}{l}\text { Viewed } \\
\text { attack }\end{array}$ & & & n.s. & & & & & & & & & \\
\hline $\begin{array}{l}\text { Attacked, } \\
\text { not held }\end{array}$ & & & & n.s. & & & & & & & & \\
\hline Held & & & & & $\begin{array}{l}-0.61 \\
* * *\end{array}$ & n.s. & \begin{tabular}{|l}
-0.45 \\
$*$
\end{tabular} & & n.s. & n.s. & n.s. & n.s. \\
\hline \multicolumn{13}{|c|}{ Demographic } \\
\hline $\begin{array}{l}\text { Age } \\
\text { (Ctr) }\end{array}$ & & & & & & n.s. & & & & & & \\
\hline Religious & & & & & & n.s. & & & & & & \\
\hline $\begin{array}{l}\text { Prior } \\
\text { trauma }\end{array}$ & & & & & & n.s. & & & n.s. & & & \\
\hline \multicolumn{13}{|c|}{ Pre-dep training } \\
\hline Had PTD & & & & & & & n.s. & & & & & \\
\hline $\begin{array}{l}\text { Usefulness } \\
\text { of PTD }\end{array}$ & & & & & & & n.s. & & & & & \\
\hline $\begin{array}{l}\text { Use X } \\
\text { Hostage }\end{array}$ & & & & & & & & & & & & \\
\hline \multicolumn{13}{|c|}{ Behavioral symptoms } \\
\hline PCL-C sum & & & & & & & & $\begin{array}{l}-0.05 \\
* * *\end{array}$ & $\begin{array}{l}-0.05 \\
* * *\end{array}$ & $\begin{array}{l}-0.5 \\
* * *\end{array}$ & $\begin{array}{l}-0.05 \\
* * *\end{array}$ & $\begin{array}{l}-0.05 \\
* * *\end{array}$ \\
\hline CESD sum & & & & & & & & n.s. & n.s. & & & \\
\hline \multicolumn{13}{|c|}{ Country } \\
\hline India & & & & & & & & & & n.s. & & \\
\hline Phi & & & & & & & & & & & n.s. & \\
\hline Ukr & & & & & & & & & & & & n.s. \\
\hline $\mathrm{N}$ & 370 & 382 & 378 & 374 & 376 & 231 & 268 & 228 & 228 & 228 & 228 & 228 \\
\hline
\end{tabular}

$* * *<0.001, * *<0.01, *<0.05,0.05>.<0.6$ 


\section{APPENDIX VII: MENTAL WELL-BEING}

\begin{tabular}{|c|c|c|c|c|c|c|c|c|c|c|c|c|}
\hline & $\begin{array}{l}\text { Model } \\
1\end{array}$ & 2 & 3 & 4 & 5 & 6 & 7 & 8 & 9 & 10 & 11 & 12 \\
\hline Intercept & $\begin{array}{l}80.97 \\
* * *\end{array}$ & $\begin{array}{l}81.00 \\
* * *\end{array}$ & $\begin{array}{l}80.88 \\
* * *\end{array}$ & $\begin{array}{l}80.69 \\
* * *\end{array}$ & $\begin{array}{l}80.80 \\
* * *\end{array}$ & $\begin{array}{l}74.41 \\
* * *\end{array}$ & \begin{tabular}{|l|}
73.4 \\
$* * *$
\end{tabular} & $\begin{array}{l}103.01 \\
* * *\end{array}$ & $\begin{array}{l}96.33 \\
* * *\end{array}$ & $\begin{array}{l}99.09 \\
* * *\end{array}$ & $\begin{array}{l}93.09 \\
* * *\end{array}$ & $\begin{array}{l}95.25 \\
* * *\end{array}$ \\
\hline \multicolumn{13}{|c|}{ Exposure } \\
\hline Transit only & n.s. & & & & & & & & & & & \\
\hline $\begin{array}{l}\text { Know hst } \\
\text { only }\end{array}$ & & n.s. & & & & & & & & & & \\
\hline $\begin{array}{l}\text { Viewed } \\
\text { attack }\end{array}$ & & & n.s. & & & & & & & & & \\
\hline $\begin{array}{l}\text { Attacked, } \\
\text { not held }\end{array}$ & & & & n.s. & & & & & & & & \\
\hline Held & & & & & n.s. & n.s. & \begin{tabular}{|l|}
6.96 \\
$*$
\end{tabular} & & $\begin{array}{l}8.87 \\
* * *\end{array}$ & $\begin{array}{l}8.52 \\
* * *\end{array}$ & $\begin{array}{l}8.51 \\
* * *\end{array}$ & $\begin{array}{l}8.51 \\
* *\end{array}$ \\
\hline \multicolumn{13}{|c|}{ Demographics } \\
\hline $\begin{array}{l}\text { Age } \\
\text { (Ctr) }\end{array}$ & & & & & & n.s. & & & & & & \\
\hline Religious & & & & & & n.s. & & & & & & \\
\hline $\begin{array}{l}\text { Prior } \\
\text { trauma }\end{array}$ & & & & & & $\begin{array}{l}-2.01 \\
* *\end{array}$ & \begin{tabular}{|l|}
-1.77 \\
$*$
\end{tabular} & & n.s. & & & \\
\hline \multicolumn{13}{|c|}{ Pre-dep training } \\
\hline Had PTD & & & & & & & n.s. & & n.s. & n.s. & n.s. & n.s. \\
\hline $\begin{array}{l}\text { Usefulness } \\
\text { of PTD }\end{array}$ & & & & & & & \begin{tabular}{|l|}
3.32 \\
$*$
\end{tabular} & & $\begin{array}{l}2.69 \\
*\end{array}$ & $\begin{array}{l}2.63 \\
*\end{array}$ & $\begin{array}{l}2.53 \\
*\end{array}$ & $\begin{array}{l}2.71 \\
*\end{array}$ \\
\hline \multicolumn{13}{|c|}{ Behavioral symptoms } \\
\hline PCL-C sum & & & & & & & & $\begin{array}{l}-0.76 \\
* * *\end{array}$ & $\begin{array}{l}-0.82 \\
* * *\end{array}$ & $\begin{array}{l}-0.87 \\
* * *\end{array}$ & $\begin{array}{l}-0.87 \\
* * *\end{array}$ & $\begin{array}{l}-0.86 \\
* * *\end{array}$ \\
\hline CESD sum & & & & & & & & n.s. & n.s. & & & \\
\hline \multicolumn{13}{|c|}{ Country } \\
\hline India & & & & & & & & & & n.s. & & \\
\hline Phi & & & & & & & & & & & n.s. & \\
\hline Ukr & & & & & & & & & & & & n.s. \\
\hline $\mathrm{N}$ & 359 & 371 & 367 & 365 & 227 & 227 & 213 & 241 & 224 & 224 & 224 & 224 \\
\hline
\end{tabular}

$* * *<0.001, * *<0.01, *<0.05,0.05>$. $<0.6$ 


\section{APPENDIX VIII: SOCIAL WELL-BEING}

\begin{tabular}{|c|c|c|c|c|c|c|c|c|c|c|c|c|}
\hline & $\begin{array}{l}\text { Model } \\
1\end{array}$ & 2 & 3 & 4 & 5 & 6 & 7 & 8 & 9 & 10 & 11 & 12 \\
\hline Intercept & $\begin{array}{l}66.65 \\
* * *\end{array}$ & $\begin{array}{l}66.68 \\
* * *\end{array}$ & $\begin{array}{l}66.40 \\
* * *\end{array}$ & $\begin{array}{l}66.55 \\
* * *\end{array}$ & $\begin{array}{l}65.30 \\
* * *\end{array}$ & $\begin{array}{l}56.04 \\
* * *\end{array}$ & \begin{tabular}{|l|}
58.99 \\
$* * *$
\end{tabular} & $\begin{array}{l}75.41 \\
* * *\end{array}$ & $\begin{array}{l}69.71 \\
* * *\end{array}$ & $\begin{array}{l}62.3 \\
* * *\end{array}$ & $\begin{array}{l}74.09 \\
* * *\end{array}$ & $\begin{array}{l}69.61 \\
* * *\end{array}$ \\
\hline \multicolumn{13}{|c|}{ Exposure } \\
\hline Transit only & n.s. & & & & & & & & & & & \\
\hline $\begin{array}{l}\text { Know hst } \\
\text { only }\end{array}$ & & n.s. & & & & & & & & & & \\
\hline $\begin{array}{l}\text { Viewed } \\
\text { attack }\end{array}$ & & & n.s. & & & & & & & & & \\
\hline $\begin{array}{l}\text { Attacked, } \\
\text { not held }\end{array}$ & & & & n.s. & & & & & & & & \\
\hline Held & & & & & n.s. & n.s. & \begin{tabular}{|l|}
6.57 \\
$*$
\end{tabular} & & $\begin{array}{l}8.42 \\
* *\end{array}$ & $\begin{array}{l}8.99 \\
* * *\end{array}$ & $\begin{array}{l}9.00 \\
* * *\end{array}$ & $\begin{array}{l}9.00 \\
* * *\end{array}$ \\
\hline \multicolumn{13}{|c|}{ Demographics } \\
\hline $\begin{array}{l}\text { Age } \\
\text { (Ctr) }\end{array}$ & & & & & & n.s. & & & & & & \\
\hline Religious & & & & & & n.s. & & & & & & \\
\hline $\begin{array}{l}\text { Prior } \\
\text { trauma }\end{array}$ & & & & & & n.s. & n.s. & & n.s. & & & \\
\hline \multicolumn{13}{|c|}{ Pre-dep training } \\
\hline Had PTD & & & & & & & n.s. & & n.s. & n.s. & n.s. & n.s. \\
\hline $\begin{array}{l}\text { Usefulness } \\
\text { of PTD }\end{array}$ & & & & & & & \begin{tabular}{|l|}
3.94 \\
$* *$
\end{tabular} & & $\begin{array}{l}3.41 \\
* *\end{array}$ & $\begin{array}{l}3.40 \\
* *\end{array}$ & $\begin{array}{l}3.57 \\
* *\end{array}$ & $\begin{array}{l}3.42 \\
* *\end{array}$ \\
\hline \multicolumn{13}{|c|}{ Behavioral symptoms } \\
\hline PCL-C sum & & & & & & & & $\begin{array}{l}-0.26 \\
*\end{array}$ & $\begin{array}{l}-0.30 \\
*\end{array}$ & $\begin{array}{l}-0.38 \\
* * *\end{array}$ & $\begin{array}{l}-0.37 \\
* * *\end{array}$ & $\begin{array}{l}-0.38 \\
* * *\end{array}$ \\
\hline CESD sum & & & & & & & & n.s. & n.s. & & & \\
\hline \multicolumn{13}{|c|}{ Country } \\
\hline India & & & & & & & & & & n.s. & & \\
\hline Phi & & & & & & & & & & & n.s. & \\
\hline Ukr & & & & & & & & & & & & n.s. \\
\hline $\mathrm{N}$ & 364 & 375 & 372 & 370 & 370 & 231 & 217 & 228 & 228 & 228 & 228 & 228 \\
\hline
\end{tabular}

$* * *<0.001, * *<0.01, *<0.05,0.05>$. $<0.6$ 


\section{APPENDIX IX: THINKING ABOUT PIRACY}

\begin{tabular}{|c|c|c|c|c|c|c|c|c|c|c|c|c|}
\hline & $\begin{array}{l}\text { Model } \\
1\end{array}$ & 2 & 3 & 4 & 5 & 6 & 7 & 8 & 9 & 10 & 11 & 12 \\
\hline Intercept & $\begin{array}{l}2.92 \\
* * *\end{array}$ & $\begin{array}{l}2.95 \\
* * *\end{array}$ & $\begin{array}{l}2.95 \\
* * *\end{array}$ & $\begin{array}{l}2.95 \\
* * *\end{array}$ & $\begin{array}{l}2.94 \\
* * *\end{array}$ & $\begin{array}{l}3.22 \\
* * *\end{array}$ & $\begin{array}{l}2.91 \\
* * *\end{array}$ & $\begin{array}{l}2.32 \\
* * *\end{array}$ & $\begin{array}{l}1.96 \\
* * *\end{array}$ & $\begin{array}{l}2.32 \\
* * *\end{array}$ & $\begin{array}{l}2.37 \\
* * *\end{array}$ & $\begin{array}{l}2.40 \\
* * *\end{array}$ \\
\hline \multicolumn{13}{|c|}{ Exposure } \\
\hline Transit only & n.s. & & & & & & & & & & & \\
\hline $\begin{array}{l}\text { Know hst } \\
\text { only }\end{array}$ & & n.s. & & & & & & & & & & \\
\hline $\begin{array}{l}\text { Viewed } \\
\text { attack }\end{array}$ & & & n.s. & & & & & & & & & \\
\hline $\begin{array}{l}\text { Attacked, } \\
\text { not held }\end{array}$ & & & & n.s. & & & & & & & & \\
\hline Held & & & & & n.s. & & & & n.s. & n.s. & n.s. & n.s. \\
\hline \multicolumn{13}{|c|}{ Demographics } \\
\hline $\begin{array}{l}\text { Age } \\
\text { (Ctr) }\end{array}$ & & & & & & n.s. & & & & & & \\
\hline Religious & & & & & & n.s. & & & & & & \\
\hline $\begin{array}{l}\text { Prior } \\
\text { trauma }\end{array}$ & & & & & & n.s. & & & n.s. & n.s. & n.s. & n.s. \\
\hline \multicolumn{13}{|c|}{ Pre-dep training } \\
\hline Had PTD & & & & & & & n.s. & & n.s. & & & \\
\hline $\begin{array}{l}\text { Usefulness } \\
\text { of PTD }\end{array}$ & & & & & & & n.s. & & n.s. & & & \\
\hline \multicolumn{13}{|c|}{ Behavioral symptoms } \\
\hline PCL-C sum & & & & & & & & $\begin{array}{l}0.03 \\
* *\end{array}$ & $\begin{array}{l}.04 \\
* * *\end{array}$ & $\begin{array}{l}.04 \\
* * *\end{array}$ & $\begin{array}{l}.04 \\
* * *\end{array}$ & $\begin{array}{l}.04 \\
* * *\end{array}$ \\
\hline CESD sum & & & & & & & & n.s. & & & & \\
\hline \multicolumn{13}{|c|}{ Country } \\
\hline India & & & & & & & & & & n.s. & & \\
\hline Phi & & & & & & & & & & & n.s. & \\
\hline Ukr & & & & & & & & & & & & n.s. \\
\hline $\mathrm{N}$ & 448 & 451 & & 451 & 452 & 215 & 215 & 227 & 227 & 227 & 227 & 227 \\
\hline
\end{tabular}

$* * *<0.001, * *<0.01, *<0.05,0.05>.<0.6$ 


\section{APPENDIX X: DECLINED A JOB DUE TO PIRACY}

\begin{tabular}{|c|c|c|c|c|c|c|c|c|c|c|c|c|}
\hline & $\begin{array}{l}\text { Model } \\
1\end{array}$ & 2 & 3 & 4 & 5 & 6 & 7 & 8 & 9 & 10 & 11 & 12 \\
\hline Intercept & $\begin{array}{l}-2.44 \\
* * *\end{array}$ & $\begin{array}{l}-2.49 \\
* * *\end{array}$ & & $\begin{array}{l}-2.65 \\
* * *\end{array}$ & $\begin{array}{l}-2.87 \\
* * *\end{array}$ & $\begin{array}{l}-3.08 \\
* * *\end{array}$ & -2.34 & $\begin{array}{l}-4.16 \\
* * *\end{array}$ & \begin{tabular}{|l|}
-3.63 \\
$* * *$
\end{tabular} & \begin{tabular}{|l|}
-3.77 \\
$* * *$
\end{tabular} & $\begin{array}{l}-3.53 \\
* * *\end{array}$ & $\begin{array}{l}-3.48 \\
* * *\end{array}$ \\
\hline \multicolumn{13}{|c|}{ Exposure } \\
\hline Transit only & n.s. & & & & & & & & & & & \\
\hline $\begin{array}{l}\text { Know hst } \\
\text { only }\end{array}$ & & n.s. & & & & & & & & & & \\
\hline $\begin{array}{l}\text { Viewed } \\
\text { attack }\end{array}$ & & & $\begin{array}{l}\text { see } \\
\text { note }\end{array}$ & & & & & & & & & \\
\hline $\begin{array}{l}\text { Attacked, } \\
\text { not held }\end{array}$ & & & & n.s. & & & & & & & & \\
\hline Held & & & & & $\begin{array}{l}1.08 \\
* *\end{array}$ & $\begin{array}{l}1.21 \\
* *\end{array}$ & \begin{tabular}{|l|}
0.92 \\
$*$
\end{tabular} & & n.s. & n.s. & n.s. & n.s. \\
\hline \multicolumn{13}{|c|}{ Demographics } \\
\hline $\begin{array}{l}\text { Age } \\
\text { (Ctr) }\end{array}$ & & & & & & n.s. & & & & & & \\
\hline Religious & & & & & & n.s. & & & & & & \\
\hline $\begin{array}{l}\text { Prior } \\
\text { trauma }\end{array}$ & & & & & & n.s. & & & & & & \\
\hline \multicolumn{13}{|c|}{ Pre-dep training } \\
\hline Had PTD & & & & & & & n.s. & & & & & \\
\hline $\begin{array}{l}\text { Usefulness } \\
\text { of PTD }\end{array}$ & & & & & & & n.s. & & & & & \\
\hline \multicolumn{13}{|c|}{ Behavioral symptoms } \\
\hline PCL-C sum & & & & & & & & $\begin{array}{l}0.05 \\
*\end{array}$ & $\begin{array}{l}0.04 \\
*\end{array}$ & $\begin{array}{l}.03 \\
*\end{array}$ & $\begin{array}{l}0.04 \\
*\end{array}$ & $\begin{array}{l}0.03 \\
*\end{array}$ \\
\hline CESD sum & & & & & & & & n.s. & & & & \\
\hline \multicolumn{13}{|c|}{ Country } \\
\hline India & & & & & & & & & & n.s. & & \\
\hline Phi & & & & & & & & & & & n.s. & \\
\hline Ukr & & & & & & & & & & & & n.s. \\
\hline $\mathrm{N}$ & 442 & 453 & & 444 & 445 & 436 & \begin{tabular}{|l|l|}
415 \\
\end{tabular} & 314 & 314 & 347 & 347 & 347 \\
\hline
\end{tabular}

$* * *<0.001, * *<0.01, *<0.05,0.05>$. $<0.6$

No seafarer who only viewed an attack also declined a job due to piracy, leading to an inability to estimate this effect. 


\section{APPENDIX XII: SOUGHT OUT A JOB FOR HIGHER PAY}

\begin{tabular}{|c|c|c|c|c|c|c|c|c|c|c|c|c|}
\hline & $\begin{array}{l}\text { Model } \\
1\end{array}$ & 2 & 3 & 4 & 5 & 6 & 7 & 8 & 9 & 10 & 11 & 12 \\
\hline Intercept & $\begin{array}{l}-2.19 \\
* * *\end{array}$ & $\begin{array}{l}-1.81 \\
* * *\end{array}$ & $\begin{array}{l}-1.86 \\
* * *\end{array}$ & $\begin{array}{l}-1.78 \\
* * *\end{array}$ & $\begin{array}{l}-1.77 \\
* * *\end{array}$ & $\begin{array}{l}-2.63 \\
* *\end{array}$ & $\begin{array}{l}-2.18 \\
*\end{array}$ & $\begin{array}{l}-3.87 \\
* * *\end{array}$ & $\begin{array}{l}-3.35 \\
* * *\end{array}$ & $\begin{array}{l}-2.55 \\
* * *\end{array}$ & $\begin{array}{l}-3.82 \\
* * *\end{array}$ & $\begin{array}{l}-2.58 \\
* *\end{array}$ \\
\hline \multicolumn{13}{|c|}{ Exposure } \\
\hline Transit only & n.s. & & & & & & & & & & & \\
\hline $\begin{array}{l}\text { Know hst } \\
\text { only }\end{array}$ & & n.s. & & & & & & & & & & \\
\hline $\begin{array}{l}\text { Viewed } \\
\text { attack }\end{array}$ & & & n.s. & & & & & & & & & \\
\hline $\begin{array}{l}\text { Attacked, } \\
\text { not held }\end{array}$ & & & & n.s. & & & & & & & & \\
\hline Held & & & & & n.s. & & & n.s. & n.s. & & & \\
\hline \multicolumn{13}{|c|}{ Demographics } \\
\hline $\begin{array}{l}\text { Age } \\
\text { (Ctr) }\end{array}$ & & & & & & n.s. & & & & & & \\
\hline Religious & & & & & & n.s. & & & & & & \\
\hline $\begin{array}{l}\text { Prior } \\
\text { trauma }\end{array}$ & & & & & & $\begin{array}{l}0.22 \\
*\end{array}$ & n.s. & $\begin{array}{l}0.30 \\
* *\end{array}$ & n.s. & & & \\
\hline \multicolumn{13}{|c|}{ Pre-dep training } \\
\hline Had PTD & & & & & & & n.s. & & & & & \\
\hline $\begin{array}{l}\text { Usefulness } \\
\text { of PTD }\end{array}$ & & & & & & & n.s. & & & & & \\
\hline \multicolumn{13}{|c|}{ Behavioral symptoms } \\
\hline PCL-C sum & & & & & & & & n.s. & $\begin{array}{l}0.04 \\
* *\end{array}$ & $\begin{array}{l}0.03 \\
* *\end{array}$ & $\begin{array}{l}0.03 \\
* *\end{array}$ & $\begin{array}{l}0.03 \\
*\end{array}$ \\
\hline CESD sum & & & & & & & & n.s. & & & & \\
\hline \multicolumn{13}{|c|}{ Country } \\
\hline India & & & & & & & & & & n.s. & & \\
\hline Phi & & & & & & & & & & & $\begin{array}{l}2.32 \\
* * *\end{array}$ & \\
\hline Ukr & & & & & & & & & & & & n.s. \\
\hline $\mathrm{N}$ & 424 & 429 & 428 & 419 & 420 & 261 & 256 & 234 & 265 & 344 & 344 & 344 \\
\hline
\end{tabular}

$* * *<0.001, * *<0.01, *<0.05,0.05>.<0.6$ 
APPENDIX XIII: TYPES OF ABUSE AND PROBABLE PTSD

\begin{tabular}{|c|c|c|c|c|c|c|c|c|c|c|c|c|c|c|c|c|c|c|c|c|}
\hline & $\begin{array}{l}\text { Model } \\
1\end{array}$ & 2 & 3 & 4 & 5 & 6 & 7 & 8 & 9 & 10 & 11 & 12 & 13 & 14 & 15 & 16 & 17 & 18 & 19 & 20 \\
\hline Intercept & \begin{tabular}{|l}
-1.54 \\
$* *$
\end{tabular} & $\begin{array}{l}-1.55 \\
* *\end{array}$ & $\begin{array}{l}-1.35 \\
* * *\end{array}$ & \begin{tabular}{|l}
-1.12 \\
$* *$
\end{tabular} & $\begin{array}{l}-1.14 \\
*\end{array}$ & \begin{tabular}{|l|}
-1.25 \\
$* *$
\end{tabular} & $\begin{array}{l}-1.32 \\
* *\end{array}$ & $\begin{array}{l}-1.19 \\
* *\end{array}$ & \begin{tabular}{|l|}
-1.58 \\
$* *$
\end{tabular} & $\begin{array}{l}-1.47 \\
* *\end{array}$ & \begin{tabular}{|l|}
-1.92 \\
$*$
\end{tabular} & $\begin{array}{l}-1.90 \\
* *\end{array}$ & $\begin{array}{l}-2.77 \\
* *\end{array}$ & \begin{tabular}{|l|}
-1.19 \\
$*$
\end{tabular} & $\begin{array}{l}-2.12 \\
* * *\end{array}$ & $\begin{array}{l}-1.99 \\
*\end{array}$ & n.s. & $\begin{array}{l}-2.21 \\
* * *\end{array}$ & $\begin{array}{l}-1.94 \\
* *\end{array}$ & $\begin{array}{l}-1.88 \\
* *\end{array}$ \\
\hline $\begin{array}{l}\text { Slapped, kicked, or punched } \\
\text { by pirates }\end{array}$ & n.s. & & & & & & & & & & & & & & & & & & & \\
\hline Beaten with an implement & & n.s. & & & & & & & & & & & & & & & & & & \\
\hline Being hung & & & n.s. & & & & & & & & & & & & & & & & & \\
\hline Hung overboard & & & & n.s. & & & & & & & & & & & & & & & & \\
\hline Uncovered outside & & & & & n.s. & & & & & & & & & & & & & & & \\
\hline Physical abuse & & & & & & n.s. & & & & & & & & & & & & & & \\
\hline Held by yourself & & & & & & & n.s. & & & & & & & & & & & & & \\
\hline Death & & & & & & & & n.s. & & & & & & & & & & & & \\
\hline Serious injury to other crew & & & & & & & & & n.s. & & & & & & & & & & & \\
\hline Serious injury to self & & & & & & & & & & 1.00 & & & & & & & & & & \\
\hline Threatened with death & & & & & & & & & & & n.s. & & & & & & & & & \\
\hline Threatened with beating & & & & & & & & & & & & n.s. & & & & & & & & \\
\hline insufficient food & & & & & & & & & & & & & n.s. & & & & & & & \\
\hline Ship used as "mother ship" & & & & & & & & & & & & & & n.s. & & & & & & \\
\hline Sum of abuse & & & & & & & & & & & & & & & $\begin{array}{l}0.18 \\
*\end{array}$ & n.s. & n.s. & n.s. & \begin{tabular}{|l|}
0.16 \\
$*$
\end{tabular} & $\begin{array}{l}0.17 \\
*\end{array}$ \\
\hline \multicolumn{21}{|c|}{ Demographics } \\
\hline $\begin{array}{l}\text { Age } \\
\text { (Ctr) }\end{array}$ & & & & & & & & & & & & & & & & n.s. & & & & \\
\hline Prior trauma & & & & & & & & & & & & & & & & n.s. & & & & \\
\hline \multicolumn{21}{|c|}{ Pre-dep training } \\
\hline Had PTD & & & & & & & & & & & & & & & & & n.s. & & & \\
\hline Usefulness of PTD & & & & & & & & & & & & & & & & & n.s. & & & \\
\hline \multicolumn{21}{|c|}{ Country } \\
\hline India & & & & & & & & & & & & & & & & & & n.s. & & \\
\hline Phi & & & & & & & & & & & & & & & & & & & n.s. & \\
\hline Ukr & & & & & & & & & & & & & & & & & & & & n.s. \\
\hline $\mathrm{N}$ & 97 & 97 & 97 & 97 & 96 & 95 & 97 & 97 & 95 & 96 & 97 & 97 & 97 & 95 & 92 & 68 & 90 & 92 & 92 & 92 \\
\hline
\end{tabular}


APPENDIX XIV: TYPES OF ABUSE AND PTS SYMPTOMS

\begin{tabular}{|c|c|c|c|c|c|c|c|c|c|c|c|c|c|c|c|c|c|c|c|c|c|}
\hline & $\begin{array}{l}\text { Model } \\
1\end{array}$ & 2 & 3 & 4 & 5 & 6 & 7 & 8 & 9 & 10 & 11 & 12 & 13 & 14 & 15 & 16 & 17 & 18 & 19 & 20 & 21 \\
\hline Intercept & $\begin{array}{l}30.93 \\
* * * \\
\end{array}$ & \begin{tabular}{|l|}
30.28 \\
$* * *$
\end{tabular} & $\begin{array}{l}30.73 \\
* * *\end{array}$ & $\begin{array}{l}33.20 \\
* * *\end{array}$ & \begin{tabular}{|l|}
33.92 \\
$* * *$
\end{tabular} & \begin{tabular}{|l|}
32.44 \\
$* * *$
\end{tabular} & $\begin{array}{l}32.10 \\
* * *\end{array}$ & $\begin{array}{l}31.82 \\
* * *\end{array}$ & $\begin{array}{l}29.07 \\
* * *\end{array}$ & $\begin{array}{l}32.12 \\
* * *\end{array}$ & $\begin{array}{l}26.42 \\
* * *\end{array}$ & $\begin{array}{l}27.19 \\
* * *\end{array}$ & $\begin{array}{l}23.92 \\
* * *\end{array}$ & $\begin{array}{l}33.20 \\
* * *\end{array}$ & $\begin{array}{l}24.36 \\
* * * \\
\end{array}$ & $\begin{array}{l}17.67 \\
* * *\end{array}$ & $\begin{array}{l}26.60 \\
* * *\end{array}$ & $\begin{array}{l}28.97 \\
* * *\end{array}$ & $\begin{array}{l}24.22 \\
* * *\end{array}$ & $\begin{array}{l}26.12 \\
* * *\end{array}$ & $\begin{array}{l}24.66 \\
* * *\end{array}$ \\
\hline $\begin{array}{l}\text { Slapped, kicked, or } \\
\text { punched by pirates }\end{array}$ & n.s. & & & & & & & & & & & & & & & & & & & & \\
\hline $\begin{array}{l}\text { Beaten with an imple- } \\
\text { ment }\end{array}$ & & $\begin{array}{l}7.38 \\
*\end{array}$ & & & & & & & & & & & & & & n.s. & & & & & \\
\hline Being hung & & & \begin{tabular}{|l|}
8.23 \\
$* *$
\end{tabular} & & & & & & & & & & & & & n.s. & & & & & \\
\hline Hung overboard & & & & n.s. & & & & & & & & & & & & & & & & & \\
\hline Uncovered outside & & & & & n.s. & & & & & & & & & & & & & & & & \\
\hline Physical abuse & & & & & & n.s. & & & & & & & & & & & & & & & \\
\hline Held by yourself & & & & & & & n.s. & & & & & & & & & & & & & & \\
\hline Death & & & & & & & & $\begin{array}{l}6.5 \\
.\end{array}$ & & & & & & & & & & & & & \\
\hline $\begin{array}{l}\text { Serious injury to other } \\
\text { crew }\end{array}$ & & & & & & & & & \begin{tabular}{|l|}
8.00 \\
$* *$ \\
\end{tabular} & & & & & & & n.s. & & & & & \\
\hline Serious injury to self & & & & & & & & & & n.s. & & & & & & & & & & & \\
\hline Threatened with death & & & & & & & & & & & 8.12 & & & & & n.s. & & & & & \\
\hline Threatened with beating & & & & & & & & & & & & $\begin{array}{l}8.72 \\
*\end{array}$ & & & & n.s. & & & & & \\
\hline insufficient food & & & & & & & & & & & & & $\begin{array}{l}12.22 \\
* *\end{array}$ & & & n.s. & & & & & \\
\hline $\begin{array}{l}\text { Ship used as "mother } \\
\text { ship" }\end{array}$ & & & & & & & & & & & & & & n.s. & & & & & & & \\
\hline Sum of abuse & & & & & & & & & & & & & & & $\begin{array}{l}1.54 \\
* * *\end{array}$ & & n.s. & $\begin{array}{l}1.32 \\
* *\end{array}$ & $\begin{array}{l}1.33 \\
* *\end{array}$ & $\begin{array}{l}1.39 \\
* *\end{array}$ & $\begin{array}{l}1.52 \\
* * *\end{array}$ \\
\hline \multicolumn{22}{|c|}{ Demographics } \\
\hline $\begin{array}{l}\text { Age } \\
\text { (Ctr) }\end{array}$ & & & & & & & & & & & & & & & & & n.s. & & & & \\
\hline Prior trauma & & & & & & & & & & & & & & & & & n.s. & & & & \\
\hline \multicolumn{22}{|c|}{ Pre-dep training } \\
\hline Had PTD & & & & & & & & & & & & & & & & & & n.s. & & & \\
\hline Usefulness of PTD & & & & & & & & & & & & & & & & & & n.s. & & & \\
\hline \multicolumn{22}{|c|}{ Country } \\
\hline India & & & & & & & & & & & & & & & & & & & n.s. & & \\
\hline Phi & & & & & & & & & & & & & & & & & & & & n.s. & \\
\hline Ukr & & & & & & & & & & & & & & & & & & & & & n.s. \\
\hline $\mathrm{N}$ & 92 & 92 & 92 & 92 & 92 & 92 & 92 & 92 & 92 & 92 & 92 & 92 & 92 & 92 & 92 & 92 & 66 & 90 & 92 & 92 & 92 \\
\hline
\end{tabular}


APPENDIX XV: TYPES OF ABUSE AND DEPRESSION SYMPTOMS

\begin{tabular}{|c|c|c|c|c|c|c|c|c|c|c|c|c|c|c|c|c|c|c|c|c|c|c|}
\hline & $\begin{array}{l}\text { Model } \\
1\end{array}$ & 2 & 3 & 4 & 5 & 6 & 7 & 8 & 9 & 10 & 11 & 12 & 13 & 14 & 15 & 16 & 17 & 18 & 19 & 20 & 21 & 22 \\
\hline Intercept & $\begin{array}{l}15.03 \\
* * *\end{array}$ & $\begin{array}{l}14.75 \\
* * *\end{array}$ & $\begin{array}{l}15.73 \\
* * *\end{array}$ & $\begin{array}{l}16.70 \\
* * *\end{array}$ & $\begin{array}{l}17.31 \\
* * *\end{array}$ & $\begin{array}{l}16.83 \\
* * *\end{array}$ & $\begin{array}{l}16.37 \\
* * *\end{array}$ & $\begin{array}{l}16.14 \\
* * *\end{array}$ & $\begin{array}{l}14.60 \\
* * *\end{array}$ & $\begin{array}{l}16.37 \\
* * *\end{array}$ & $\begin{array}{l}13.16 \\
* * *\end{array}$ & $\begin{array}{l}13.14 \\
* * *\end{array}$ & $\begin{array}{l}11.35 \\
* * *\end{array}$ & $\begin{array}{l}16.44 \\
* * *\end{array}$ & $\begin{array}{l}12.52 \\
* * *\end{array}$ & $\begin{array}{l}8.31 \\
* * *\end{array}$ & $\begin{array}{l}8.73 \\
* * *\end{array}$ & $\begin{array}{l}6.88 \\
*\end{array}$ & $\begin{array}{l}10.52 \\
*\end{array}$ & $\begin{array}{l}8.56 \\
* * *\end{array}$ & $\begin{array}{l}8.92 \\
* * *\end{array}$ & $\begin{array}{l}8.43 \\
* * *\end{array}$ \\
\hline $\begin{array}{l}\text { Slapped, kicked, or } \\
\text { punched by pirates }\end{array}$ & 3.29 & & & & & & & & & & & & & & & n.s. & & & & & & \\
\hline $\begin{array}{l}\text { Beaten with an imple- } \\
\text { ment }\end{array}$ & & $\begin{array}{l}4.72 \\
* *\end{array}$ & & & & & & & & & & & & & & $\begin{array}{l}5.13 \\
*\end{array}$ & n.s. & & & & & \\
\hline Being hung & & & 3.32 & & & & & & & & & & & & & n.s. & & & & & & \\
\hline Hung overboard & & & & n.s. & & & & & & & & & & & & & & & & & & \\
\hline Uncovered outside & & & & & n.s. & & & & & & & & & & & & & & & & & \\
\hline Physical abuse & & & & & & n.s. & & & & & & & & & & & & & & & & \\
\hline Held by yourself & & & & & & & n.s. & & & & & & & & & & & & & & & \\
\hline Death & & & & & & & & n.s. & & & & & & & & & & & & & & \\
\hline $\begin{array}{l}\text { Serious injury to other } \\
\text { crew }\end{array}$ & & & & & & & & & $\begin{array}{l}4.15 \\
*\end{array}$ & & & & & & & n.s. & & & & & & \\
\hline Serious injury to self & & & & & & & & & & n.s. & & & & & & & & & & & & \\
\hline Threatened with death & & & & & & & & & & & n.s. & & & & & & & & & & & \\
\hline $\begin{array}{l}\text { Threatened with } \\
\text { beating }\end{array}$ & & & & & & & & & & & & $\begin{array}{l}5.06 \\
* *\end{array}$ & & & & 3.81 & $\begin{array}{l}4.41 \\
*\end{array}$ & $\begin{array}{l}5.56 \\
*\end{array}$ & $\begin{array}{l}4.08 \\
*\end{array}$ & $\begin{array}{l}4.30 \\
*\end{array}$ & $\begin{array}{l}4.28 \\
*\end{array}$ & $\begin{array}{l}4.37 \\
*\end{array}$ \\
\hline insufficient food & & & & & & & & & & & & & $\begin{array}{l}6.93 \\
* * *\end{array}$ & & & $\begin{array}{l}5.11 \\
*\end{array}$ & $\begin{array}{l}6.48 \\
* *\end{array}$ & $\begin{array}{l}6.10 \\
*\end{array}$ & $\begin{array}{l}5.79 \\
* *\end{array}$ & $\begin{array}{l}6.23 \\
* *\end{array}$ & $\begin{array}{l}6.12 \\
* *\end{array}$ & $\begin{array}{l}6.33 \\
* *\end{array}$ \\
\hline $\begin{array}{l}\text { Ship used as "mother } \\
\text { ship" }\end{array}$ & & & & & & & & & & & & & & n.s. & & & & & & & & \\
\hline Sum of abuse & & & & & & & & & & & & & & & \begin{tabular}{|l|}
0.72 \\
$* *$
\end{tabular} & & n.s. & & & & & \\
\hline \multicolumn{23}{|c|}{ Demographics } \\
\hline $\begin{array}{l}\text { Age } \\
\text { (Ctr) }\end{array}$ & & & & & & & & & & & & & & & & & & n.s. & & & & \\
\hline Prior trauma & & & & & & & & & & & & & & & & & & n.s. & & & & \\
\hline \multicolumn{23}{|c|}{ Pre-dep training } \\
\hline Had PTD & & & & & & & & & & & & & & & & & & & n.s. & & & \\
\hline Usefulness of PTD & & & & & & & & & & & & & & & & & & & n.s. & & & \\
\hline \multicolumn{23}{|c|}{ Country } \\
\hline India & & & & & & & & & & & & & & & & & & & & n.s. & & \\
\hline Phi & & & & & & & & & & & & & & & & & & & & & n.s. & \\
\hline Ukr & & & & & & & & & & & & & & & & & & & & & & n.s. \\
\hline $\mathrm{N}$ & 88 & 88 & 88 & 88 & 88 & 88 & 88 & 88 & 88 & 88 & 88 & 88 & 88 & 88 & 88 & 88 & 88 & 62 & 88 & 90 & 90 & 90 \\
\hline
\end{tabular}

$* * *<0.001, * *<0.01, *<0.05,0.05>$. $<0.6$ 


\section{APPENDIX XVI: ACKNOWLEDGMENT OF THE RESEARCH TEAMS}

This research was carried out with the support of a large number of people who contributed their time and effort to assist with data collection and the support of seafarers in all of the target countries. The project would not have been possible without their work, and we are grateful to them for their dedication and help.

\section{IN THE PHILIPPINES}

Sanley Abila

Ralph Doval-Santos

Charisse Grantoza

Krista Serrano

Evee Kae Simon

Pocholo Velasquez

\section{IN UKRAINE}

Anna Murugova

Zoya Vasilchenko

Inna Zvezdun

Elena Kazakova

Vladimir Khalupenko

\section{IN INDIA}

Zankhana Joshi

Sashi Rekha Tallapragada

Raosaheb Vitthal Raut

Mildred Rodrigues

Sujata Gupta 


\section{NOTES FOR APPENDICES}

Frank W. Weathers et al., The PTSD Checklist-Civilian Version (PCL-C) (Boston, MA: National Center for PTSD, 1994).

2 Scott D. McDonald and Patrick S. Calhoun, "The Diagnostic Accuracy of the PTSD Checklist: A Critical Review," Clinical Psychology Review 30, no. 8 (December 2010): 976-87, doi:10.1016/j.cpr.2010.06.012; Artin Terhakopian et al., "Estimating Population Prevalence of Posttraumatic Stress Disorder: An Example Using the PTSD Checklist," Journal of Traumatic Stress 21, no. 3 (June 1, 2008): 290-300, doi:10.1002/jts.20341. \\uc0\\u8221\{\}\{\|i\{\}Clinical Psychology Review\} 30, no. 8 (December 2010

Lenore Sawyer Radloff, "The CES-D Scale: a Self-Report Depression Scale for Research in the General Population," Applied Psychological Measurement 1, no. 3 (1977): 385-401.

Maenge Je Cho and Kye Hee Kim, "Use of the Center for Epidemiologic Studies Depression (CES-D) Scale in Korea," Jounal of Nervous and Mental Disease 186, no. 5 (1998): 304-10; Koji Wada et al., "Validity of the Center for Epidemiologic Studies Depression Scale as a Screening Instrument of Major Depressive Disorder among Japanese Workers," American Journal of Industrial Medicine 50, no. 1 (2007): 8-12; Andrew Mackinnon et al., "The Center for Epidemiological Studies Depression Scale in Older Community Samples in Indonesia, North Korea, Myanmar, Sri Lanka, and Thailand," The Journals of Gerontology Series B: Psychological Sciences and Social Sciences 53, no. 6 (1998): P343-P352.

5 G. R. Parkerson, W. E. Broadhead, and C. K. Tse, "The Duke Health Profile. A 17-Item Measure of Health and Dysfunction," Medical Care 28, no. 11 (November 1990): 1056-72.

6 Janet Osterman and Joop de Jong, "Cultural Issues and Trauma," in Handbook of PTSD: Science and Practice, ed. Matthew J. Friedman, Terence M. Keane, and Patricia A. Resick (Guilford Press, 2010), 425-46.

7 Stephen W. Raudenbush and Anthony S. Bryk, Hierarchical Linear Models: Applications and Data Analysis Methods, 2nd edition (Thousand Oaks: SAGE Publications, Inc, 2001). 


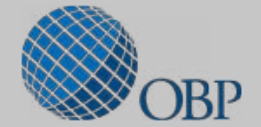

\section{3 one earth \\ (3.) FUTURE}

R E S E A R C H

Oceans Beyond Piracy and OEF Research are programs of the One Earth Future Foundation

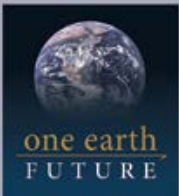

525 Zang Street, Suite $C$

Broomfield, CO 80021 USA

www.oneearthfuture.org 